\title{
ESPECIES DE LA FAMILIA BRUCHIDAE (COLEOPTERA) EN ZIMAPÁN, HIDALGO, MÉXICO: NUEVOS REGISTROS, HOSPEDEROS Y CLAVE PARA SU IDENTIFICACIÓN
}

\author{
SPECIES OF THE BRUCHIDAE FAMILY (COLEOPTERA) AT ZIMAPÁN, \\ HIDALGO, MEXICO: NEW RECORDS, HOST PLANTS, AND KEY \\ FOR THEIR IDENTIFICATION
}

\section{SERGIO GODÍNEZ-CORTÉS, ${ }^{1, *}$ JESÚS ROMERO NÁPOLES $^{\mathbf{1}}$ E IGNACIO CASTELLANOS ${ }^{2}$}

\author{
${ }^{1}$ Programa de Entomología y Acarología, Instituto de Fitosanidad, Colegio de Postgraduados (Campus \\ Montecillo), Carretera México-Texcoco, km 36.5, C. P. 56230, Montecillo, Texcoco de Mora, Estado de México, \\ México<godinezcortes@gmail.com>; <jnapoles@colpos.mx>. \\ ${ }^{2}$ Laboratorio de Interacciones Biológicas, Centro de Investigaciones Biológicas, Universidad Autónoma del \\ Estado de Hidalgo, C. P. 42184, Mineral de la Reforma, Hidalgo, México <ignacioe@uaeh.edu.mx>. \\ * Autor de correspondencia: <godinezcortes@gmail.com>. \\ Recibido: 02/09/2016; aceptado: 26/04/2017 \\ Editor responsable: Arturo Bonet Ceballos.
}

\begin{abstract}
Godínez-Cortés, S., Romero N., J.y Castellanos, I. (2017). Especies de la familia Bruchidae (Coleoptera) en Zimapán, Hidalgo, México: nuevos registros, hospederos y clave para su identificación. Acta Zoológica Mexicana (n.s.), 33(2), 266-313.
\end{abstract}

RESUMEN. Como resultado de la compaginación de colectas en campo y de la base de datos BRUCOL, se presentan, ilustran y determinan las 27 especies hasta ahora conocidas de brúquidos en el municipio de Zimapán, Hidalgo, México. Se identifican plantas hospederas, nuevas distribuciones y el tipo de vegetación en el que se les encuentra; se aborda a su vez aspectos importantes de su biología como son la oviposición y su voltinismo. Entre los resultados más relevantes están, un nuevo registro del género Abutiloneus y nueve nuevos registros de especies para el estado de Hidalgo, México: Abutiloneus idoneus Bridwell, 1946; Acanthoscelides aequalis (Sharp, 1885), Acanthoscelides speciosus (Schaeffer, 1907); Meibomeus hidalgoi Kingsolver \& Whitehead, 1976; Merobruchus porphyreus Kingsolver, 1988; Mimosestes humeralis (Gyllenhal, 1833); Mimosestes janzeni Kingsolver \& Johnson, 1978; Sennius discolor (Horn, 1873) y Stator vachelliae Bottimer, 1973; así como dos nuevos registros de plantas hospederas, Acacia farnesiana (L.) Willd. para M. humeralis y M. janzeni, y Senna guatemalensis (Donn. Sm.) H. S. Irwin \& Barneby variedad hidalgensis H. S. Irwin \& Barneby para S. discolor y S. fallax; además de un nuevo registro de hospedero en México para Megacerus maculiventris (Fåhraeus, 1839), Ipomoea purpurea (L.) Roth. Finalmente, se proporciona una clave dicotómica para facilitar la identificación de dichas especies de brúquidos. Por lo tanto, el presente estudio adentra al conocimiento taxonómico-faunístico de este grupo de insectos en esta zona del país y sienta las bases para estudios futuros.

Palabras clave: Bruchidae, Bruchinae, escarabajos de las semillas, brúquidos, gorgojos, clave, Hidalgo, Zimapán.
Godínez-Cortés, S., Romero N., J., \& Castellanos, I. (2017). Species of the Bruchidae family (Coleoptera) at Zimapán, Hidalgo, Mexico: new records, host plants, and key for their identification. Acta Zoológica Mexicana (n.s.), 33(2), 266-313.

ABSTRACT. Results of field collects and the BRUCOL database, we present and illustrate 27 know bruchids species, recorded in the municipality of Zimapán, Hidalgo, México. Their host plants, new distributions, and the type of vegetation where it can be find are presented, addressing important aspects of their biology such as oviposition and voltinism. The most relevant results is a new record of the genus Abutiloneus and nine new species records to Hidalgo, México: Abutiloneus idoneus Bridwell, 1946; Acanthoscelides aequalis (Sharp, 1885), Acanthoscelides speciosus (Schaeffer, 1907); Meibomeus hidalgoi Kingsolver \& Whitehead, 1976; Merobruchus porphyreus Kingsolver, 1988; Mimosestes humeralis (Gyllenhal, 1833); Mimosestes janzeni Kingsolver \& Johnson, 1978; Sennius discolor (Horn, 1873) and Stator vachelliae Bottimer, 1973; two new host plants, Acacia farnesiana (L.) Willd. for M. humeralis and M. janzeni, and Senna guatemalensis (Donn. Sm.) H. S. Irwin \& Barneby variety hidalgensis H. S. Irwin \& Barneby for S. discolor and S. fallax; and a new host plant recorded in Mexico for Megacerus maculiventris (Fåhraeus, 1839), Ipomoea purpurea (L.) Roth. Finally, a taxonomic key is provided to identify the bruchid species. This study offers insights to the taxonomic-faunal knowledge of this group of insects and lays the basis for future studies.

Key words: Bruchidae, Bruchinae, seed beetles, bruchids, weevils, keys, Hidalgo, Zimapán. 


\section{INTRODUCCIÓN}

Los brúquidos, mejor conocidos como escarabajos de las semillas, representan una familia monofilética dentro del orden Coleoptera, cercanamente emparentada a los Chrysomelidae y a los Cerambycidae (Kingsolver, 2002; Yus et al., 2007). Estos insectos se caracterizan por tener el rol ecológico obligado de comer semillas durante su estado larvario (espermofagia), alimentándose de aproximadamente 46 familias de angiospermas, aunque principalmente de plantas de la familia Leguminosae (Romero, 2002; Romero \& Johnson, 2002; Ribeiro-Costa \& Almeida, 2012).

Debido a su gran capacidad adaptativa, la familia posee una distribución cosmopolita, colonizando casi cualquier región del mundo (a excepción de la Antártida) (Kergoat 2004, Robinson 2005, Eaton \& Kaufman 2007, RibeiroCosta \& Almeida 2012, Thakur 2012); aunque algunos grupos de esta familia tienen distribuciones más restringidas. Según distintos conteos -sin considerar fósiles-, en la actualidad, la familia está representada por aproximadamente 1800 especies descritas en el mundo, agrupadas en 66 géneros y seis subfamilias (Arnett 2000, Kingsolver 2002, Johnson \& Romero 2004, Romero 2009, Reid \& Beatson 2012, Ribeiro-Costa \& Almeida 2012, Romero 2016); mientras que en México se encuentran 376 especies, distribuidas en 27 géneros y tres subfamilias (Romero \& Johnson 2004, Romero 2016).

A pesar de que en México existe una gran riqueza de especies de este grupo de insectos, se cree que aún faltan muchas especies más por describir, especialmente porque son pocos los estudios enfocados en esta fauna (Romero 2002). En el estado de Hidalgo y para el municipio de Zimapán, en particular, no hay excepción, pues el estudio taxonómico-faunístico de los brúquidos ha sido nulo (Godínez-Cortés et al. 2011). Pocos son los estudios realizados sobre brúquidos en el estado y ninguno con el carácter de conocer su taxonomía y diversidad a detalle (GodínezCortés et al. 2012), sino más bien aspectos de su ecología, tal como está reflejado en los trabajos de Pérez (2007), Baltazar (2011) y Parra (2011). Para el municipio de Zimapán, existen reportes de algunas especies, las cuales fueron colectadas a través de los años y registradas en la base de datos BRUCOL (Romero 2016), y que han servido para aportar nuevas distribuciones y datos de colecta durante la revisión de algunos géneros específicos (Romero \& Johnson 2002, Romero 2016).

Sin embargo, es hasta el presente estudio que se presentan en detalle el nombre y número de las especies de brúquidos presentes en este municipio de Hidalgo, la relación con sus hospederos y distribuciones, así como aspectos importantes de su biología de oviposición y voltinísmo; además, una clave basada en caracteres morfológicos para su correcta identificación. Así, el principal objetivo de este estudio es adentrar de manera precisa al conocimiento taxonómico-faunístico de este grupo de insectos en esta zona del país y sentar las bases para los posibles estudios futuros que lleguen a realizarse.

\section{MATERIALES Y MÉTODOS}

Los esfuerzos realizados para la obtención de los resultados de este trabajo están basados en el análisis minucioso de dos fuentes principales de información; en la compaginación de la base de datos BRUCOL (Romero 2016), más el trabajo de campo y de laboratorio que se explica a continuación.

La zona referente al presente estudio corresponde al municipio número 084 del estado de Hidalgo, conocido como Zimapán (Instituto Nacional de Estadística Geografía e Informática 1994). El cual se encuentra enclavado en una zona biogeográfica de transición entre la región Neártica y la región Neotropical; y a menor escala ubicado en una zona de transición de dos provincias geológicas y fisiográficas mexicanas conocidas como la provincia de la Sierra Madre Oriental y el Altiplano Mexicano (Zunino \& Zullini 2003, Morrone 2005).

Para llevar a a cabo esta investigación, se realizaron ocho salidas de campo en un lapso de 22 meses (julio 2010-abril 2012) con intervalos esporádicos e irregulares entre las salidas; en cinco tipos distintos de vegetación (según Zamudio et al. 1992): matorral crasicaule, matorral micrófilo, matorral submontano, bosque espinoso y bosque espinoso perturbado y asociación de encino-pino; donde se lograron georreferenciar 35 puntos de muestreo exitosos, distribuidos en 14 localidades. Los puntos de colecta fueron elegidos al azar, realizándose bajo la Licencia de Colector Científico: FAUT.0097.

Para la obtención de los ejemplares de brúquidos adultos se recurrió a dos métodos de colecta: colecta manual de frutos (vainas o semillas) y colecta de insectos adultos mediante la ayuda de una red entomológica de golpeo. Para la colecta manual de semillas y vainas se realizó una evaluación visual preliminar de frutos maduros y marcas de daño sobre éstos, tales como orificios de emergencia de larvas en su superficie o presencia de huevos; posteriormente se colectó un número indeterminado de frutos y 
un segmento representativo de la planta para su posterior determinación taxonómica. Para la colecta de brúquidos adultos con red entomológica de golpeo, se recurrió también a una evaluación visual preliminar de las plantas y la presencia de frutos maduros y flores. La aplicación de éste método consistió en un golpeo sostenido de al menos tres segundos con una rama seca de madera sobre la planta, colocando al mismo tiempo la red por debajo de ésta, con lo cual descendió la entomofauna asociada. En ambos tipos de colecta, el material vegetal se depositó en bolsas de papel estraza, etiquetándose y sellándose con ligas de goma para su traslado al Laboratorio de Interacciones Biológicas del Centro de Investigaciones Biológicas en la Universidad Autónoma del Estado de Hidalgo (CIBUAEH), donde fueron examinadas.

Una vez en el laboratorio, se procedió a preparar el material para su incubación, colocando el contenido vegetal en recipientes de plástico transparentes, sellándolos con tela de fibra sintética y ligas de goma a su alrededor. Lo siguiente fue esperar la emergencia de los primeros brúquidos. Una vez ocurrido esto, se extrajeron con un aspirador entomológico y se fijaron en alcohol al 70\%. La revisión de recipientes se realizó periódicamente, aproximadamente cada mes (calculado a partir de un ciclo de vida común en los escarabajos de las semillas, que es alrededor de cinco semanas), siguiendo la técnica anterior. Una vez fijados, cada uno de los ejemplares de brúquidos fue determinado taxonómicamente por medio de su morfología externa hasta nivel de especie y en caso de requerirse, mediante la genitalia de los machos; siempre utilizando claves especializadas de carácter taxonómico (literatura citada particularmente en la discusión para cada especie.). Para la preparación de la genitalia se recurrió a las técnicas elaboradas por Kingsolver (1970, 2004) y modificadas por Romero \& Johnson (1999).

La información sobre las especies encontradas en Zimapán fue registrada en la base de datos BRUCOL; y los ejemplares obtenidos, depositados en la Colección Entomológica del Instituto de Fitosanidad del Colegio de Postgraduados (Campus Montecillo) (CEAM) (Reg. SEMARNAT MEX.INV.108.0401); una muestra significativa fue depositada en la Colección de Artrópodos adjunta al Laboratorio de Interacciones Biológicas, de la Universidad Autónoma del Estado de Hidalgo (IB-UAEH).

Las colecciones donde se encuentra el material incluido en este trabajo son:

CEAM. Colección Entomológica del Colegio de Postgraduados, Estado de México, México.
CNIN. Colección Nacional de Insectos, Ciudad de México, México.

IB-UAEH. Colección de Artrópodos adjunta al Laboratorio de Interacciones Biológicas de la Universidad Autónoma del Estado de Hidalgo, Hidalgo, México.

TAMU. Texas A\&M University Insect Collection, Texas, United States of America.

UCMC. University of Colorado Museum of Natural History Entomology Collection. Colorado, United States of America.

USNM. National Museum of Natural History, Washington, D. C., United States of America.

Las tomas fotográficas de las especies fueron realizadas mediante la utilización de un microscopio estereoscopio Olympus ${ }^{\circledR}$ SZX7, bajo una fuente de iluminación Fiber-Lite ${ }^{\circledR}$ MI-150, una cámara digital Olympus ${ }^{\circledR}$ E-620 y el software Olympus Studio ${ }^{\circledR} 2.22$; las imágenes fueron procesadas y editadas mediante los softwares libres GIMP2, CombineZP e ImageJ.

El material vegetal colectado en campo se determinó en su mayoría hasta el nivel de especie, recurriendo a la consulta de ejemplares de herbario en la red, así como a los reportes previos conocidos de la interacción brúquido-planta, en la base de datos BRUCOL y una visita al Herbario de la UAEH (HGOM) para la comparación de ejemplares botánicos. Una vez determinadas las plantas colectadas y después de analizar su relación con los brúquidos encontrados en éstas, fueron asignadas a las siguientes categorías: planta hospedera, si los brúquidos emergieron de las semillas; o plantas de visita, si los brúquidos se colectaron sobre la planta, pero no emergieron de las semillas. Debido a la baja calidad de herborización de los ejemplares identificados, no pudieron ser integradas en algún herbario.

Se utilizó la clasificación propuesta por Johnson \& Romero (2004), para asignar el tipo oviposición correspondiente para cada especie de brúquido, la cual consiste en: tipo A, oviposición sobre los frutos indehiscentes que aún están sobre la planta; tipo B, oviposición sobre las semillas de los frutos dehiscentes o expuestos que aún están sobre la planta; tipo C, sobre las semillas que están disponibles y expuestas en el sustrato.

Para indicar el tipo de voltinismo, se consideraron datos de literatura, los datos de captura de los ejemplares en los diferentes meses del año y en algunos casos la fenología de los hospederos; se consideró como monovoltino a aquellas especies con solo un ciclo generacional al año; bivoltino a aquellas con dos; y multivoltino a aquellas con tres o más ciclos generacionales por año. 
Para corroborar el estatus taxonómico válido de las plantas relacionadas con brúquidos en este trabajo, se recurrió a la ILDIS, International Legume Database \& Information Service (para leguminosas) y a la ITIS, Integrated Taxonomic Information System (para el resto de plantas).

La compaginación de los datos existentes en la literatura y las bases de datos fue necesaria junto con los datos de campo para validar las determinaciones taxonómicas, datos de colecta, material examinado, distribuciones y registros incluyendo datos de oviposición y voltinismo para las especies de brúquidos incluidos en este trabajo.

Finalmente, se elaboró una clave dicotómica para facilitar la identificación de las especies de brúquidos presentes en el municipio de Zimapán, Hidalgo.

\section{RESULTADOS}

Como resultado final, se contabilizaron 2652 ejemplares de coleópteros brúquidos revisados, distribuidos en 27 especies, pertenecientes a las subfamilias Amblycerinae y Bruchinae y a tres tribus distintas, Spermophagini, Acanthoscelidini, Megacerini. Las especies identificadas fueron: Abutiloneus idoneus Bridwell, 1946; Acanthoscelides aequalis (Sharp, 1885), Acanthoscelides chiricahuae (Fall, 1910); Acanthoscelides macrophthalmus (Schaeffer, 1907); Acanthoscelides mexicanus (Sharp, 1885); Acanthoscelides speciosus (Schaeffer, 1907); Acanthoscelides stylifer (Sharp, 1885); Algarobius atratus Kingsolver, 1986; Algarobius johnsoni Kingsolver, 1986; Gibbobruchus cristicollis (Sharp, 1885); Megacerus maculiventris (Fåhraeus, 1839); Meibomeus hidalgoi Kingsolver \& Whitehead, 1976; Meibomeus serraticulus (Sharp, 1885); Merobruchus julianus (Horn, 1894); Merobruchus major (Fall, 1912); Merobruchus porphyreus Kingsolver, 1988; Mimosestes humeralis (Gyllenhal, 1833); Mimosestes janzeni Kingsolver \& Johnson, 1978; Mimosestes nubigens (Motschulsky, 1874); Sennius discolor (Horn, 1873); Sennius durangensis Johnson \& Kingsolver, 1973; Sennius fallax (Boheman, 1839); Stator limbatus (Horn, 1873); Stator sordidus (Horn, 1873); Stator vachelliae Bottimer, 1973; Stylantheus macrocerus (Horn, 1873) y Zabrotes spectabilis Horn, 1885.

Asimismo, se registraron 12 especies de plantas hospederas, pertenecientes a las familias Convolvulaceae y Leguminosae, las cuales se enlistan a continuación: Acacia coulteri A. Gray, Acacia farnesiana (L.) Willd., Acacia schaffneri (S. Watson) F. J. Herm. variedad bra- voensis Isely, Acacia schaffneri (S. Watson) F. J. Herm. variedad schaffneri (S. Watson) F. J. Herm.; Leucaena leucocephala (Lam.) de Wit, Leucaena pulverulenta (Schltdl.) Benth.; Mimosa aculeaticarpa Ortega, Mimosa lacerata Rose; Prosopis laevigata (Willd.) M. C. Johnst; Senna guatemalensis (Donn. Sm.) H. S. Irwin \& Barneby variedad hidalgensis $\mathrm{H}$. S. Irwin \& Barneby; Ipomoea purpurea (L.) Roth e Ipomoea tricolor Cav.; así como otras exclusivamente determinadas como plantas de visita: Acacia berlandieri Benth.; Barkleyanthus salicifolius (Kunth) H. Rob. \& Brettell; Karwinskia humboldtiana (Schult.) Zucc. y Senna crotalarioides (Kunth) H.S. Irwin \& Barneby.

\section{Clave dicotómica para la identificación taxonómica de las especies de coleópteros brúquidos presentes en el municipio de Zimapán, Hidalgo, México.}

1. Metatibia con un par de espinas móviles largas proyectadas apicalmente; borde elitral posterior no delineado con pequeñas setas; tegumento corporal negro; élitros con un par de bandas blancas transversales en el centro; superficie del pronoto completamente foveolada (Fig. 1a) ................ Zabrotes spectabilis Horn - Metatibia sin un par de espinas móviles largas proyectadas apicalmente; borde elitral posterior delineado con pequeñas setas...................... 2. Décima estría elitral extendiéndose cerca de la mitad del élitro; machos con antenas pectinadas (fig. 27b); margen ventral del metafémur serrado uniformemente; puntuaciones interestriales superficiales y alargadas; tegumento pigidial rojo, cubierto por pubescencia uniforme amarilla o blanca, o con una alternancia de parches de estos colores (fig. 27c) ..........Megacerus maculiventris (Fåhraeus) - Décima estría elitral extendiéndose cerca del ápice del élitro; machos nunca con antenas pectinadas . . . . . . . 3 3. Metafémur sin espinas subapicales en el margen ventral, o con sólo una espina. ............... 4 - Metafémur con al menos dos espinas subapicales en el margen ventral . ..................... 10 4. Metafémur sin espinas subapicales en el margen ventral, tegumento corporal uniformemente negro, sin dimorfismo sexual (fig. 2a) .... Abutiloneus idoneus Bridwell - Metafémur con una espina subapical en el margen ventral; patrones tegumentales corporales de distintas combinaciones; con o sin dimorfismo sexual. .......... 5 5. Carina lateral del pronoto completa, extendiéndose 
hasta la cavidad procoxal; carina lateroventral en el metafémur alcanzando el margen distal del mismo; lóbulo medio de la genitalia del macho desprovisto de dos escleritos grandes y curvos . . . . . . . . . . . . . . 6 - Carina lateral del pronoto incompleta, trunca o ausente y sin alcanzar la cavidad procoxal; carina lateroventral en el metafémur sin alcanzar el margen distal o ausente; lóbulo medio de la genitalia del macho con dos escleritos grandes y curvos, cuyas bases son toscas y romos y apicalmente son finos y agudos, acomodados equidistantemente como paréntesis invertidos. . . . . . . . . . 8 6. Cara visible de la metacoxa completamente puntuada ......................... - Cara visible de la metacoxa lisa, únicamente puntuada en la parte distal; séptima a novena estrías elitrales abreviadas en su base y quinta y sexta estrías uniéndose en su parte distal; genitalia del macho con un gran esclerito curvado, en forma de silla de montar, situada en la parte media del saco interno (fig. 24e) ...................... Stator sordidus (Horn) 7. Tegumento elitral formado por maculas naranja-rojizas en el centro, de tamaño variable y de aspecto reniforme, bordeadas por tegumento negro (fig. 23a); metafémur y metatibia completamente negros; superficie dorsal de la metatibia con una fosa pequeña y tenue ................... Stator limbatus (Horn) - Tegumento elitral completamente negro, sin máculas naranja-rojizas (fig. 25a); metafémur bicolor, negro en la base y naranja en su ápice, metatibia completamente naranja (fig. 25b); superficie dorsal de la tibia sin una pequeña fosa ............. Stator vachelliae Bottimer 8. Tegumento elitral completamente negro (fig. 22a) u opaco, pero nunca con máculas naranja-rojizas; élitros con un patrón tenue y débil de líneas de pelos blancos, el resto de la vestimenta formada de pelos cafés entremezclados; espina del ápice metafemoral tan largo como un tercio o menos del ancho de la base de la metatibia; pigidio con tres parches o líneas triangulares de pelos blancos o dorados en su base (fig. 22c); lóbulo medio de la genitalia del macho con un par de paquetes de espinas en la parte central apiladas diagonalmente, con la parte más fina dirigida hacia el centro del lóbulo (fig. 22e) .............. Sennius fallax (Boheman) - Tegumento elitral negro, con máculas naranja-rojizas; espina cerca del ápice metafemoral tan largo como un medio o tres cuartos del ancho de la base de la meta-

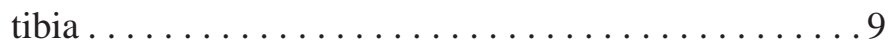
9. Máculas naranja-rojizas elitrales comenzando a un quinto de la base del mismo y extendiéndose hasta un quinto del ápice, dicha mácula está delimitada lateralmente por la tercer estría y hasta alcanzar el borde lateral, algunas veces la mácula es de menor tamaño pero siempre comienza en la tercera estría elitral (fig. 21a); lóbulo medio de la genitalia del macho como en la figura 21e. ....... Sennius durangensis Johnson y Kingsolver - Máculas naranja-rojizas de gran tamaño, extendiéndose sobre la mayor parte de la superficie elitral, enmarcada en sus bordes por el tegumento negro, a veces alcanzando los márgenes laterales (fig. 20a); esta especie también se puede encontrar en una fase oscura (fig. 20b), en la que no se presentan maculas naranjas; lóbulo medio de la genitalia del macho como en la figura 20f . . . . . . . . . . . . . Sennius discolor (Horn) 10. Metafémur notablemente agrandado, con al menos cuatro espinas subapicales en el margen ventral; si presenta tres espinas, entonces la metatibia es arqueada........................... 11 - Metafémur no agrandado, cuando más con tres espinas subapicales en el margen ventral; si presenta más de tres espinas, entonces la metatibia es recta . . . . . . . 16 11. Pronoto con gibas (fig. 11b); base de la cresta pronotal con un patrón bien marcado de vestidura pálida (fig. 11a); con una marca oscura corta en la segunda interestría; carina lateroventral externa del metafémur con una fila de pequeños dentículos que dan la apariencia de una sierra; pigidio de las hembras con un espéculo convexo y glabro, sin puntuaciones dispersas (fig. 11d) ... . Gibbobruchus cristicollis (Sharp)

- Pronoto sin gibas . . . . . . . . . . . . . . . . . 12 12. Vestidura elitral poco densa, sin patrones contrastantes; normalmente solamente la cuarta estría elitral originándose basalmente en un diente; lóbulo medio de la genitalia del macho muy delgado y elongado; lóbulos laterales de la genitalia del macho ligeramente divididos (fig. 13d) . . . . . . . . . . . . . . . . 13 - Vestidura elitral densa, con patrones contrastantes; normalmente la tercera y cuarta estría elitral originándose basalmente en un tubérculo bidentado; lóbulo medio de la genitalia del macho ancho y corto; lóbulos laterales de la genitalia del macho profundamente divididos (fig. 14d) .......................... . . 14 13. Vestidura pigidial con una banda parda de pelos densos en la base central (fig. 13c) .............. Meibomeus serraticulus (Sharp) - Vestidura pigidial uniformemente de pelos color blanco o grisáceo (fig. 12c) .... . Meibomeus hidalgoi Kingsolver y Whitehead 14. Élitros sin una gibosidad bidentada sobre la ter- 
cer y cuarta estría; tercera a sexta estrías elitrales mucronadas basalmente; saco interno sin escleritos (fig. 15e) . . . . . . . . . . . . Merobruchus major (Fall) - Élitros con una gibosidad bidentada sobre la tercer y cuarta estría; tercera a sexta estrías elitrales basalmente; saco interno con escleritos (fig. 14e) . . . . . . . . . 15 15. Pronoto con indumento mayoritariamente gris en sus márgenes laterales, seguido de color cobrizo en el centro y con franja amarillo parduzca o dorada cobriza en el centro; superficie elitral densamente cubierto densamente cubierto y formando un patrón moteado; tercer interestría elitral con un intersticio alargado en el punto medio, que adquiere una coloración dorada, distinta de todo el indumento (fig. 14a); lóbulo medio de la genitalia del macho como en la figura 14e .... Merobruchus julianus (Horn) - Pronoto con indumento mayoritariamente amarillo en sus márgenes laterales, sin formar una franja amarillo parduzca o dorada cobriza en el centro; superficie elitral con pubescencia blanca escasa, contrastando con el tegumento oscuro, sin formar un patrón notorio tercer interestría elitral sin un intersticio alargado en el punto medio (fig. 16a); lóbulo medio de la genitalia del macho como en la figura $16 \mathrm{e} . . .$. .. Merobruchus porphyreus Kingsolver 16. Cabeza con un área glabra en la frente que se extiende hacia el vertex; metafémur del macho profundamente acanalado en su parte ventral . . . . . . . . . . . 17 - Cabeza sin un área glabra en la frente que se extiende hacia el vertex; metafémur del macho sin tal canaladura. . . . . . . . . . . . . . . . . . . . . . 19 17. Margen posterior del ojo que no sobresale de las superficies adyacentes; lóbulo postocular que se funde suavemente en el contorno de la cabeza; élitros negros con una amplia maculación naranja-rojiza en los húmeros, extendiéndose de la segunda estría elitral hasta el margen lateral y desde la base del élitro hasta un tercio de este (fig. 18a) ... . Mimosestes janzeni Kingsolver y Johnson - Margen posterior del ojo que sobresale de las superficies adyacentes; lóbulo postocular sin fundirse con el contorno de la cabeza . . . . . . . . . . . . . 18 18. Élitros negros con una amplia maculación naranja-rojiza en los húmeros, extendiéndose de la tercera estría elitral hasta el margen lateral y desde la base del élitro hasta un tercio de este (fig. 17a); con dos carinas ventrales sobre el primer metatarsómero; márgenes laterales del pronoto no hinchados, sin fuertes espinas. . ........ Mimosestes humeralis (Gyllenhal) - Élitros negros o cafés, sin una maculación amplia naranja rojiza en los húmeros (fig. 19a); sin dos carinas ventrales sobre el primer metatarsómero; márgenes laterales del pronoto hinchados cerca del ápice, provisto con fuertes espinas ........ Mimosestes nubigens (Motschulsky) 19. Escutelo rectangular, elongado, cerca de dos veces su anchura del mismo; hembras con un par de surcos profundos y glabros en el pigidio, paralelos entre sí (fig. 9d) ....................... 20 - Escutelo cuadrado, corto, no más de 1.5 veces su anchura del mismo; hembras sin un par de surcos profundos y glabros en el pigidio . ................... 21 20. Dorso con patrones tegumentales oscuros fuertemente marcados o contrastantes, alternados con pubescencia amarilla o dorada (fig. 9a); pubescencia preescutelar prominente, alargada y amarillenta; hembras con surcos pigidiales amplios y largos (fig. 9d); lóbulo medio de la genitalia del macho como en la figura 9f . .............. Algarobius atratus Kingsolver - Dorso con patrones oscuro-rojizo fuertemente marcados o contrastantes, alternados con pubescencia blanca o amarillo pálido (fig. 10a); pubescencia preescutelar blanca, bien marcada, indistinta o ausente; hembras con surcos pigidiales estrechos y pequeños (fig. 10d); lóbulo medio de la genitalia del macho como en la figura $10 f . . . . . . .$. Algarobius johnsoni Kingsolver 21. Sinus ocular alcanzando hasta 0.9 del ancho del ojo; antenas extremadamente largas, extendiéndose más allá del límite corporal (fig. 26b), más allá del pigidio en machos y hasta alcanzar los ápices elitrales en las hembras; metafémur del macho con tres espinas subapicales en el margen ventral interno, delgadas, equidistantes y casi de la misma longitud ...... Stylantheus macrocerus (Horn) - Sinus ocular sin alcanzar el 0.9 del ancho del ojo; antenas de distintos tamaños, pero nunca tan largas o extendiéndose más allá de la longitud corporal; metafémur del macho con diferentes arreglo de espinas subapicales en el margen ventral interno ................. 22 22. Longitud del mucro de la metatibia del tamaño de un sexto, o menor a la mitad de la longitud del primer metatarsómero; mucro no sinuado . . . . . . . . . . . . 23 - Longitud del mucro de la metatibia del tamaño de un quinto, o mayor, de la longitud del primer metatarsómero; mucro sinuado.....................26 23. Primeros cuatro segmentos antenales naranja-rojizo, el resto marrón oscuro (fig. 3b); pubescencia dorsal generalizada de pelos dorados (fig. 3a), sin formar patrones en mosaico; húmeros elitrales negros, puntulados, glabros y brillosos; metafémur bicolor, mitad café oscuro y mitad naranja rojizo (fig. 3a) ......... . Acanthoscelides aequalis (Sharp, 1885) - Segmentos antenales naranja-rojizo; pubescencia dorsal 
de pelos plancos, cafés y dorados, formando patrones en mosaico; húmeros elitrales naranja-rojizo, cubiertos de pubescencia; metafémur naranja-rojizo . . . . . . . . 24 24. Tegumento completamente naranja-rojizo (fig. 5b) o rojizo-café parduzco en algunos casos; élitros sin máculas intersticiales negras (fig. 5a); metafémur con un pecten en el margen ventral interno con tres espinas subapicales, la primera de ellas larga y aguda seguido de dos más pequeñas de igual tamaño; lóbulo medio de la genitalia del macho como en la figura 5e...... Acanthoscelides macrophthalmus (Schaeffer) - Tegumento en su mayoría negro, con algunas partes rojizas; élitros con máculas intersticiales negras; metafemur sin pecten en el margen ventral interno, pero si con tres espinas subapicales .................... 25 25. Octava interestría elitral con un intersticio alargado en el punto medio de color negro (fig. 7a); tres espinas subapicales en el margen ventral interno, la primera de ellas es larga y delgada seguido de un ligero espacio vacío y éste a su vez seguido de dos espinas más pequeñas de igual tamaño; lóbulo medio de la genitalia del macho como en la figura 7e ..... Acanthoscelides speciosus (Schaeffer) - Octava interestría elitral sin un intersticio alargado en el punto medio de color negro (fig. 6a); tres espinas subapicales en el margen ventral interno, la primera de ellas es larga pero su base es más ancha que en $A$. speciosus, seguido de un espacio vacío del tamaño del ancho de las espinas subsecuentes, que son de igual tamaño; lóbulo medio de la genitalia del macho como en la figura 6e ........ Acanthoscelides mexicanus (Sharp) 26. Vestidura elitral tenue y uniforme de color blanco-dorada (fig. 4a), sin manchas patrones o máculas; base de la tercera y cuarta estría elitral acercándose la una a la otra y con una espina pequeña y roma en la base; metacoxa con una leve depresión muy cerca del centro y estriada radialmente al borde; longitud del mucro de la metatibia menor a la mitad de la longitud del primer metatarsómero........... Acanthoscelides chiricahuae (Fall) - Vestidura elitral con pubescencia uniforme gris (fig. 8a), con algunas máculas de intensidad variable o espacios semiglabros formando un patrón; base de la tercera y cuarta sin cerrarse la una a la otra adyacentemente; metacoxa sin depresión; longitud del mucro de la metatibia mayor a la longitud del primer metatarsómero. . . . ........ Acanthoscelides stylifer (Sharp)

La compaginación de los datos antes mencionados se enlista a continuación, para cada una de las especies y en orden filogenético:
Subfamilia Amblycerinae Bridwell, 1932 Tribu Spermophagini Borowiec, 1987 Zabrotes spectabilis Horn, 1885 (fig. 1 a-e)

Material examinado. México: Hidalgo: ZIMAPÁN, Zimapán, 26/III/1997, colector Braylovsky H., CNIN (2 ex).

Distribución en México. Baja California, Baja California Sur, Durango, Guerrero, Hidalgo (Zimapán), Morelos, Sinaloa, Sonora, Tamaulipas, Zacatecas.

Hospedero asociado. No registrado.

Discusión taxonómica y comentarios ecológicos. No se registró el hospedero en Zimapán; anteriormente se ha reportado que $Z$. spectabilis se alimenta de las semillas de Senna covesii en otras partes de México (Romero 2016). Así mismo, aunque su tipo de oviposición no ha sido observado (Romero \& Johnson 2000), es posible que las hembras de esta especie presenten oviposición del tipo B (Johnson \& Romero 2004), ya que la planta hospedera de la que se alimenta presenta frutos parcialmente dehiscentes (McClintock 2002) y aparentemente un multivoltinismo de varios ciclos generacionales por año, ya que se le ha colectado en casi todos los meses del año, a excepción de enero, noviembre y diciembre (Kingsolver 1990). En el 2011 se amplió la distribución de esta especie por Romero et al. con los datos antes mencionados.

\section{Subfamilia Bruchinae Latreille 1802}

Tribu Acanthoscelidini Bridwell 1946

Abutiloneus idoneus Bridwell, 1945 (fig. 2 a-e)

Material examinado. México: Hidalgo: ZIMAPÁN, Km 79 Carr. Ixmiquilpan-Zimapán, 19/VI/2004, 1800 m, colector Romero N. J., 20³5'48" N, 99²0'26" W, CEAM (4 ex).

Distribución en México. Baja California Sur, Coahuila, Guanajuato, Guerrero, Nuevo León, Querétaro, Sinaloa, Sonora, Tamaulipas, Veracruz. Nuevos registros. Hidalgo (Zimapán).

Hospedero asociado. No registrado.

Discusión taxonómica y comentarios ecológicos. Se encontró al brúquido $A$. idoneus como visitante de la asterácea Barkleyanthus salicifolius. No se registró el hospedero en Zimapán; se le ha reportado alimentándose de las semillas de Abutilon abutiloides, A. berlandieri, A. palmeri, Abutilon sp. y Allowissadula holosericea en otras partes de México y de los Estados Unidos (Kingsolver 1965, Johnson 1983b, Kingsolver 2004, Romero 2016). Aunque su tipo de oviposición y voltinismo no pudieron ser observados y hasta la fecha aún son desconocidos, podría presentar una oviposición del tipo B (Johnson 


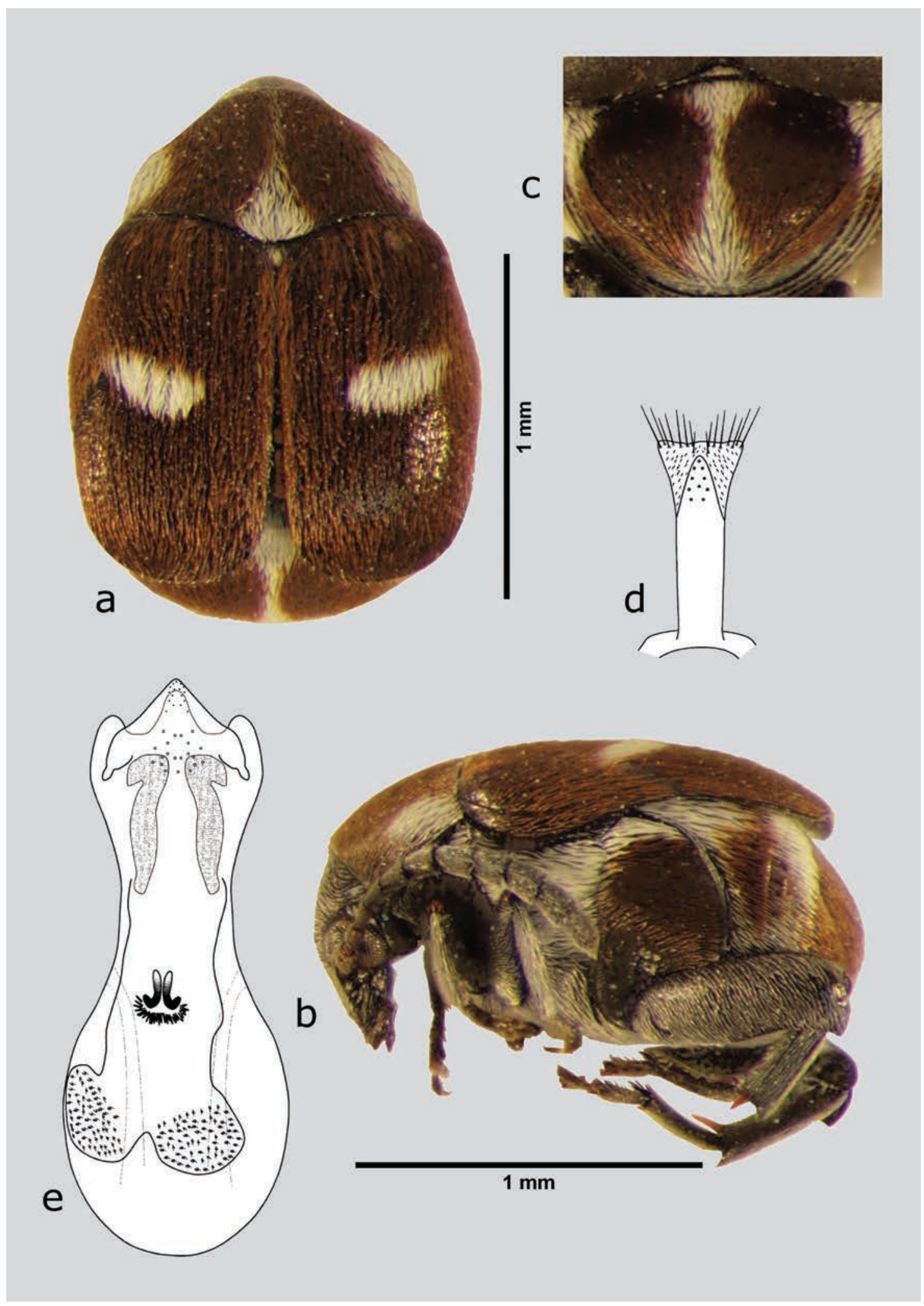

Figura 1. Z. spectabilis (macho), a) dorsal, b) lateral, c) pigidio, d) lóbulos laterales, e) lóbulo medio. Dibujos tomados de Romero \& Johnson (2000). 




Figura 2. A. idoneus (macho), a) dorsal, b) lateral, c) pigidio, d) lóbulos laterales, e) lóbulo medio. Dibujos tomados de Kingsolver (1965). 
\& Romero 2004), ya que los hospederos en los que se ha criado y colectado presentan frutos dehiscentes (Fryxell 1997). La presencia de A. idoneus en el municipio de Zimapán representa un nuevo registro de esta especie y de este género para el estado de Hidalgo.

Acanthoscelides aequalis (Sharp, 1885) (fig. 3 a-e) Material examinado. México: Hidalgo: 2 mi. N Zimapán, colector Clark y Schaffner, 18/III/1975, TAMU (1 ex).

Distribución en México. Campeche, Colima, Guanajuato, Hidalgo, Jalisco, Oaxaca, Puebla, Querétaro, Sinaloa, Sonora, Tamaulipas. Nuevos registros. Hidalgo (Zimapán).

Hospedero asociado. No registrado.

Discusión taxonómica y comentarios ecológicos. Se debe tener cuidado al momento de determinar esta especie, debido a su gran similitud con A. idoneus. No se registró el hospedero en Zimapán; aunque se le ha reportado alimentándose de las semillas de Abutilon berlandieri, A. incanum, Abutilon sp., A. trisulcatum; Allowissadula holosericea, A. lozanii y Wissadula amplissima, en otras partes de México y de los Estados Unidos (Johnson 1983a, Kingsolver 2004, Romero 2016). Aunque su tipo de oviposición y voltinismo no pudieron ser observados y hasta la fecha aún son desconocidos, podría presentar una oviposición del tipo B (Johnson \& Romero 2004), ya que los hospederos en los que se ha colectado presentan frutos dehiscentes (Fryxell 1997). La presencia de A. aequalis en el municipio de Zimapán representa un nuevo registro de esta especie para el estado de Hidalgo.

Acanthoscelides chiricahuae (Fall, 1910) (fig. 4 a-e) Material examinado. México: Hidalgo: ZIMAPÁN, 3.7 Km N Tasquillo, colector Westcott R. L., 15/VI/2004, 1730 m, 20³5'23.16" N, 99²0'25.5" W, CEAM (1ex); ZIMAPÁN, a un costado de un camino de terracería, bosque espinoso, colecta de la cría en vainas de aculeaticarpa, 26/VIII/2011, 1794 m, colector Godínez-Cortés S., 20³5'50.8" N, 99²0'14.9" W, CEAM (6 ex); ZIMAPÁN, Km 97 Carr. Ixmiquilpan-Tamazunchale, 15/VI/2004, 1750 m, colector Romero N. J., 20³5'21" N, 99²0'27" W, CEAM (1ex); ZIMAPÁN, Km 97 Carr. IxmiquilpanTamazunchale, 15/VI/2004, 1750 m, colector Romero N. J., 20³5'21" N, 99²0'27" W, UCMC (2 ex); ZIMAPÁN, Km 97 Carr. Ixmiquilpan-Zimapán, 19/VI/2004, 1800 m, colector Romero N. J., 20³5'48" N, 99²0'26" W, CEAM (3ex); ZIMAPÁN, Camino a la hidroeléctrica de Zimapán, matorral micrófilo, colecta con red de golpeo en $\mathrm{Mi}$ - mosa sp., 26/IV/2012, 1907 m, colector Godínez-Cortés, 20³9'34.6" N, 99²4'19.4" W, CEAM (4 ex); ZIMAPÁN, El Barrón, sobre el camino Jorge Pressier Terán, bosque espinoso perturbado, colecta con red de golpeo en Prosopis laevigata, 26/IV/2012, 1823 m, colector Godínez-Cortés S., 2045'23.5" N 99²3'57.3" W, CEAM (1 ex); ZIMAPÁN, Francisco Villa, cerca de campos agrícolas y terrenos baldíos cercados, bosque espinoso perturbado, colecta de la cría en vainas de Mimosa lacerata y colecta con red de golpeo en Karwinskia humboldtiana, 25/IV/2012, 1915 m, colector Godínez-Cortés S., 2041'32.4" N, 99¹9'16.9" W, CEAM (2 ex); ZIMAPÁN, La Cruz, a un costado de la carretera federal 85 MéxicoNuevo Laredo y el Río Tula, matorral crasicaule, colecta con red de golpeo en Acacia coulteri, 8/X/2010, 1633 m, colector Godínez-Cortés S., 20³4'42.1" N, 99²0'35.5" W, IB-UAEH (6 ex); ZIMAPÁN, La Cruz, a un costado de la carretera federal 85 México-Nuevo Laredo y el Río Tula, matorral crasicaule, colecta con red de golpeo en Prosopis laevigata, 8/X/2010, 1633 m, colector Godínez-Cortés S., 20³4'42.1" N, 99²0'35.5" W, IB-UAEH (1 ex); ZIMAPÁN, La Cruz, a un costado de la carretera federal 85 México-Nuevo Laredo y el Río Tula, matorral crasicaule, colecta de la cría en vainas de Mimosa aculeaticarpa, 8/X/2010, 1633 m, colector Godínez-Cortés S., 20³4'42.1" N, 99²0'35.5" W, IB-UAEH (1 ex); ZIMAPÁN, Megui, Camino a Puerto Juárez, encinar, colecta con red de golpeo sobre leguminosa, 5/I/2011, $2523 \mathrm{~m}$, colector Godínez-Cortés S., 20³8'28.1" N, 99¹6'30.1" W, CEAM (1 ex); ZIMAPÁN, Saucillo, en una ladera, bosque espinoso perturbado, colecta de la cría en vainas de Mimosa aculeaticarpa asociada a Tillandsia recurvata, 4/I/2011, 1875 m, colector Godínez Cortés S., 20³8'31.9" N, 99²7'15.7" W, CEAM (3 ex); ZIMAPÁN, Saucillo, en una ladera, bosque espinoso perturbado, colecta de la cría en vainas de Mimosa lacerata asociada a Tillandsia recurvata, 4/I/2011, 1875 m, colector Godínez-Cortés S., 20³8'31.9" N, 99²7'15.7" W, CEAM (15 ex).

Distribución en México. Baja California, Baja California Sur, Chiapas, Chihuahua, Coahuila, Durango, Estado de México, Guanajuato, Hidalgo (Alfajayucan, Cardonal, Pachuca, Tasquillo, Tepetitlán, Zimapán), Jalisco, Michoacán, Morelos, Nuevo León, Oaxaca, Puebla, Querétaro, San Luis Potosí, Sinaloa, Sonora, Tamaulipas, Veracruz, Zacatecas.

Hospedero asociado. M. aculeaticarpa, M. lacerata, Mimosa sp.

Discusión taxonómica y comentarios ecológicos. Además de las plantas hospederas antes mencionadas, A. chi- 


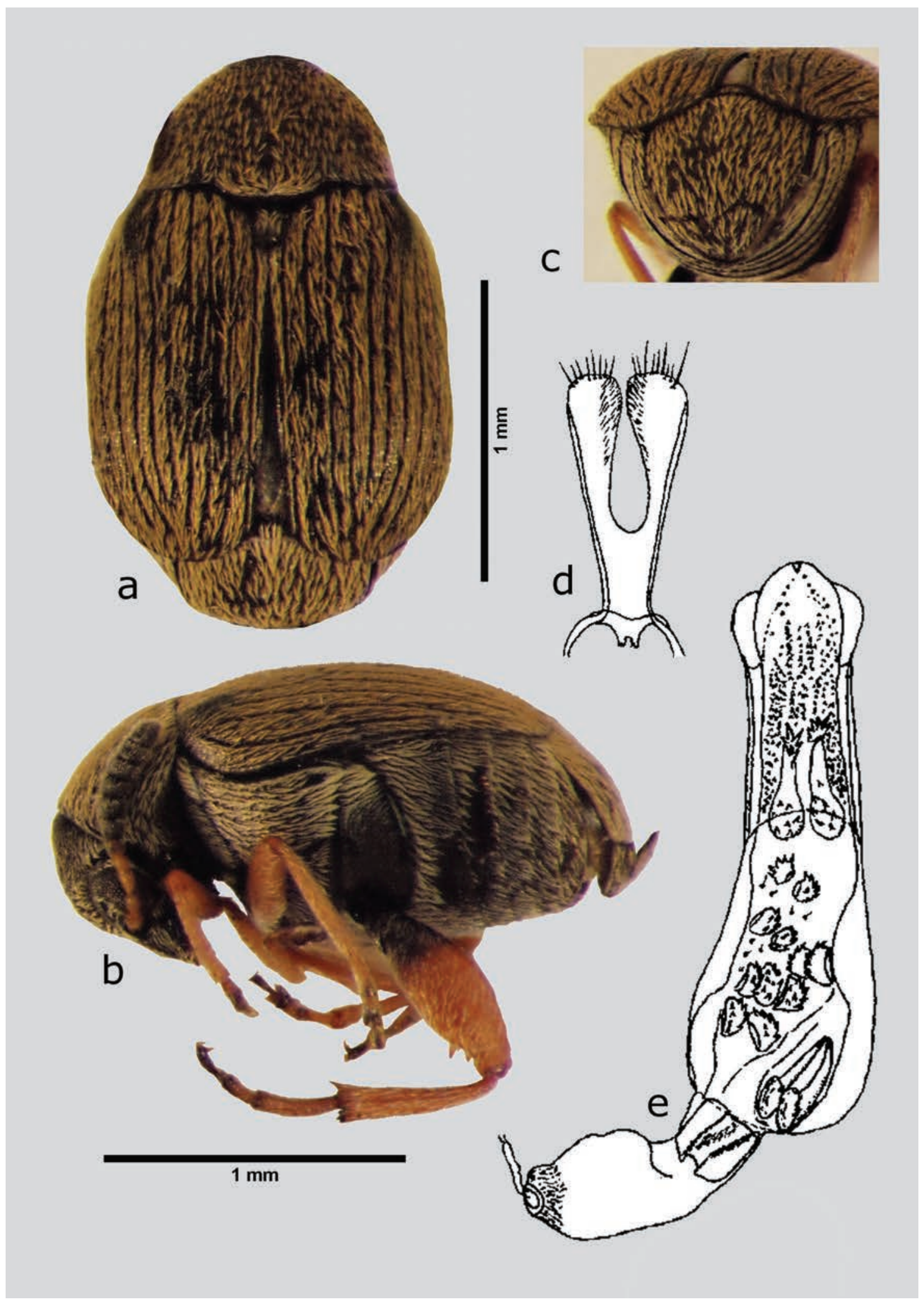

Figura 3. A. aequalis (macho), a) dorsal, b) lateral, c) pigidio, d) lóbulos laterales, e) lóbulo medio. Dibujos tomados de Kingsolver (2004). 


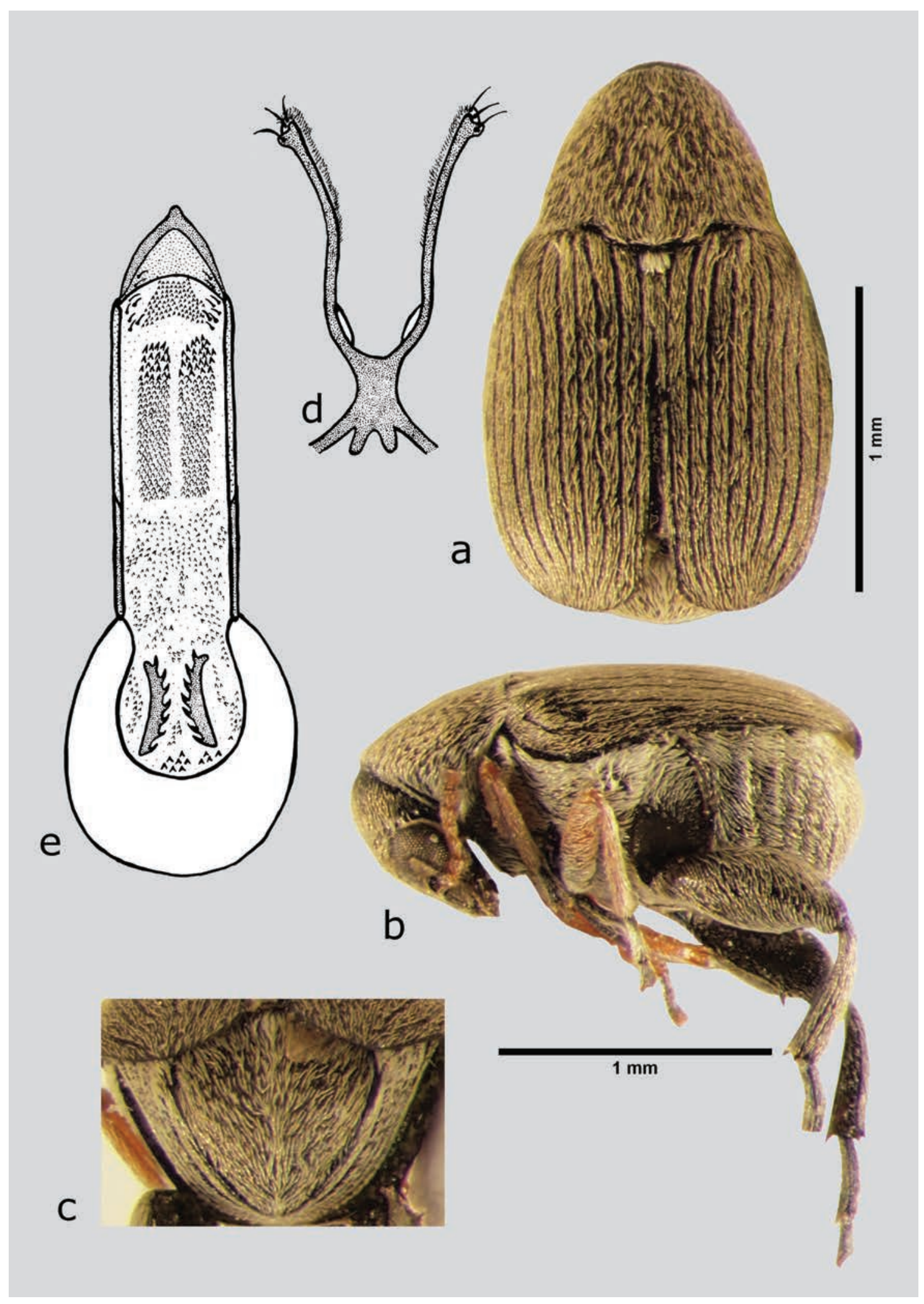

Figura 4. A. chiricahuae (hembra), a) dorsal, b) lateral, c) pigidio, d) lóbulos laterales, e) lóbulo medio. Dibujos tomados de Johnson (1983a). 
ricahuae también se alimenta de las semillas de al menos 15 especies más de mimosas en otras partes de México y de los Estados Unidos (Johnson 1970, Johnson 1983a); además de habérsele encontrado como visitante de las leguminosas $A$. coulteri y $P$. laevigata y de la ramnácea $K$. humboldtiana. Las hembras de esta especie presentan una oviposición tipo A (Johnson \& Romero 2004) y aparentemente un multivoltinismo de tres o varios ciclos generacionales más por año (observado durante su manipulación en campo y laboratorio), dependiendo mucho del recurso de sus plantas hospederas. Los hallazgos de este estudio amplían la distribución de esta especie en Zimapán y dentro del estado de Hidalgo.

Acanthoscelides macrophthalmus (Schaeffer, 1907) (fig. 5 a-e)

Material examinado. México: Hidalgo: ZIMAPÁN, Cruz Pintada, en una jardinera fuera de una escuela primaria, colecta de la cría en vainas de Leucaena pulverulenta, 26/IV/2012, 1753 m, colector Godínez-Cortes S., 2042'30.2" N, 99²2'32.7" W, IB-UAEH (5 ex); ZIMAPÁN, dentro del jardín de una casa, calle Centenario, colecta de la cría en vainas de Leucaena leucocephala, 5/ I/2011, 1789 m, colector Godínez-Cortes S, 2044'25.9" N, 99²2'46.7" W, CEAM (4 ex); ZIMAPÁN, Francisco Villa, cerca de campos agrícolas y terrenos baldíos cercados, bosque espinoso perturbado, colecta de la cría en vainas de Leucaena pulverulenta, 25/IV/2012, $1870 \mathrm{~m}$, colector Godínez-Cortes S., 2041'39.4" N, 99¹9'59.7" W, CEAM (1 ex); ZIMAPÁN, La Cruz, a un costado de la carretera federal 85 México-Nuevo Laredo y el Río Tula, matorral crasicaule, colecta con red de golpeo en Acacia coulteri, 8/X/2010, 1633 m, colector Godínez-Cortes S., 20³4'42.1" N, 99²0'35.5" W, CEAM (3 ex).

Distribución en México. Baja California Sur, Campeche, Chiapas, Estado de México, Guerrero, Hidalgo (Chapulhuacán, Ixmiquilpan, Huejutla, Zimapán), Jalisco, Morelos, Nuevo León, Oaxaca, Puebla, Querétaro, Quintana Roo, San Luis Potosí, Sinaloa, Sonora, Tabasco, Tamaulipas, Veracruz, Yucatán.

Hospedero asociado. L. leucocephala, L. pulverulenta. Discusión taxonómica y comentarios ecológicos. Además de las plantas hospederas antes mencionadas, $A$. macrophthalmus se alimenta de las semillas de al menos 13 especies más de leucaenas en otras partes de México (Johnson 1983a, Kingsolver 2004). Las hembras de esta especie presentan una oviposición tipo A (Tuda et al. 2009), ya que los frutos sobre los que ovipositan permanecen mucho más tiempo sobre el árbol del que deja caer sus semillas (Zárate 1994) y un multivoltinismo de tres o varios ciclos generacionales más por año, dependiendo del recurso y la temperatura (observado durante su manipulación en campo y laboratorio). Los hallazgos de este estudio amplían la distribución de esta especie en Zimapán y en el estado de Hidalgo.

Acanthoscelides mexicanus (Sharp, 1885) (fig. 6 a-e) Material examinado. México: Hidalgo: ZIMAPÁN, Saucillo, en una ladera, bosque espinoso perturbado, colecta con red de golpeo en Mimosa aculeaticarpa asociada a Tillandsia recurvata, 4/I/2011, 1875 m, colector Godínez-Cortés S., 20³8'31.9" N, 99²7'15.7" W, CEAM (1 ex).

Distribución en México. Aguascalientes, Baja California Sur, Campeche, Chiapas, Colima, Durango, Estado de México, Guanajuato, Guerrero, Hidalgo (Cardonal, Jacala, Nicolás Flores, Pachuca, Tepetitlán, Zempoala, Zimapán), Jalisco, Michoacán, Morelos, Nayarit, Oaxaca, Puebla, Querétaro, San Luis Potosí, Sinaloa, Sonora, Tamaulipas, Tlaxcala, Veracruz.

Hospedero asociado. No registrado.

Discusión taxonómica y comentarios ecológicos. Acanthoscelides mexicanus se encontró golpeando plantas de M. aculeaticarpa, aunque en ese tiempo no tenía vainas los insectos ya estaban sobre una de sus hospederos; a este brúquido se le ha reportado alimentándose de al menos 30 especies de mimosas más (Johnson 1983a, Romero 2016), entre otros géneros de plantas que necesitan corroborarse. Si es así, las hembras de esta especie presentan una oviposición tipo B, ya que los hospederos en los que se ha criado y colectado (Johnson 1983a) presentan frutos dehiscentes (Andrade et al. 2007); sin embargo, el tipo de voltinismo aún es desconocido. Vale la pena señalar también, que es muy común confundir esta especie con su especie hermana A. speciosus, de distribución más restringida; prueba de ello, los constantes reordenamientos taxonómicos que sufrieron ambas especies hasta su situación actual (Johnson 1983a, Kingsolver 2004). Los hallazgos de este estudio amplían la distribución de esta especie en Zimapán y en el estado de Hidalgo.

Acanthoscelides speciosus (Schaeffer, 1907) (fig. 7 a-e) Material examinado. México: Hidalgo: ZIMAPÁN, 18 km NE Santuario, vic. Potrero, 12/VI/2004, 2364 m, colector Westcott R. L., 2043'52.38" N, 9907'21.72" W, CEAM (1 ex).

Distribución en México. Coahuila, Durango, Estado de México, Guanajuato, Morelos, Nuevo León, Oaxaca, Que- 


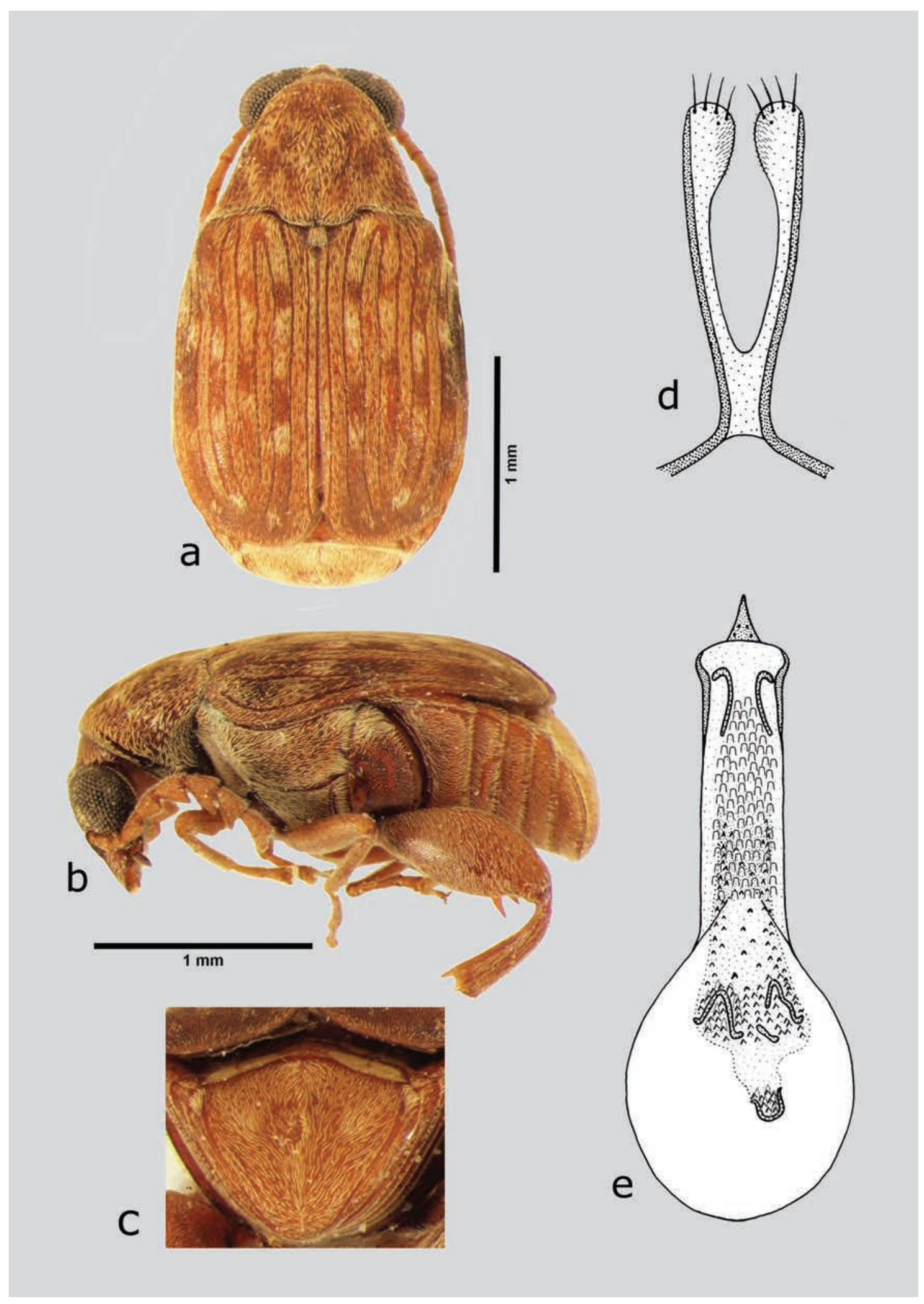

Figura 5. A. macrophthalmus (macho), a) dorsal, b) lateral, c) pigidio, d) lóbulos laterales, e) lóbulo medio. Dibujos tomados de Johnson (1983a). 


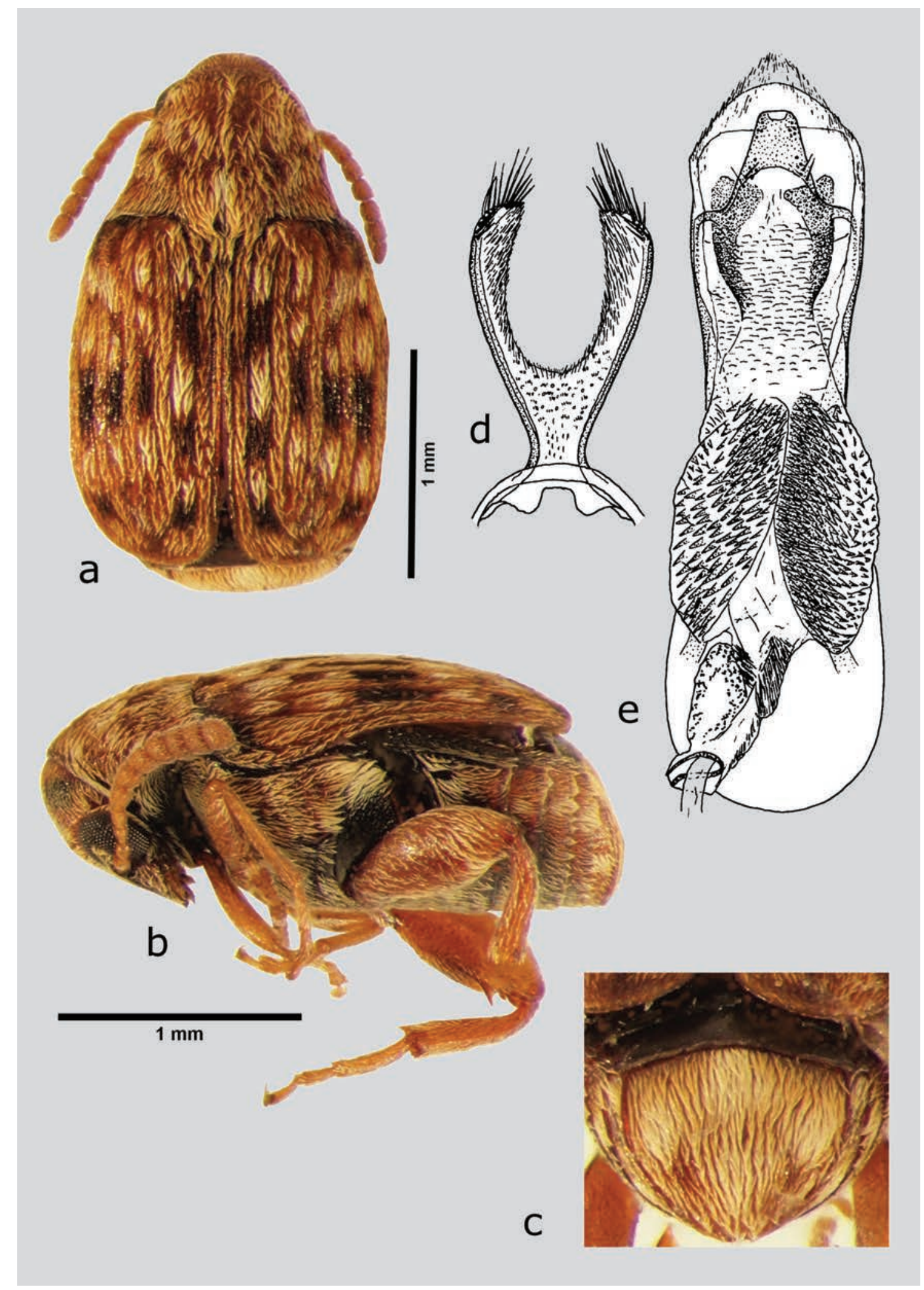

Figura 6. A. mexicanus (macho), a) dorsal, b) lateral, c) pigidio, d) lóbulos laterales, e) lóbulo medio. Dibujos tomados de Johnson (1983a). 


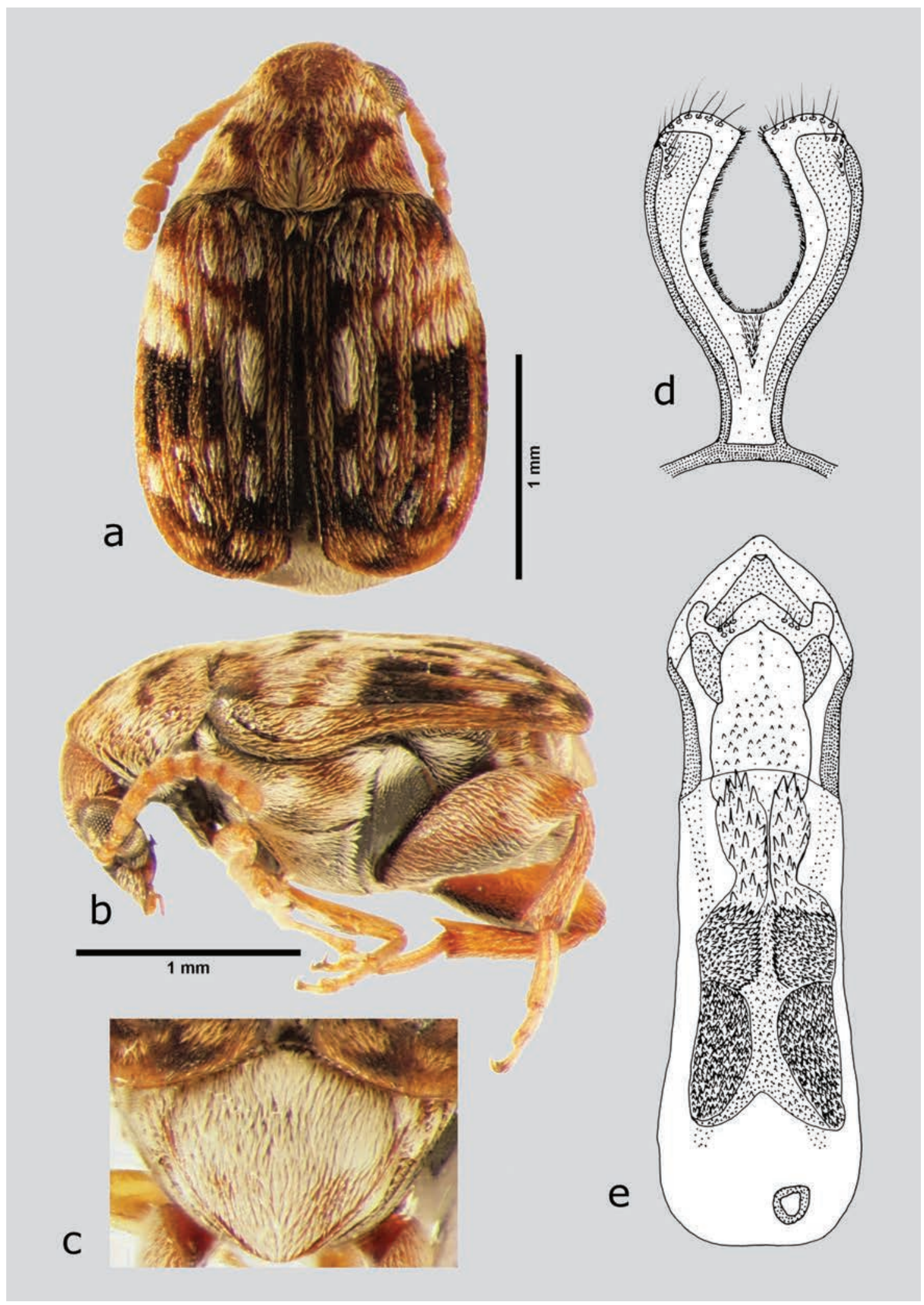

Figura 7. A. speciosus (macho), a) dorsal, b) lateral, c) pigidio, d) lóbulos laterales, e) lóbulo medio. Dibujos tomados de Johnson (1983a). 
rétaro, Tamaulipas. Nuevos registros. Hidalgo (Cardonal, Jacala, Pachuca, Tepetitlán, Tulancingo, Zimapán).

Hospedero asociado. No registrado.

Discusión taxonómica y comentarios ecológicos. No se registró el hospedero en Zimapán para A. speciosus; se sabe que se alimenta de las semillas de al menos cuatro mimosas más en México y Estados Unidos, M. aculeaticarpa, M. galeottii, M. malacophylla y M. martindelcampoi (Romero 2016). Así mismo, aunque su tipo de oviposición no ha sido observado, es posible que las hembras de esta especie presenten del tipo B (Johnson \& Romero 2004), ya que los hospederos en los que se ha criado y colectado (Johnson 1983a, Romero 2016) presentan frutos dehiscentes (Andrade et al. 2007); sin embargo, el tipo de voltinismo aún es desconocido. Al igual que con A. mexicanus, es muy común confundir ambas especies; prueba de ello, los constantes reordenamientos taxonómicos que sufrieron ambas especies hasta su situación actual (Johnson 1983a, Kingsolver 2004). La presencia de $A$. speciosus en el municipio de Zimapán y en otros municipios del estado (datos no publicados), representa un nuevo dato de distribución y un nuevo registro de esta especie para el estado de Hidalgo.

Acanthoscelides stylifer (Sharp, 1885) (fig. 8 a-e)

Material examinado. México: Hidalgo: ZIMAPÁN, a un costado de la carretera federal 85 México-Nuevo Laredo, ecotono de matorral micrófilo-encinar, colecta con red de golpeo en Barkleyanthus salicifolius, 25/IV/2012, 1940 m, colector Godínez-Cortés S., 2050'30.0" N, 99¹5'01.8" W, CEAM (2 ex).

Distribución en México. Chihuahua, Colima, Distrito Federal, Durango, Guanajuato, Hidalgo (Cardonal, Zimapán), Jalisco, Morelos, Oaxaca, Puebla, Querétaro.

Hospedero asociado. No registrado.

Discusión taxonómica y comentarios ecológicos. Esta especie fue encontrada ocupando como planta de visita a la asterácea $B$. salicifolius; aunque se ha reportado como hospedero de Desmodium grahamii en México y en parte de los Estados Unidos (Johnson 1983a). Derivado de esto, las hembras de esta especie pueden presentar una oviposición tipo A (Johnson \& Romero 2004), ya que Desmodium, el género registrado como hospedero (Johnson 1983a), es una leguminosa con tomentos e indehiscente (Torres-Colín \& Delgado-Salinas 2008); sin embargo, el tipo de voltinismo aún es desconocido. Es importante señalar que dentro de Hidalgo y en el país, en general, sólo se le ha encontrado en escasos sitios y en una distribución restringida. Los hallazgos de este estudio amplían la dis- tribución de esta especie en Zimapán y dentro del estado de Hidalgo.

Algarobius atratus Kingsolver, 1986 (fig. 9 a-f)

Material examinado. México: Hidalgo: ZIMAPÁN, Megui, camino a Puerto Juárez, alrededor de campos agrícolas, borde agrícola, colectado de las vainas postdispersadas de Acacia schaffneri variedad bravoensis, 26/ IV/2012, 2414 m, colector Godínez-Cortés S., 20³8'42.3" N, 99¹6'57.1" W, IB-UAEH (1 ex); ZIMAPÁN, Megui, cerca de libramiento norte Centro-Carretera federal 85 México-Nuevo Laredo, matorral micrófilo, colecta de la cría en vainas de Prosopis laevigata, 28/VII/2011, 1873 m, colector Godínez-Cortés S., 2044'59.5" N, 99²0'33.7" W, CEAM (34 ex).

Distribución en México. Coahuila, Durango, Guanajuato, Hidalgo (Cardonal, El Arenal, Ixmiquilpan, San Salvador, Santiago de Anaya, Tasquillo, Zimapán), Jalisco, Puebla, San Luis Potosí, Tamaulipas, Zacatecas.

Hospedero asociado. $P$. laevigata.

Discusión taxonómica y comentarios ecológicos. Un solo ejemplar de A. atratus se encontró ocupando como planta de visita a la leguminosa A. schaffneri variedad bravoensis, por lo que se descarta como un hospedero de esta especie. Además de P. laevigata, $P$. juliflora es su hospedero en otras partes de México (Kingsolver 1986). Las hembras de esta especie presentan una oviposición tipo A (observado durante su manipulación en campo y laboratorio) en vainas colectadas de $P$. laevigata antes de la dispersión. Al parecer A. atratus posee un multivoltinismo de al menos cuatro ciclos generacionales por año, dependiendo mucho del recurso de la planta y de la zona geográfica, ya que su planta hospedera presenta frutos indehiscentes disponibles en tres temporadas del año (Andrade et al. 2007), además de las vainas encontradas en el sustrato que al ser indehiscentes perduran por mucho más tiempo y pueden ser utilizadas por estos (Parra 2011). Esta especie endémica de México, es fácilmente confundible con su especie hermana $A$. johnsoni, debido en parte por compartir el mismo hospedero.

Los hallazgos de este estudio amplían la distribución de esta especie en Zimapán y dentro del estado de Hidalgo.

Algarobius johnsoni Kingsolver, 1986 (fig. 10 a-f) Material examinado. México: Hidalgo: ZIMAPÁN, 3 mi. E Zimapán, 31/VII/1963, 1950 m, colector Duckworth \& Davis, USNM (3 ex); ZIMAPÁN, 3 mi. S Zimapán, 30/VI/1971, 2362 m, colector Ward \& Brothers, USNM (1 ex); ZIMAPÁN, 11 mi. S Zimapán, 25/VI/1971, 1676 


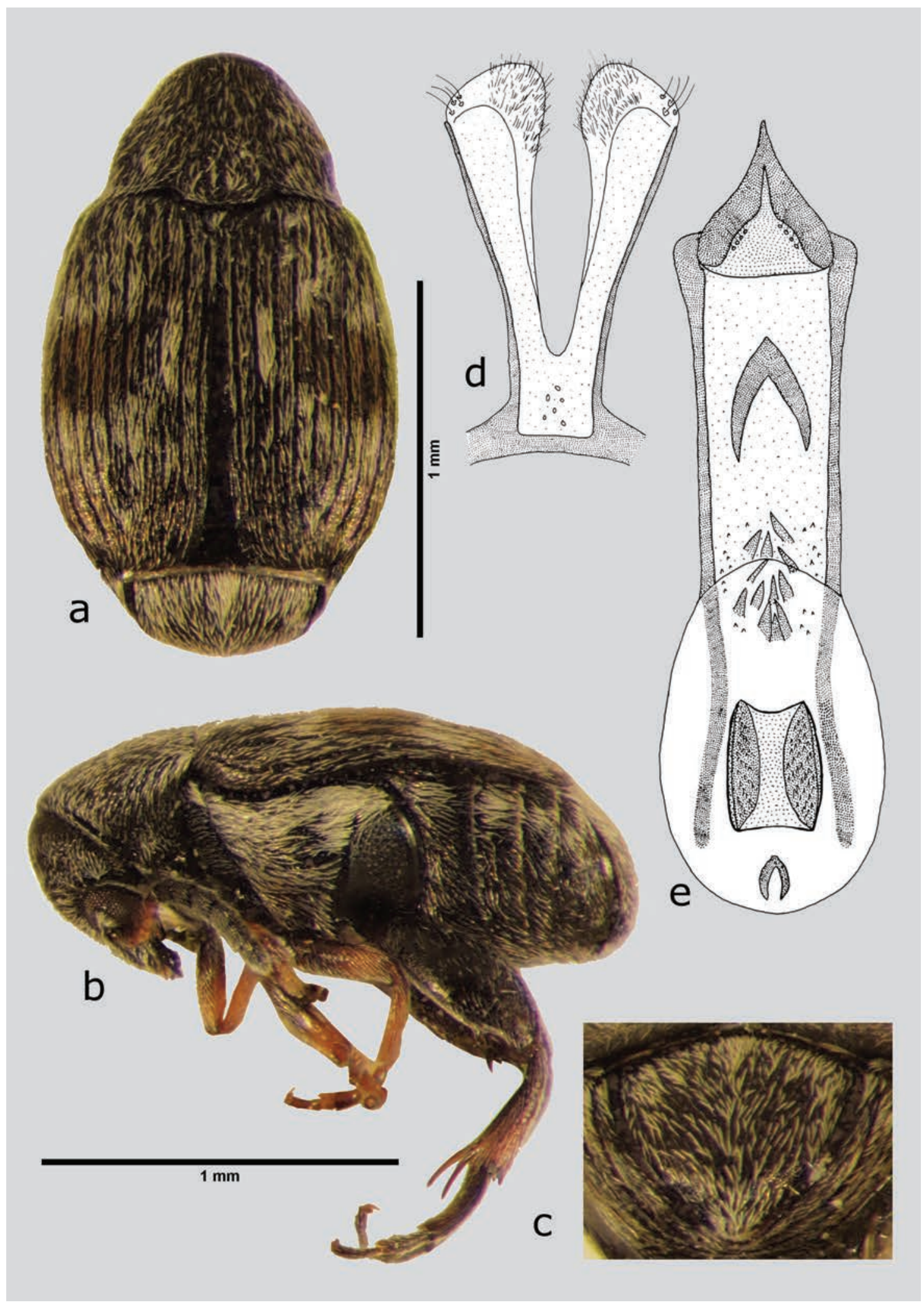

Figura 8. A. stylifer (macho), a) dorsal, b) lateral, c) pigidio, d) lóbulos laterales, e) lóbulo medio. Dibujos tomados de Johnson (1983a). 


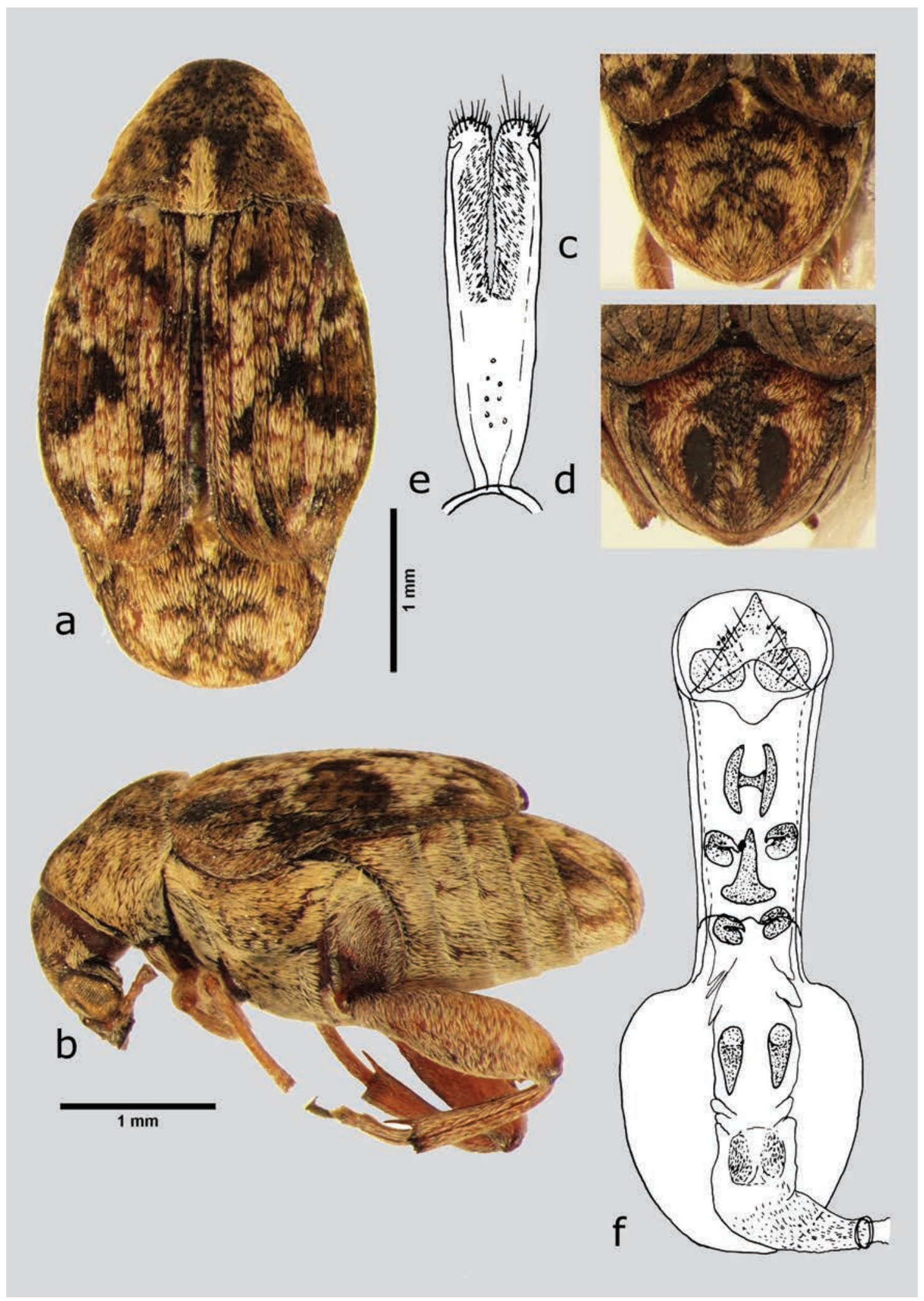

Figura 9. A. atratus (macho), a) dorsal, b) lateral, c) pigidio, d) pigidio (hembra), e) lóbulos laterales, f) lóbulo medio. Dibujos tomados de Kingsolver (1986). 


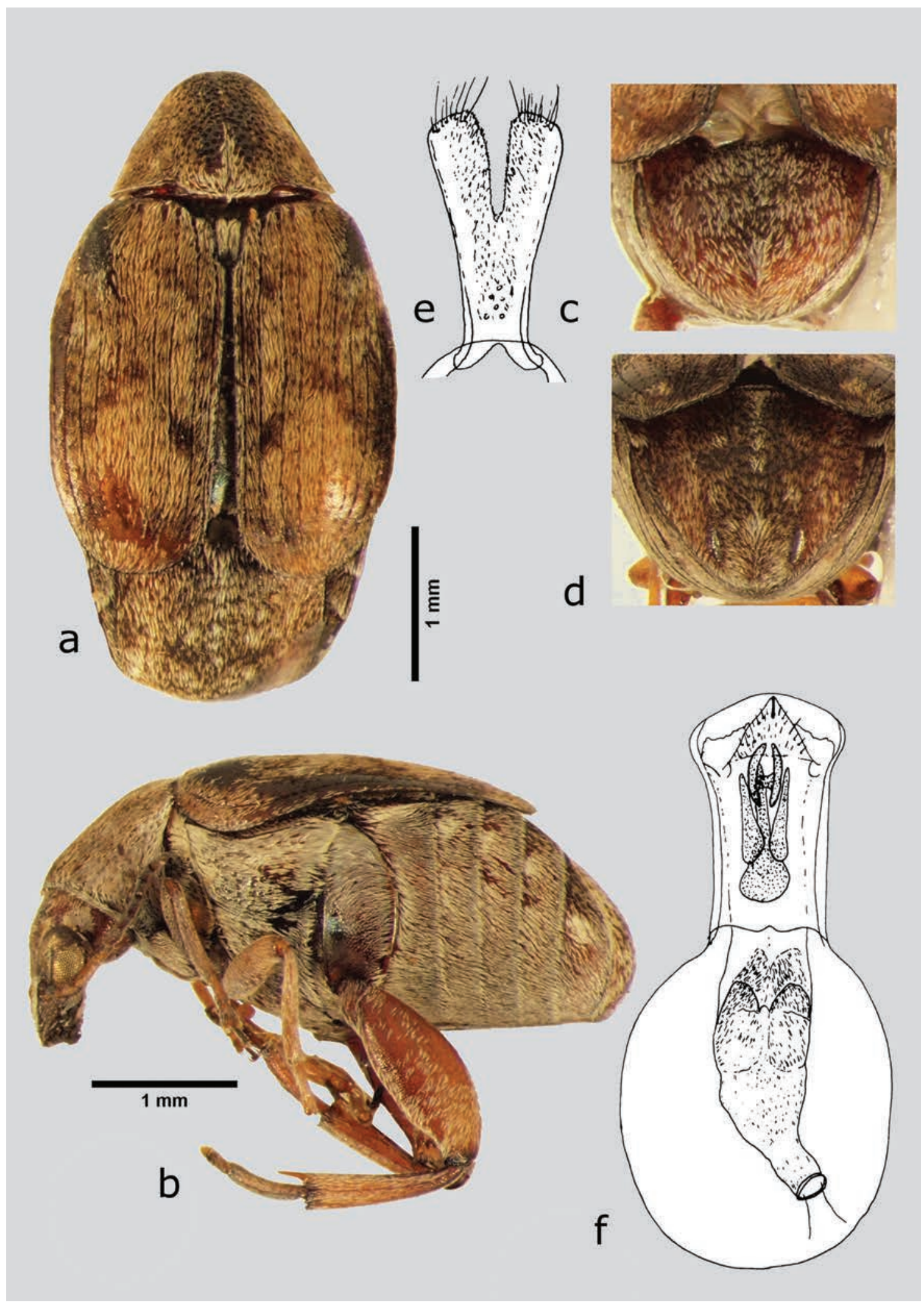

Figura 10. A. johnsoni (macho), a) dorsal, b) lateral, c) pigidio, d) pigidio (hembra), e) lóbulos laterales, f) lóbulo medio. Dibujos tomados de Kingsolver (1986). 
m, colector Ward \& Brothers, sobre mesquite, USNM (2 ex); ZIMAPÁN, 16/VIII/1956, colector Vasquez, criados de semillas de Prosopis sp., USNM (2 ex); ZIMAPÁN, Aguacatal, a un costado de la carretera federal 85 México-Nuevo Laredo, bosque espinoso, colecta con red de golpeo en Acacia farnesiana, 5/I/2011, 1959 m, colector Godínez-Cortés S., 20³6'47.7" N, 99²0'03.4" W, CEAM (1 ex); ZIMAPÁN, Aguacatal, a un costado de la carretera federal 85 México-Nuevo Laredo, matorral crasicaule, colecta con red de golpeo en Prosopis laevigata, 20/VII/2010 2008 m, colector Godínez-Cortés S., 20³7'21.8" N, 99¹9'49.6" W, CEAM (1 ex); ZIMAPÁN, Cruz Pintada, en una jardinera fuera de una escuela primaria, colecta con red de golpeo en Leucaena pulverulenta, 26/IV/2012, 1753 m, colector Godínez-Cortés S., 2042'30.2" N, 99²2'32.7" W, CEAM (2 ex); ZIMAPÁN, El Barrón, sobre el camino Jorge Pressier Terán, bosque espinoso perturbado, colecta con red de golpeo en Acacia berlandieri, 26/IV/2012, 1823 m, colector GodínezCortés S., 2045'23.5" N 99²3'57.3" W, CEAM (2 ex); ZIMAPÁN, Francisco Villa, cerca de campos agrícolas y terrenos baldíos cercados, bosque espinoso perturbado, colecta con red de golpeo en Karwinskia humboldtiana, 25/IV/2012, 1915 m, colector Godínez-Cortés S., 2041'32.4" N, 99¹9'16.9" W, CEAM (1 ex); ZIMAPÁN, La Cruz, a un costado de la carretera federal 85 México-Nuevo Laredo y el Río Tula, matorral crasicaule, colecta de la cría en vainas de Prosopis laevigata, 8/ X/2010, 1633 m, colector Godínez-Cortés S., 20³4'42.1" N, 99²0'35.5" W, IB-UAEH (5 ex); ZIMAPÁN, Megui, Camino a Puerto Juárez, alrededor de campos agrícolas, borde agrícola, colectado de las vainas postdispersadas de Acacia schaffneri variedad bravoensis, 26/IV/2012, 2414 m, colector Godínez-Cortés S., 20³8'42.3" N, 99¹6'57.1" W, CEAM (1 ex); ZIMAPÁN, Megui, cerca de libramiento norte Centro-Carretera federal 85 México-Nuevo Laredo, matorral micrófilo, colecta de la cría en vainas de Prosopis laevigata, 28/VII/2011, $1873 \mathrm{~m}$, colector Godínez-Cortés S., 2044'59.5" N, 99²0'33.7" W, CEAM (467 ex); ZIMAPÁN, Saucillo, en una ladera, bosque espinoso perturbado, colecta con red de golpeo en Mimosa aculeaticarpa asociada a Tillandsia recurvata, 4/ I/2011, 1875 m, colector Godínez-Cortés S., 20³8'31.9" N, 99²7'15.7" W, CEAM (1 ex); ZIMAPÁN, Saucillo, en una ladera, bosque espinoso perturbado, colecta con red de golpeo en Mimosa lacerata asociada a Tillandsia recurvata, 4/I/2011, 1875 m, colector Godínez-Cortés S., 20³8'31.9" N, 99²7'15.7" W, CEAM (1 ex); ZIMAPÁN, Xindho, lindero de campo agrícola, borde agrícola, colec- ta de la cría en vainas de Prosopis laevigata, 25/IV/2012, 1894 m, colector Godínez-Cortés S., 2043'31.0" N, 99॰19'39.1" W, IB-UAEH (9 ex).

Distribución en México. Aguascalientes, Chiapas, Chihuahua, Coahuila, Distrito Federal, Durango, Estado de México, Guanajuato, Guerrero, Hidalgo (Actopan, Cardonal, Ixmiquilpan, San Salvador, Santiago Anaya, Tasquillo, Tepetitlán, Zimapán), Jalisco, Michoacán, Morelos, Nayarit, Nuevo León, Oaxaca, Puebla, Querétaro, San Luis Potosí, Sinaloa, Sonora, Tamaulipas, Veracruz, Zacatecas.

Hospedero asociado. P. laevigata.

Discusión taxonómica y comentarios ecológicos. Algarobius johnsoni ya se conocía previamente en el estado de Hidalgo y particularmente en Zimapán, ya que parte de los datos de colecta reportados anteriormente fueron utilizados por Kingsolver (1986) cuando describió la especie por primera vez para la ciencia. Además de colectarse de su hospedero habitual, también se colectó sobre el follaje de cinco leguminosas más: A. berlandieri, A. farnesiana, L. pulverulenta, M. aculeaticarpa y M. lacerata y una ramnácea ( $K$. humboldtiana); y sobre las vainas postdispersadas de $A$. schaffneri variedad bravoensis, consideradas todas como plantas de visita. A. johnsoni al igual que A. atratus presenta el tipo de oviposición A (Johnson \& Romero 2004), observado en vainas colectadas de $P$. laevigata antes de la dispersión; también posee un multivoltinismo de al menos cuatro ciclos generacionales por año (observado durante su manipulación en campo y laboratorio). Es importante mencionar que esta especie es fácilmente confundible con su especie hermana A. atratus. Los hallazgos de este estudio amplían la distribución de esta especie en el estado de Hidalgo.

Gibbobruchus cristicollis (Sharp, 1885) (fig. 11 a-f) Material examinado. México: Hidalgo: ZIMAPÁN, 16 mi. N Zimapán Hwy 85, ejemplares emergidos de Bauhinia macranthera Benth. ex Hemsl. procedente de un Herbario, 21/VIII/1971, colector R. P. Wunderlin, TAMU (4 ex).

Distribución en México. Chiapas, Durango, Guerrero, Hidalgo (Zimapán), Michoacán, Oaxaca, Quintana Roo, San Luis Potosí, Tamaulipas, Veracruz.

Hospedero asociado. B. macranthera.

Discusión taxonómica y comentarios ecológicos. Gibbobruchus cristicollis ya se conocía previamente en el estado de Hidalgo y particularmente en Zimapán, ya que parte de los datos de colecta reportados anteriormente fueron utilizados por Whitehead \& Kingsolver (1975) 


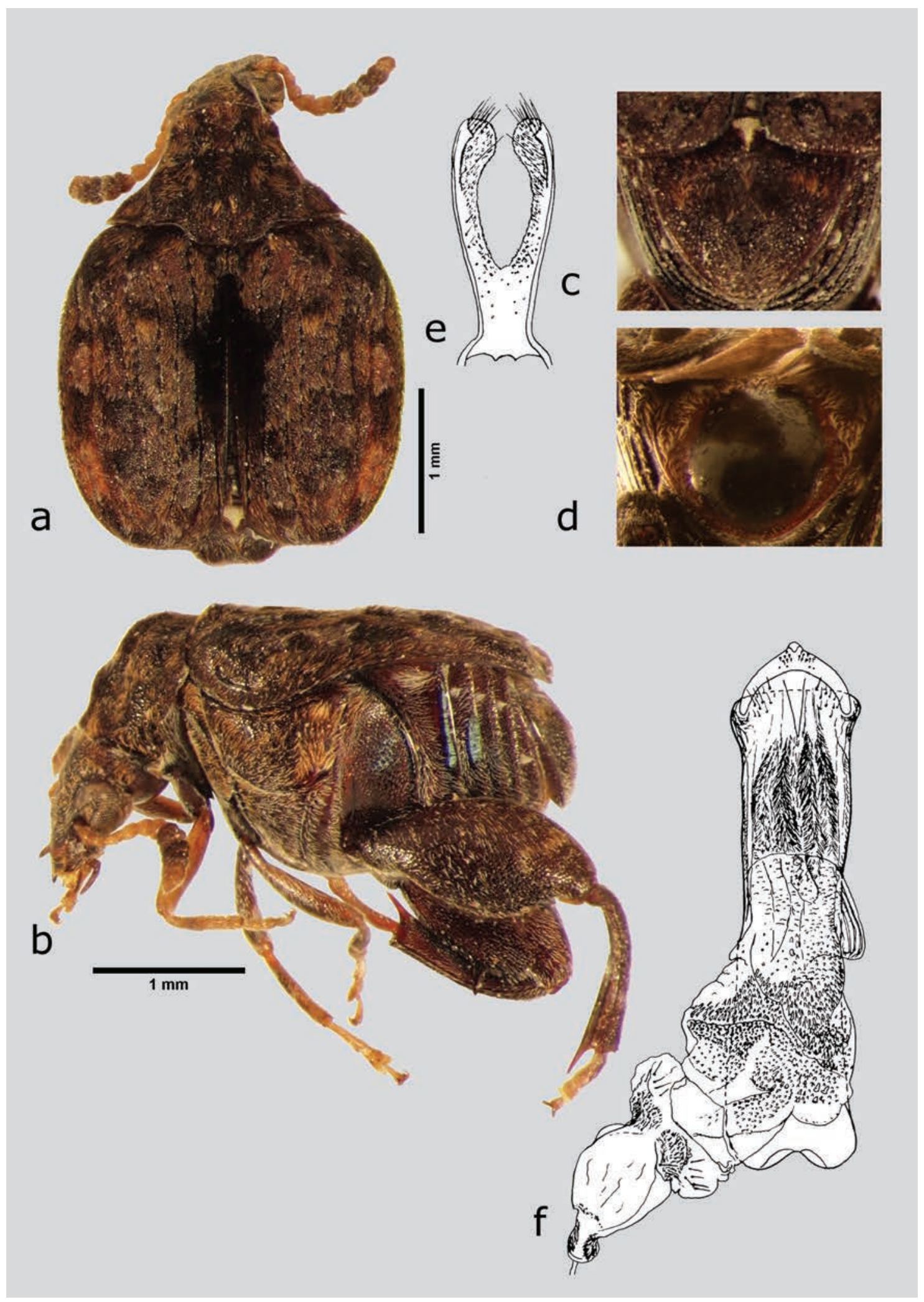

Figura 11. G. cristicollis (macho), a) dorsal, b) lateral, c) pigidio, d) pigidio (hembra), e) lóbulos laterales, f) lóbulo medio. Dibujos tomados de Whitehead \& Kingsolver (1975). 
cuando se indicó una nueva combinación taxonómica de esta especie. G. cristicollis también puede alimentarse de cuatro especies más de bahuinas en América y una de Cercis: B. lunarioides, B. coulteri, B. divaricata, B. pauletia y C. canadensis variedad mexicana (Whitehead \& Kingsolver 1975, Manfio 2011). Aunque su oviposición no ha sido observada, según Whitehead \& Kingsolver (1975) las hembras de esta especie pueden presentar dos tipos de oviposición, tipo A y tipo B (Johnson \& Romero 2004), aunque tienen preferencia por la segunda, ya que la planta hospedera de la que se alimenta presenta frutos dehiscentes (Whitehead \& Kingsolver 1975); sin embargo, el tipo de voltinismo aún es desconocido.

Meibomeus hidalgoi Kingsolver y\& Whitehead, 1976 (fig. 12 a-e)

Material examinado. México: Hidalgo: ZIMAPÁN, Puerto del Ángel, encinar, colecta con red de golpeo en Senna guatemalensis variedad hidalgensis, 8/X/2010, 2607 m, colector Godínez-Cortés S., 2047'33.9" N, 99²3'04.1" W, CEAM (1 ex).

Distribución en México. Chiapas, Estado de México, Guerrero, Jalisco, Morelos, Oaxaca. Nuevos registros. Hidalgo (Zimapán).

Hospedero asociado. No registrado.

Discusión taxonómica y comentarios ecológicos. Meibomeus hidalgoi fue encontrado como visitante de la leguminosa S. guatemalensis variedad hidalgensis. Debido a que la literatura reporta un desconocimiento total del hospedero de esta especie, no es posible conocer el tipo de oviposición que presenta (Kingsolver \& Whitehead 1976); sin embargo, se podría discernir a partir de que la mayoría de las especies del género Meibomeus llevan a cabo su puesta de huevos sobre las leguminosas de vainas indehiscentes de Desmodium (Kingsolver \& Whitehead 1976, Torres-Colín \& Delgado-Salinas 2008), lo que correspondería a un tipo de oviposición A (Johnson \& Romero 2004). En consecuencia a lo antes mencionado, no se conoce su voltinismo; sin embargo, los datos ecológicos indican que se puede colectar en los meses de julio, agosto y octubre, lo que indica al menos dos ciclos generacionales. La presencia de $M$. hidalgoi representa un nuevo dato de distribución en el municipio de Zimapán y un nuevo registro de esta especie para el estado de Hidalgo.

Meibomeus serraticulus (Sharp, 1885) (fig. 13 a-e) Material examinado. México: Hidalgo: ZIMAPÁN, Durango, USNM (2 ex).
Distribución en México. Durango, Estado de México, Guanajuato, Hidalgo (Zimapán), Jalisco, Michoacán, Morelos, Oaxaca, Sinaloa, Tamaulipas.

Hospedero asociado. No registrado.

Discusión taxonómica y comentarios ecológicos. A pesar de no haber registro del hospedero en Zimapán para $M$. serraticulus, se sabe que se alimenta de las semillas de Desmodium bellum en otras partes de México por el reporte de colecta de ejemplares de herbario (Kingsolver \& Whitehead 1976). Aunque su tipo de oviposición no ha sido observado, es posible que las hembras de esta especie presenten una oviposición del tipo A (Johnson \& Romero 2004), ya que Desmodium, el género en el que se ha reportado, es una leguminosa con tomentos e indehiscente (Torres-Colín \& Delgado-Salinas 2008). A pesar de que el tipo de voltinismo aún es desconocido podrían considerarse los datos de colecta que reportan Kingsolver \& Whitehead (1976), los cuales corresponden de mayo a septiembre y por lo tanto un bivoltinismo.

Merobruchus julianus (Horn, 1894) (fig. 14 a-e)

Material examinado. México: Hidalgo: ZIMAPÁN, La Cruz, a un costado de la carretera federal 85 México-Nuevo Laredo y Río Tula, matorral crasicaule, colecta de la cría en vainas de Acacia coulteri, 8/X/2010, 1633 m, colector Godínez-Cortés S., 20³4'42.1" N, 99²0'35.5" W, CEAM (3ex).

Distribución en México. Baja California, Baja California Norte, Chihuahua, Coahuila, Hidalgo (Zimapán), Morelos, Nuevo León, Sonora, Tamaulipas.

Hospedero asociado. A. coulteri.

Discusión taxonómica y comentarios ecológicos. Además de $A$. coulteri, en la literatura se reportan al menos cuatro especies más de acacias hospederas para este brúquido: A. berlandieri, A. greggii, A. roemeriana y A. wrightii, además de una mimosa, $M$. borealis y una de ébeno, Ebenopsis ebano, tanto en Estados Unidos como en México (Kingsolver 1988, Kingsolver 2004, Romero 2016); además, siete especies más en las que se ha encontrado, sin la certeza de que efectivamente emergieron de las semillas y que necesitan ser corroborados en el futuro (Kingsolver 1988). Las hembras de esta especie presentan una oviposición tipo A (Johnson \& Romero 2004), observado a partir del tipo de frutos del que se colectaron y emergieron; y aunque no se conoce con precisión su voltinismo (Kingsolver 1988), es posible que fuese multivoltino con un periodo de diapausa en otoño e invierno, 


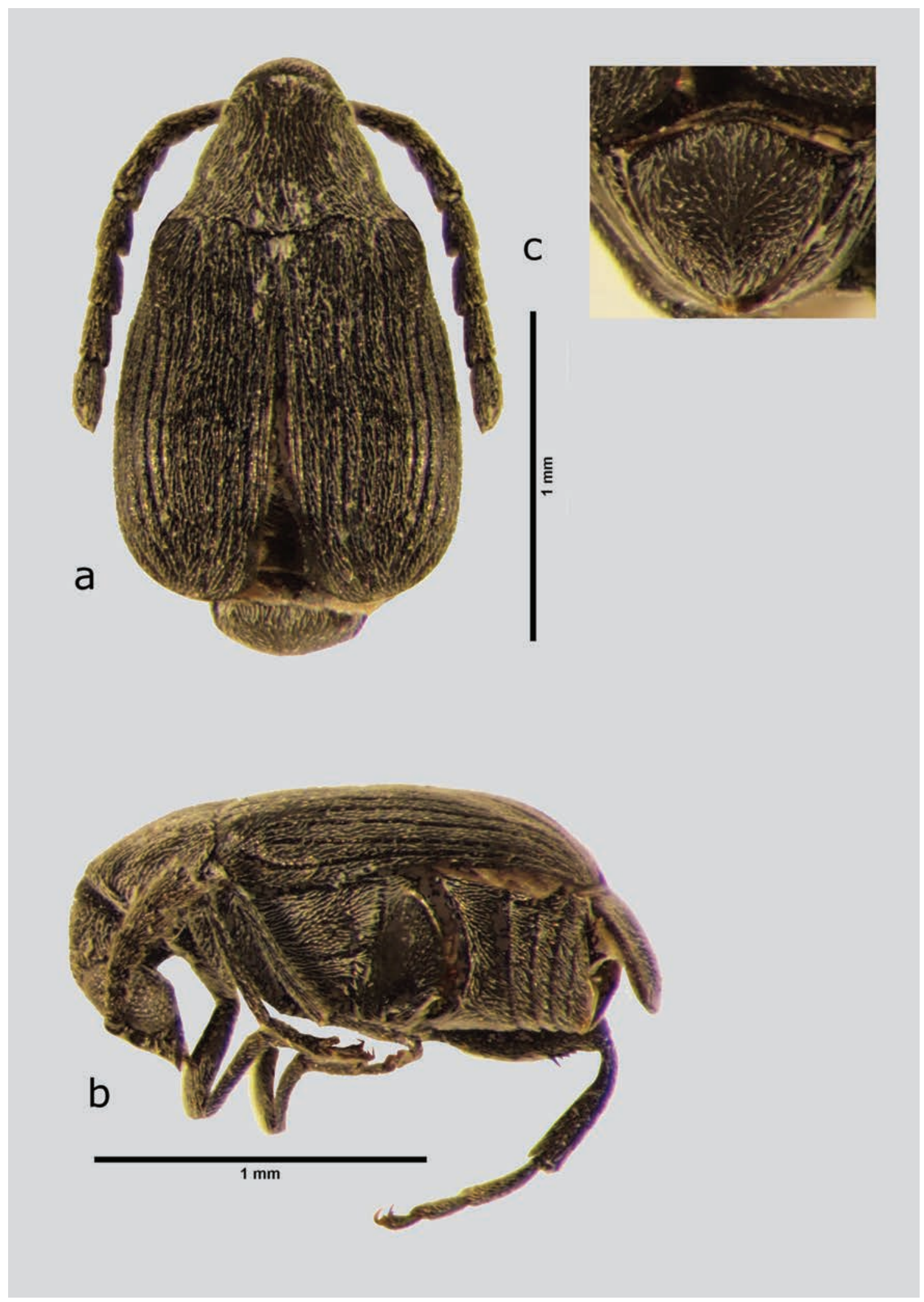

Figura 12. M. hidalgoi (macho), a) dorsal, b) lateral, c) pigidio, d) lóbulos laterales, e) lóbulo medio. Debido a que no existe aún la descripción de la genitalia del macho de esta especie para la ciencia, se está trabajando en su preparación y esquematización para publicarse en un futuro. 


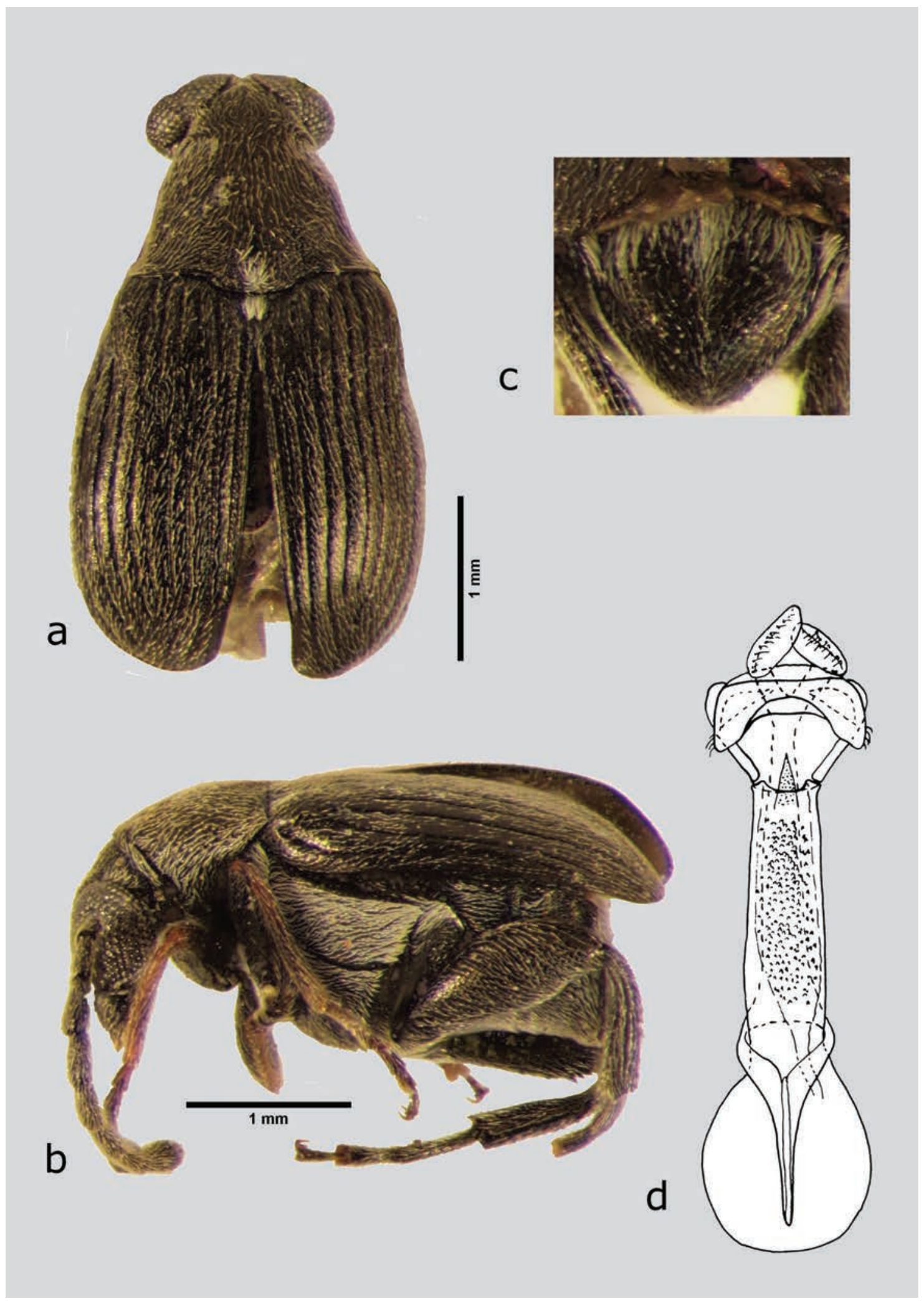

Figura 13. M. serraticulus (macho), a) dorsal, b) lateral, c) pigidio, d) lóbulos laterales y lóbulo medio. Dibujos tomados de Kingsolver \& Whitehead (1976). 


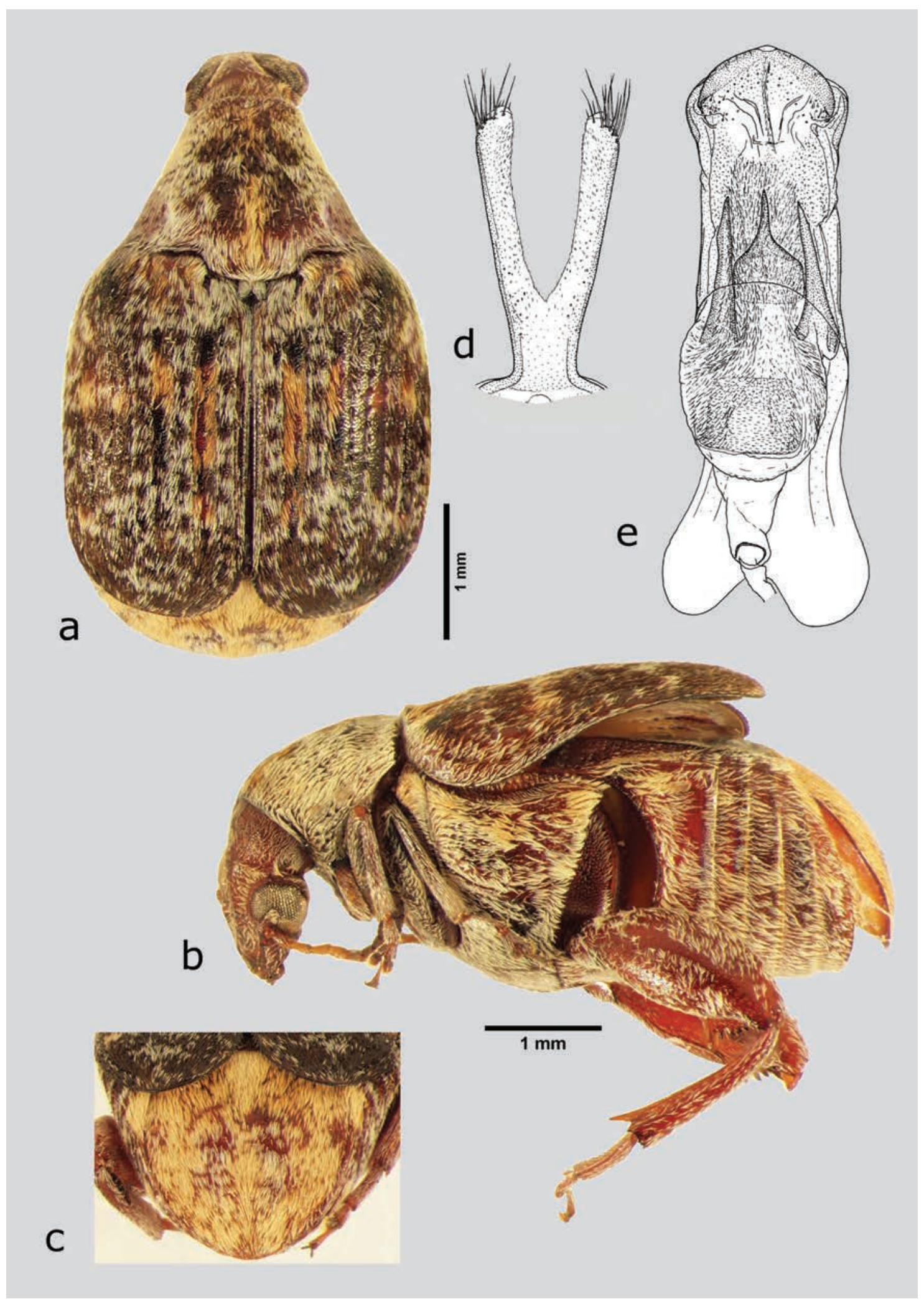

Figura 14. M. julianus (macho), a) dorsal, b) lateral, c) pigidio, d) lóbulos laterales, e) lóbulo medio. Dibujos tomados de Kingsolver (1988). 
debido a que se le ha colectado únicamente en los meses de abril a octubre (Kingsolver 1988, Godínez-Cortes et al. 2011).

Merobruchus major (Fall, 1912) (fig. 15 a-e)

Material examinado. México: Hidalgo: 26 mi. S Jacala, Hwy 85, 28/VII/1968, colector Garrison R. W., CEAM (1 ex).

Distribución en México. Hidalgo (Zimapán), Tamaulipas, Veracruz.

Hospedero asociado. No registrado.

Discusión taxonómica y comentarios ecológicos. A pesar de no haber registró del hospedero en Zimapán para $M$. major, se sabe que se alimenta de las semillas de $E$. ebano (Kingsolver 1988, Romero 2016). Su tipo de oviposición no ha sido observada, pero es posible que las hembras de esta especie presenten una oviposición del tipo A (Johnson \& Romero 2004), ya que E. ébano presenta frutos indehiscentes los cuales tiene que perforar para poder desarrollarse (Kingsolver 1988); con respecto al tipo de voltinismo, aún es desconocido. Es importante señalar, que esta especie de brúquido se le ha encontrado asociado únicamente a esta planta, endémica del Golfo de México (García et al. 2007). Los hallazgos de este estudio amplían la distribución de esta especie en Zimapán y dentro del estado de Hidalgo.

Merobruchus porphyreus Kingsolver, 1988 (fig. 16 a-e) Material examinado. México: Hidalgo: 3 km SW Jacala, 25/X/2004, 1320 m, colector Romero N. J., 2050'52" N, 99²'07" W, CEAM (1 ex).

Distribución en México. Chiapas, Colima, Durango, Jalisco, Sinaloa, Tamaulipas, Veracruz. Nuevos registros. Hidalgo (Zimapán).

Hospedero asociado. No registrado.

Discusión taxonómica y comentarios ecológicos. A pesar de no haber registro del hospedero en Zimapán para $M$. porphyreus, se sabe que se alimenta de las semillas de dos leguminosas del género Lysiloma, L. acapulcensis y L. divaricatum en otras partes de México (Kingsolver 1988). Es muy probable que las hembras de esta especie presenten una oviposición tipo B, ya que los hospederos en los que se ha colectado (Kingsolver 1988) presentan frutos dehiscentes (Pennington \& Sarukhán. 2005); con respecto al tipo de voltinismo, éste aún es desconocido. La presencia de $M$. porphyreus representa un nuevo dato de distribución en el municipio de Zimapán y un nuevo registro de esta especie para el estado de Hidalgo.
Mimosestes humeralis (Gyllenhal, 1833) (fig. 17 a-e)

Material examinado. México: Hidalgo: ZIMAPÁN, Las Limas, A un costado de la pista aérea, bosque espinoso perturbado, colecta de la cría en vainas de Acacia farnesiana, 28/VII/2011, 1819 m, colector Godínez-Cortés S., 2044'38.4" N, 99²0'00.9" W, IB-UAEH (3 ex).

Distribución en México. Chiapas, Colima, Durango, Estado de México, Guanajuato, Guerrero, Jalisco, Michoacán, Morelos, Nayarit, Oaxaca, Puebla, Querétaro, Sinaloa, Sonora, Veracruz, Zacatecas. Nuevos registros. Hidalgo (Zimapán).

Hospedero asociado. A. farnesiana, nuevo hospedero.

Discusión taxonómica y comentarios ecológicos. Además del nuevo hospedero registrado, $M$. humeralis se alimenta de al menos tres especies más de acacias: $A$. cochliacantha, A. pennatula y A. schaffneri (Kingsolver \& Johnson 1978, Romero 2016). A pesar de los números bajos en la colecta, esto no debe de sorprender, ya que ocurre un fenómeno parecido al de $M$. janzeni (ver discusión de la especie). Relacionado con la biología de acacias, las cual posee vainas indehiscentes bien cerradas (Andrade et al. 2007), las hembras de esta especie presentan una oviposición tipo A (Johnson \& Romero 2004), observado a partir del tipo de frutos del que emergieron. Por otro lado, esta especie podría ser multivoltina, de más de cuatro ciclos generacionales por año, debido a que se le ha colectado en al menos cuatro meses del año y tres estaciones distintas; enero, marzo, abril y agosto (Kingsolver \& Johnson 1978). La presencia de $M$. humeralis representa un nuevo dato de distribución en el municipio de Zimapán y un nuevo registro de esta especie para el estado de Hidalgo, así como un nuevo hospedero para esta especie.

Mimosestes janzeni Kingsolver \& Johnson, 1978 (fig. 18 a-e)

Material examinado. México: Hidalgo: ZIMAPÁN, Libramiento sur Centro-Carretera federal 85 México-Nuevo Laredo, bosque espinoso perturbado, colecta de la cría en vainas de Acacia farnesiana, 3/VIII/2011, 1795 m, colector Godínez-Cortés S., 2043'03.8" N, 99²1'41.1" W, CEAM (1 ex).

Distribución en México. Chiapas, Colima, Guerrero, Jalisco, Morelos, Nayarit, Oaxaca, Puebla, Sonora, Veracruz. Nuevos registros. Hidalgo (Zimapán).

Hospedero asociado. A. farnesiana, nuevo hospedero. Discusión taxonómica y comentarios ecológicos. Además del nuevo hospedero registrado, $M$. janzeni se alimenta de al menos tres especies más de acacias: $A$. cochliacantha, A. pennatula y A. pringlei subespecie cali- 


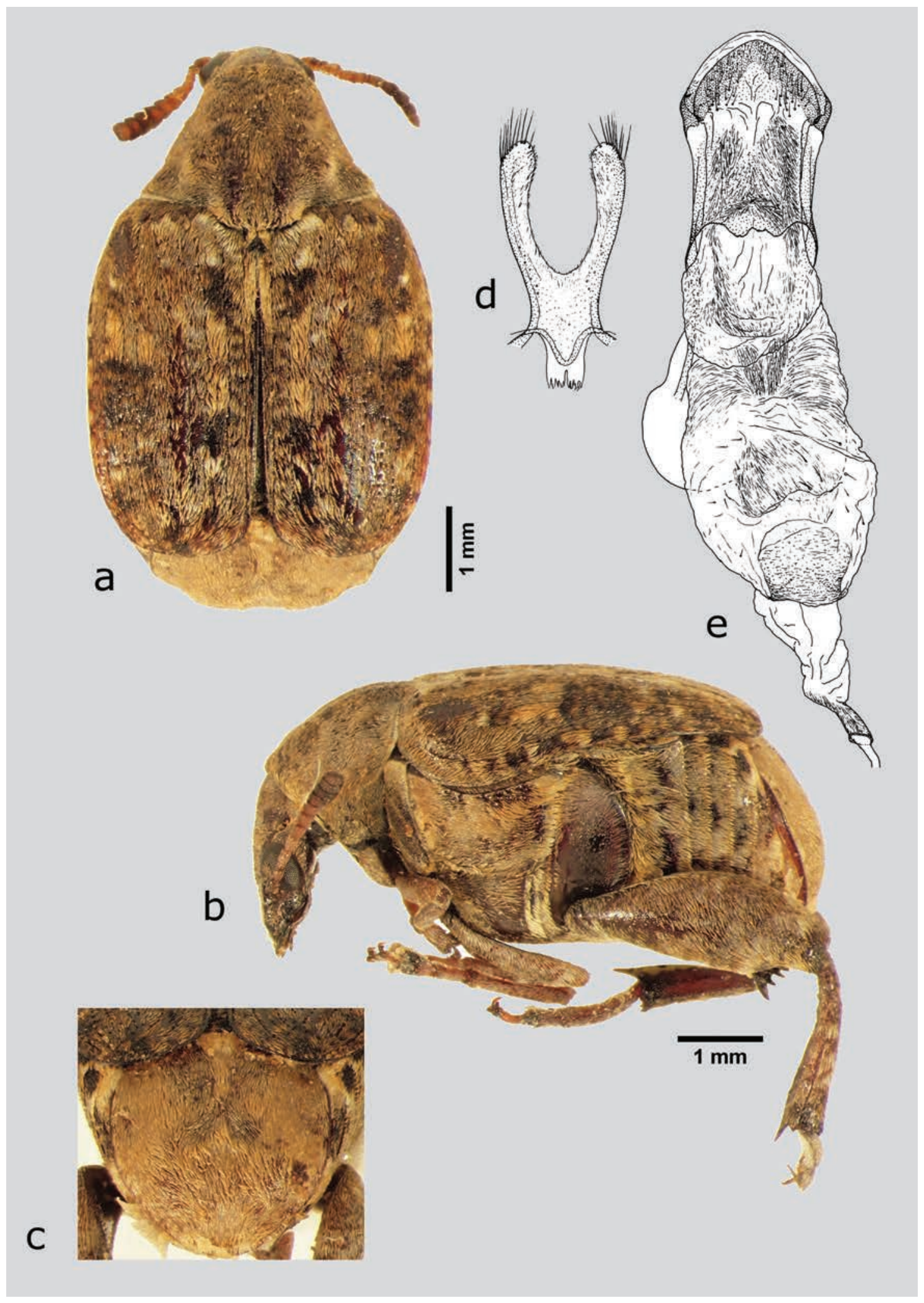

Figura 15. M. major (macho), a) dorsal, b) lateral, c) pigidio, d) lóbulos laterales, e) lóbulo medio. Dibujos tomados de Kingsolver (1988). 

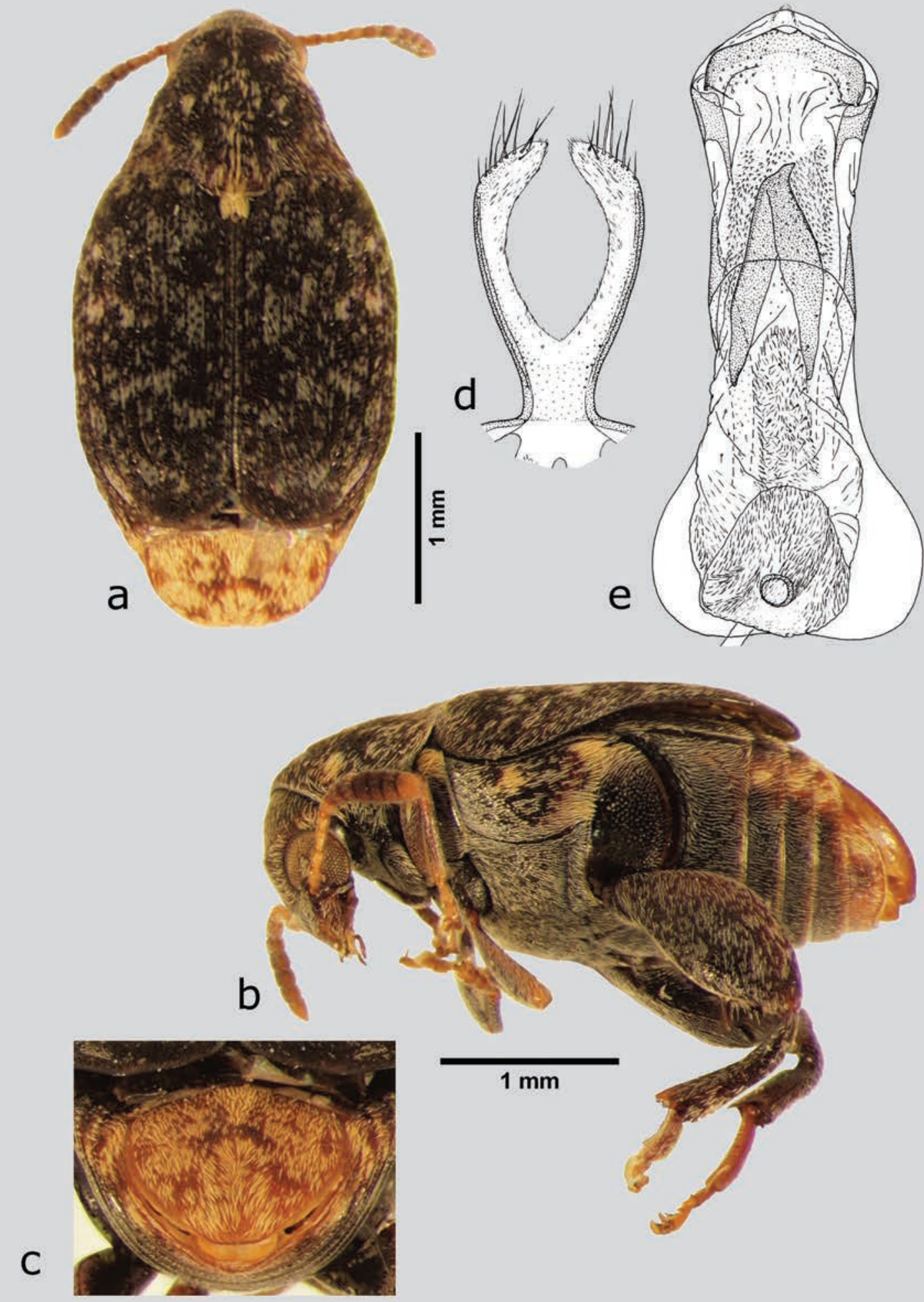

Figura 16. M. porphyreus (macho), a) dorsal, b) lateral, c) pigidio, d) lóbulos laterales, e) lóbulo medio. Dibujos tomados de Kingsolver (1988). 




Figura 17. M. humeralis (macho), a) dorsal, b) lateral, c) pigidio, d) lóbulos laterales, e) lóbulo medio. Dibujos tomados de Kingsolver \& Johnson (1978). 


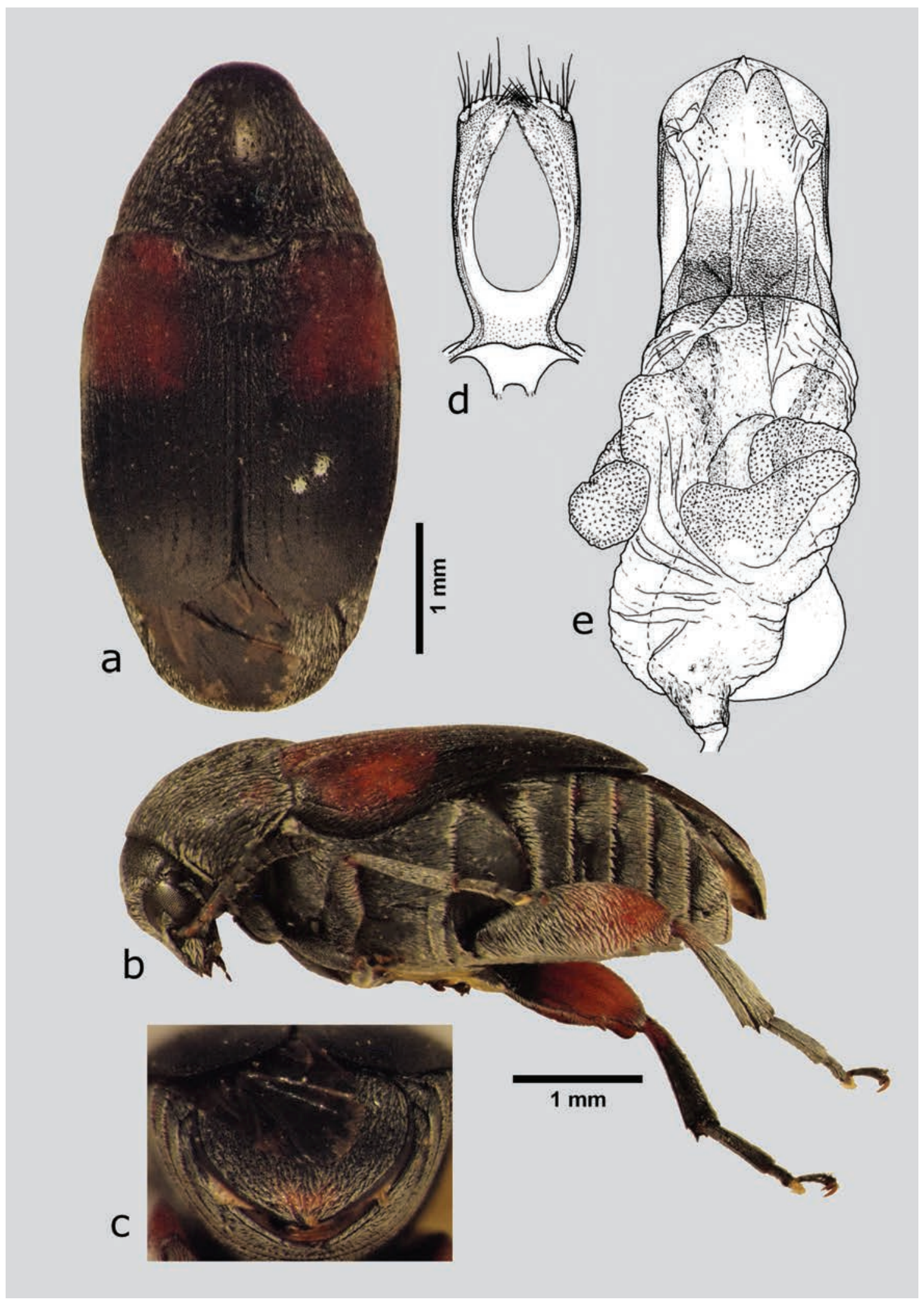

Figura 18. M. janzeni (macho), a) dorsal, b) lateral, c) pigidio, d) lóbulos laterales, e) lóbulo medio. Dibujos tomados de Kingsolver \& Johnson (1978). 
fornica (Kingsolver \& Johnson 1978, Romero 2016). Un solo ejemplar de esta especie fue encontrado en la colecta antes mencionada; y a pesar de los números bajos en la colecta, esto no debe de sorprender, pues en general Kingsolver \& Johnson (1978) ya habían considerado como "normal” el bajo número de individuos encontrados (no sólo en este hospedero, sino también en los hospederos restantes conocidos), considerando a esta especie como un mal competidor frente a otras especie de brúquidos; siendo A. farnesiana cómo un hospedero alternativo, pero, no predilecto, o como parte de un proceso evolutivo en proceso en el que esta especie explora nuevos nichos. Relacionado con la biología de acacias, las cual posee vainas indehiscentes bien cerradas (Andrade et al. 2007), las hembras de esta especie presentan una oviposición tipo A (Johnson \& Romero 2004), observado a partir del tipo de frutos del que emergieron. Por otro lado, esta especie podría ser multivoltina, de más de cuatro ciclos generacionales por año, debido a que se le ha colectado en casi todos los meses del año (Kingsolver \& Johnson 1978). La presencia de $M$. janzeni representa un nuevo dato de distribución en el municipio de Zimapán y un nuevo registro de esta especie para el estado de Hidalgo, así como un nuevo hospedero para esta especie.

Mimosestes nubigens (Motschulsky, 1874) (fig. 19 a-e) Material examinado. México: Hidalgo: ZIMAPÁN, 3 mi. N Las Trancas, Parque Nacional Los Mármoles, Acacia farnesiana, colector Romero N. J., 20/VII/1999, 2050 m, 2049'14" N, 99¹5'28" W, CEAM (500 ex); ZIMAPÁN, 3 mi. N Las Trancas, Parque Nacional Los Mármoles, Acacia farnesiana, colector Romero N. J., 20/VII/1999, 2050 m, 2049'14" N, 99¹5'28" W, CNIN (5 ex); ZIMAPÁN, a un costado de la carretera federal 85 México-Nuevo Laredo, bosque espinoso, colecta de la cría en vainas de Acacia schaffneri variedad schaffneri, 27/VII/2010, 1998 m, colector Godínez-Cortés S., 20³7'23.2" N, 99¹9'53.6" W, IB-UAEH (318 ex); ZIMAPÁN, a un costado de la carretera federal 85 México-Nuevo Laredo, matorral submontano, colecta por redeo con golpeo de Acacia sp., 25/IV/2012, 1894 m, colector Godínez-Cortés S., 2047'25.5" N, 99¹7'33.2" W, CEAM (1 ex); ZIMAPÁN, Aguacatal, a un costado de la carretera federal 85 México-Nuevo Laredo, bosque espinoso perturbado, colecta de la cría en vainas de Acacia schaffneri variedad schaffneri, 8/X/2010, 1918 m, colector Godínez-Cortés S., 20³9'40.5" N, 99²0'05.3" W, CEAM (161ex); ZIMAPÁN, Aguacatal, a un costado de la carretera federal 85 México-Nuevo Laredo, bosque espinoso, colecta de la cría en vainas de Acacia farnesiana, 5/I/2011, 1959 m, colector Godínez-Cortés S., 20³6'47.7" N, 99²0'03.4" W, CEAM (170 ex); ZIMAPÁN, Aguacatal, cerca de la carretera federal 85 México-Nuevo Laredo, bosque espinoso, colecta de la cría en vainas de Acacia farnesiana, 3/VIII/2011, 2003 m, colector Godínez-Cortés S., 20³7'11.4" N, 99¹9'47.9" W, CEAM (30 ex); ZIMAPÁN, cerca de la carretera federal 85 México-Nuevo Laredo, bosque espinoso, colecta de la cría en vainas de Acacia farnesiana, 28/VII/2011, 1923 m, colector Godínez-Cortés S., 2046'19.9" N, 99¹9'13.3" W, CEAM (30 ex); ZIMAPÁN, Francisco Villa, cerca de campos agrícolas y terrenos baldíos cercados, bosque espinoso perturbado, colecta de la cría en vainas de Acacia farnesiana, 25/IV/2012, 1870 m, colector Godínez-Cortés S., 2041'39.4" N, 99¹9'59.7" W, CEAM (2 ex); ZIMAPÁN, La Cruz, cerca de la carretera federal 85 MéxicoNuevo Laredo, bosque espinoso perturbado, colecta de la cría en vainas de Acacia farnesiana, 26/VIII/2011, 1625 m, colector Godínez-Cortés S., 20³4'50.9" N, 99²0'40.7" W, CEAM (30 ex); ZIMAPÁN, La Majada, km 135.5 carr. Zimapán-Tamazunchale, colector Romero N. J., 24/X/2004, 1955 m, 2149'13" N, 99¹5'29" W; CEAM (1 ex); ZIMAPÁN, Las Limas, a un costado de la pista aérea, bosque espinoso perturbado, colecta de la cría en vainas de Acacia farnesiana, 28/VII/2011, $1819 \mathrm{~m}$, colector Godínez-Cortés S., 2044'38.4" N, 99²0'00.9" W, CEAM (100 ex); ZIMAPÁN, libramiento sur CentroCarretera federal 85 México-Nuevo Laredo, bosque espinoso perturbado, colecta de la cría en vainas de Acacia farnesiana, 3/VIII/2011, 1795 m, colector Godínez-Cortés S., 2043'03.8" N, 99²1'41.1" W, CEAM (100 ex); ZIMAPÁN, Megui, camino a Puerto Juárez, alrededor de campos agrícolas, borde agrícola, colecta de la cría en vainas postdispersadas de Acacia schaffneri variedad bravoensis, 26/IV/2012, 2414 m, colector Godínez-Cortés S., 20³8'42.3" N, 99¹6'57.1" W, CEAM (228 ex); ZIMAPÁN, Saucillo, a un costado de un camino rural, borde agrícola, colecta de la cría en vainas de Acacia sp., 4/ I/2011, 1904 m, colector Godínez-Cortés S., 20³8'50.7" N, 99²6'40.6" W, CEAM (7 ex); ZIMAPÁN, Xindho, Libramiento norte Centro-Carretera federal 85 MéxicoNuevo Laredo, bosque espinoso perturbado, colecta de la cría en vainas de Acacia farnesiana, 28/VII/2011, $1880 \mathrm{~m}$, colector Godínez-Cortés S., 2044'59.3" N, 99²0'20.9" W, CEAM (40 ex).

Distribución en México. Aguascalientes, Baja California, Baja California Sur, Campeche, Chiapas, Chihuahua, Coahuila, Colima, Durango, Estado de México, 


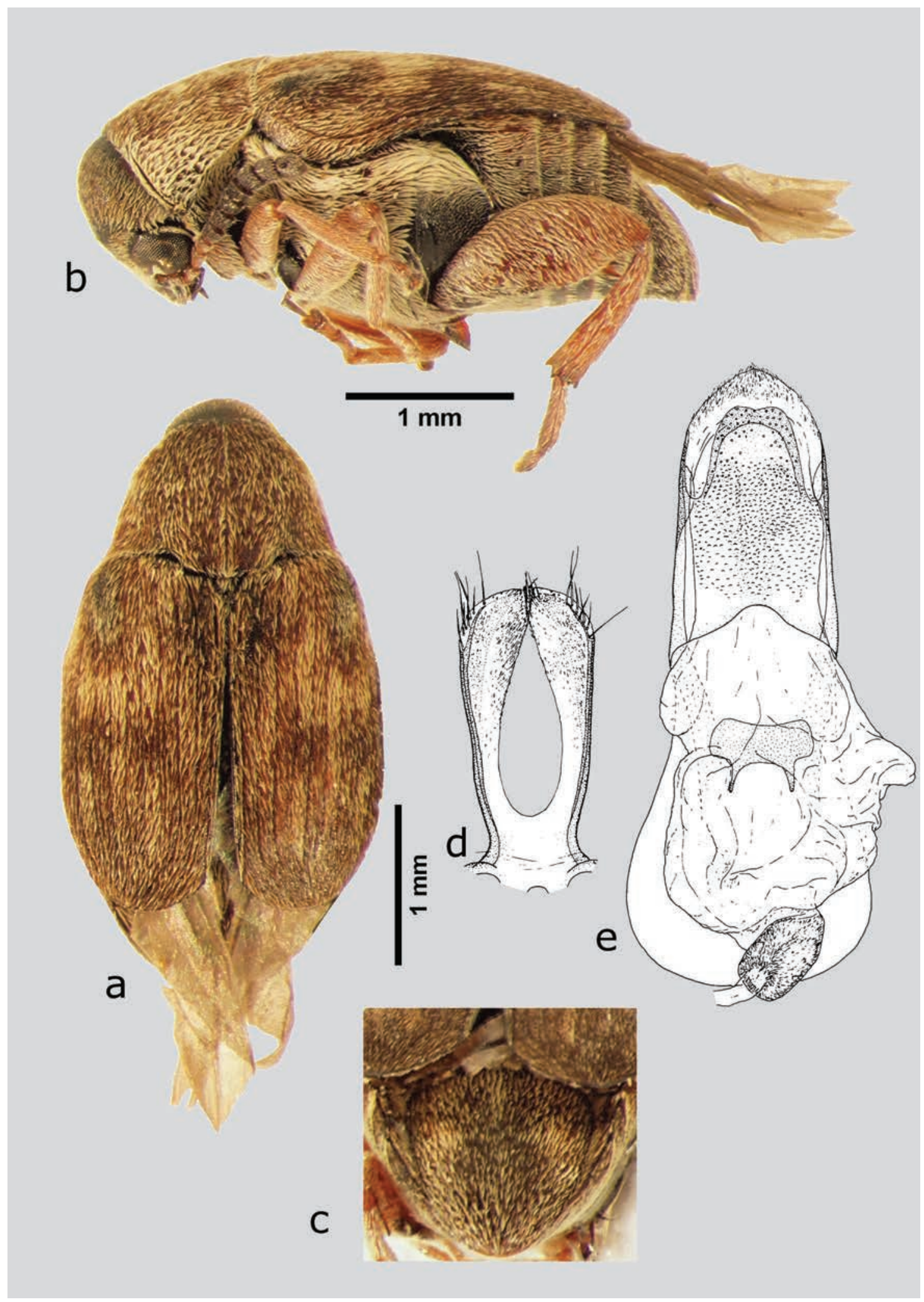

Figura 19. M. nubigens (macho), a) dorsal, b) lateral, c) pigidio, d) lóbulos laterales, e) lóbulo medio. Dibujos tomados de Kingsolver \& Johnson (1978). 
Guanajuato Guerrero, Hidalgo (Atotonilco el Grande, Cardonal, Jacala, San Agustín Tlaxiaca, Tasquillo, Zimapán), Jalisco, Michoacán, Morelos, Nayarit, Nuevo León, Oaxaca, Puebla, Querétaro, San Luis Potosí, Sinaloa, Sonora, Tamaulipas, Veracruz, Zacatecas.

Hospedero asociado. A. farnesiana, A. schaffneri variedad bravoensis, A. schaffneri variedad schaffneri, Acacia sp.

Discusióntaxonómicaycomentariosecológicos. Además de las plantas hospederas registradas, existen cinco especies más de acacias hospederas de esta especie: A. amentacea, A. cochliacantha, A. cornigera, A. globulifera y A. tortuosa; además de plantas de otros géneros, tales como: Caesalpinia coriaria, Ceratonia siliqua, Cercidium floridum subespecie peninsulare, Cordia sp., Gleditsia triacanthos, L. leucocephala, L. divaricatum, P. glandulosa variedad glandulosa, P. glandulosa variedad torreyana y P. pallida (Kingsolver \& Johnson 1978, Kingsolver 2004, Romero et al. 2009). Las hembras de esta especie presentan una oviposición tipo A (Johnson \& Romero 2004), observado a partir del tipo de frutos del que emergieron y de sus hospederos reportados en la literatura (Kingsolver \& Johnson 1978, Johnson \& Romero 2004). Esta especie es multivoltina, de más de cuatro ciclos generacionales por año, pues se le ha colectado en todos los meses del año (Kingsolver \& Johnson 1978, Kingsolver 2004, Romero et al. 2009), lo que indica que presenta una gran actividad. Los hallazgos de este estudio amplían la distribución de esta especie en Zimapán y en el estado de Hidalgo.

Sennius discolor (Horn, 1873) (fig. 20 a-f)

Material examinado. México: Hidalgo: ZIMAPÁN, La Cruz, a un costado de la carretera federal 85 México-Nuevo Laredo y Río Tula, matorral crasicaule, colecta por redeo con golpeo de Acacia coulteri, 8/X/2010, $1633 \mathrm{~m}$, colector Godínez-Cortés S., 20³4'42.1" N, 99²0'35.5" W, CEAM (1 ex); ZIMAPÁN, Las Trancas, km 32 carr. Zimapán-Tamazunchale, Senna guatemalensis variedad hidalgensis, se le encontró junto con Sennius fallax en el mismo hospedero y su densidad muy baja en comparación con S. fallax, 24/X/2004, 1995 m, colector Romero N. J., 2047'52" N, 99¹5'56" W, CEAM (6 ex); ZIMAPÁN, Puerto del Ángel, a un costado del camino Centenario-Puerto del Ángel, encinar, colecta de la cría en vainas de Senna guatemalensis variedad hidalgensis, 8/ X/2010, 2467 m, colector Godínez-Cortés S., 2047'25.1" N, 99²3'10.2" W, IB-UAEH (82 ex); ZIMAPÁN, Puerto del Ángel, camino Centenario-Puerto del Ángel, matorral submontano, colecta de la cría en vainas de Senna guate- malensis variedad hidalgensis, 20/VII/2010, $2031 \mathrm{~m}$, colector Godínez-Cortés S., 2045'26.3" N, 99²2'54.8" W, CEAM (104 ex); ZIMAPÁN, Puerto del Ángel, encinar, colecta de la cría en vainas de Senna guatemalensis variedad hidalgensis, 8/X/2010, 2607 m, colector GodínezCortés S., 2047'33.9" N, 99²3'04.1" W, CEAM (1 ex). Distribución en México. Chiapas, Chihuahua, Coahuila, Guerrero, Michoacán, Nayarit, Nuevo León, Querétaro, San Luis Potosí, Sinaloa, Sonora, Tamaulipas. Nuevos registros. Hidalgo (Zimapán).

Hospedero asociado. S. guatemalensis variedad hidalgensis, nuevo hospedero.

Discusión taxonómica y comentarios ecológicos. Sumado al nuevo hospedero, $S$. discolor puede alimentarse de por lo menos seis leguminosas más: S. covesii, S. galegifolia, S. lindheimeriana, S. pallida variedad pallida, S. roemeriana y S. wislizeni (Johnson \& Kingsolver 1973, Kingsolver 2004, Romero 2016), además de haberse encontrado como visitante en A. coulteri. S. discolor presenta una oviposición tipo B (Johnson \& Romero 2004), observado a partir del tipo de frutos del que emergieron y de sus hospederos reportados en la literatura (Johnson \& Kingsolver 1973, Kingsolver 2004); además de ser una especie multivoltina, de más de cuatro ciclos generacionales por año, observado en laboratorio de los ejemplares colectados que venían de campo, además de la literatura que reportan su colecta en casi todos los meses del año (Johnson \& Kingsolver 1973, Kingsolver 2004). Es importante señalar que Sennius discolor puede confundirse a simple vista con otras especies de Sennius e incluso de Stator, confundiéndose por las dos fases elitrales que presenta (clara y oscura) (Johnson \& Kingsolver 1973). La presencia de $S$. discolor representa un nuevo dato de distribución en el municipio de Zimapán y un nuevo registro de esta especie para el estado de Hidalgo, así como un nuevo hospedero.

Sennius durangensis Johnson \& Kingsolver, 1973 (fig. 21 a-e)

Material examinado. México: Hidalgo: ZIMAPÁN, 7 mi. NE Zimapán, 15/VIII/1958, colector H. F. Howden, USNM (2ex); ZIMAPÁN, a un costado de la vieja carretera a Pacula, ecotono de matorral micrófilo-encinar, colecta con red de golpeo en Senna crotalarioides, 25/ IV/2012, 2107 m, colector Godínez-Cortés S., 2048'43.9" N, 99¹8'49.6" W, CEAM (1ex);

Distribución en México. Coahuila, Durango, Hidalgo (Zimapán, Cardonal), Nuevo León, Querétaro, San Luis Potosí, Sinaloa, Sonora, Zacatecas. 


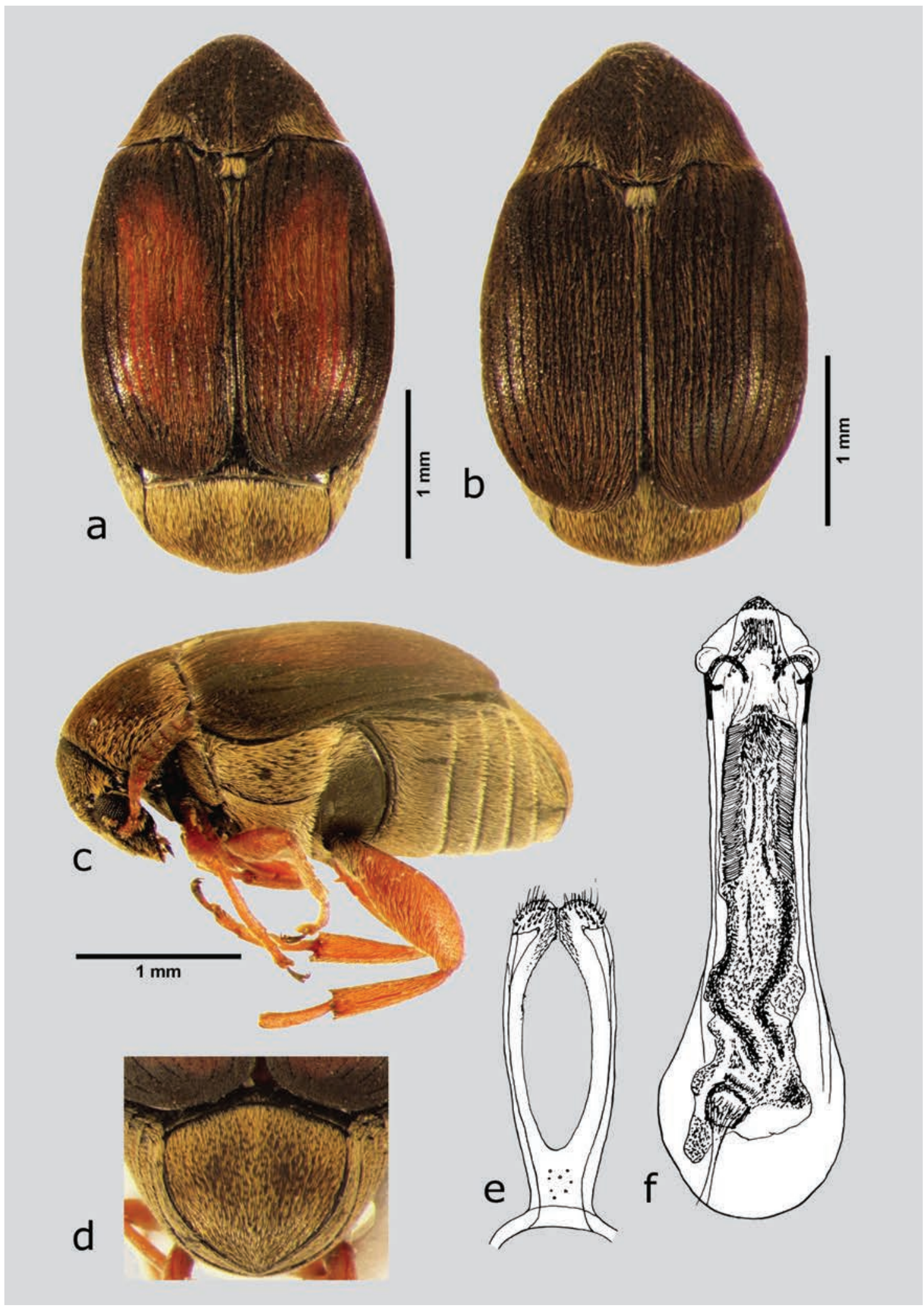

Figura 20. S. discolor (macho), a) dorsal (fase clara), b) dorsal (fase oscura), c) lateral, d) pigidio, e) lóbulos laterales, f) lóbulo medio. Dibujos tomados de Johnson \& Kingsolver (1973). 


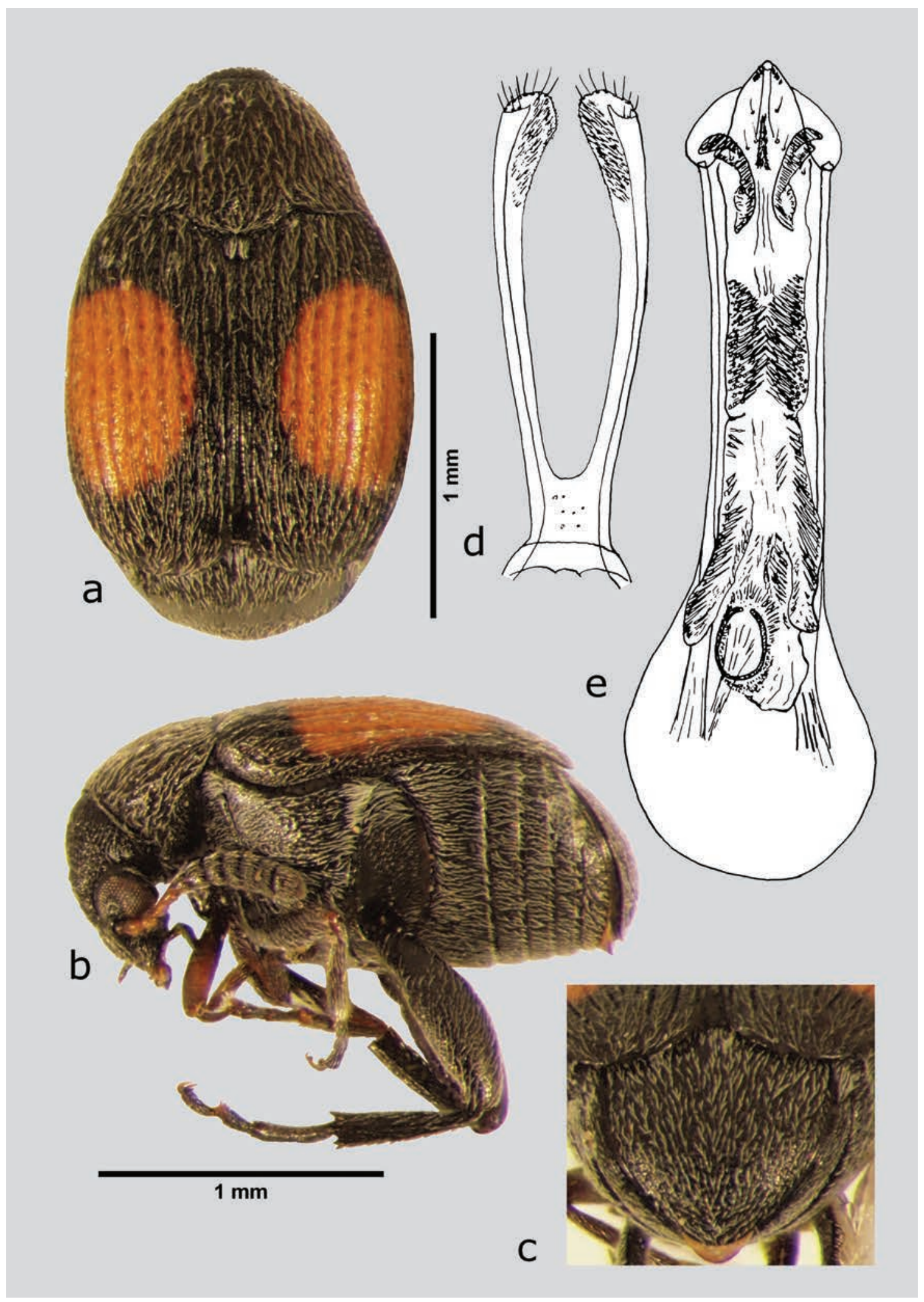

Figura 21. S. durangensis (macho), a) dorsal, b) lateral, c) pigidio, d) lóbulos laterales, e) lóbulo medio. Dibujos tomados de Johnson \& Kingsolver (1973). 
Hospedero asociado. No registrado.

Discusión taxonómica y comentarios ecológicos. Sennius durangensis ya se conocía previamente en el estado de Hidalgo y particularmente en Zimapán, ya que parte de los datos de colecta reportados arriba fueron utilizados por Johnson \& Kingsolver (1973) cuando describieron la especie por primera vez para la ciencia. A pesar de habérsele encontrado sobre $S$. crotalarioides, no se puede asegurar o considerársele un verdadero hospedero, pues jamás se le ha observado emerger de semillas de dicha planta (Johnson \& Kingsolver 1973), ni de alguna otra, aunque $S$. covesii fue reportada reporta como hospedero de eta especie Johnson (1980). Lo mismo ocurre con su tipo de oviposición y voltinismo, los cuales son desconocidos. Es importante mencionar que $S$. durangensis es una especie endémica de México. Los hallazgos de este estudio amplían la distribución de esta especie en Zimapán y en el estado de Hidalgo.

Sennius fallax (Boheman, 1839) (fig. 22 a-e)

Material examinado. México: Hidalgo: ZIMAPÁN, Las Codornices, a un costado de la vieja carretera a Pacula, encinar, colecta con red de golpeo en Senna crotalarioides, 25/IV/2012, 1904 m, colector Godínez-Cortés S., 2050'32.1" N, 99¹9'12.5" W, CEAM (3 ex); ZIMAPÁN, Las Trancas, km 32 carr. Zimapán -Tamazunchale, Senna guatemalensis variedad hidalgensis, se le encontró junto con $S$. discolor en el mismo hospedero y su densidad muy alta en comparación con S. discolor, 24/X/2004, 1995 m, colector Romero N. J., 2047'52" N, 99¹5'56" W, CEAM (100 ex); ZIMAPÁN, Puerto del Ángel, encinar, colecta de la cría en vainas de Senna guatemalensis variedad hidalgensis, 20/VII/2010, 2536 m, colector Godínez-Cortés S., 2047'28.3" N, 99²3'07.8" W, IB-UAEH (3 ex).

Distribución en México. Chiapas, Colima, Estado de México, Guanajuato, Guerrero, Hidalgo (Zimapán), Jalisco, Michoacán, Nayarit, Oaxaca, San Luis Potosí, Sinaloa, Tabasco, Veracruz,

Hospedero asociado. Senna guatemalensis variedad hidalgensis, nuevo hospedero.

Discusión taxonómica y comentarios ecológicos. Sumado al nuevo hospedero, $S$. fallax puede alimentarse de al menos 16 especies más de Senna (Johnson \& Kingsolver 1973, Kingsolver 2004, Romero 2016); además de habérsele encontrado como visitante de $S$. crotalarioides. S. fallax presenta una oviposición tipo B (Johnson \& Romero 2004), observado a partir del tipo de frutos del que emergieron y de sus hospederos reportados en la literatura (Johnson \& Kingsolver 1973, Kingsolver 2004); además de ser una especie multivoltina, por los datos de colecta en al menos tres estaciones de año y a la gran cantidad de hospederos asociados (Johnson \& Kingsolver 1973, Kingsolver 2004).

Stator limbatus (Horn, 1873) (fig. 23 a-e)

Material examinado. México: Hidalgo: ZIMAPÁN, 16/ VIII/1956, colector Vásquez A. W., USNM (2 ex); ZIMAPÁN, La Cruz, a un costado de la carretera federal 85 México-Nuevo Laredo y Río Tula, matorral crasicaule, colecta de la cría en vainas de Acacia coulteri, 8/X/2010, 1633 m, colector Godínez-Cortés S., 20³4'42.1" N, 99²0'35.5" W, CEAM (2 ex).

Distribución en México. Baja California, Baja California Sur, Campeche, Chiapas, Chihuahua, Coahuila, Colima, Estado de México, Guanajuato, Guerrero, Hidalgo (Cardonal, Zimapán), Jalisco, Michoacán, Morelos, Nayarit, Nuevo León, Oaxaca, Puebla, Querétaro, Quintana Roo, San Luis Potosí, Sinaloa, Sonora, Tabasco, Tamaulipas, Veracruz, Yucatán.

Hospedero asociado. A. coulteri.

Discusión taxonómica y comentarios ecológicos. Stator limbatus es una de las especies de brúquidos más polífagas que existen, pues se alimenta de más de 80 hospederos, de los cuales al menos 30 son especies de Acacia, 16 de Pithecellobium, siete de Albizia, seis de Lysiloma, cinco de Calliandra, cuatro de Leucaena, cuatro de Parkinsonia y tres de Prosopis, entre muchos otros géneros y especies; siendo las acacias siempre las preferidas (Johnson \& Kingsolver 1976, Kingsolver 2004, Romero-Gómez 2013). Debido a la capacidad para alimentarse de un gran número de plantas, es probable que $S$. limbatus presente todas las formas posibles de oviposición propuestas por Johnson \& Romero (2004); así mismo, una condición de multivoltinismo, debido a la gran cantidad de hospederos de los que se alimenta (Johnson \& Kingsolver 1976, Kingsolver 2004, Romero-Gómez 2013). A pesar de que S. limbatus está reportado para el estado de Hidalgo, este es el primer registro completo de una distribución de esta especie en Zimapán y para el estado de Hidalgo.

Stator sordidus (Horn, 1873) (fig. 24 a-e)

Material examinado. México: Hidalgo: ZIMAPÁN, 7 mi. NE Zimapán, 15/VIII/1958, colector Howden H. F., TAMU (1 ex).

Distribución en México. Baja California, Baja California Sur, Chiapas, Chihuahua, Durango,

Estado de México, Guanajuato, Guerrero, Hidalgo (Pacula, Zimapán), Jalisco, Michoacán, 


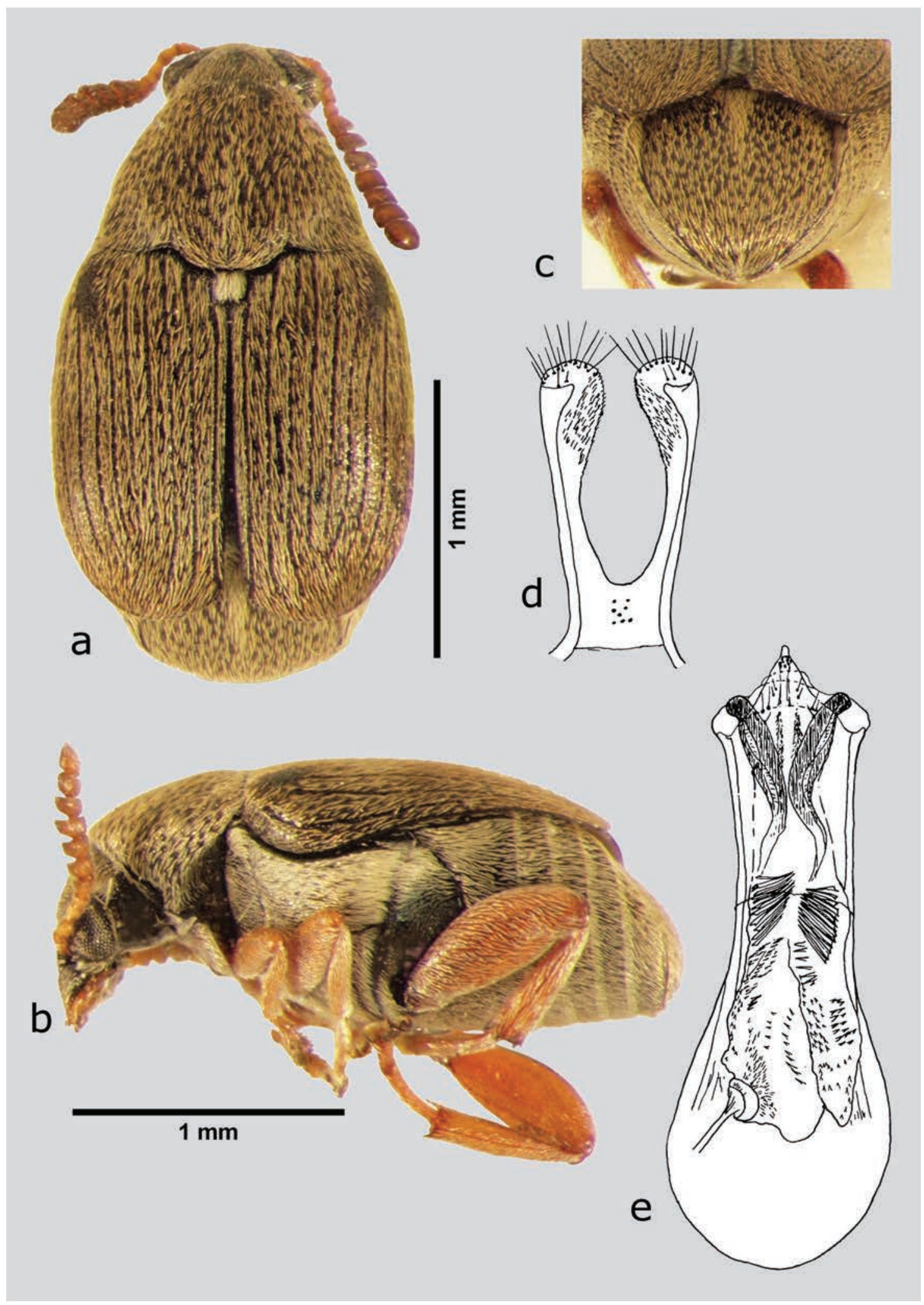

Figura 22. S. fallax (macho), a) dorsal, b) lateral, c) pigidio, d) lóbulos laterales, e) lóbulo medio. Dibujos tomados de Johnson \& Kingsolver (1973). 


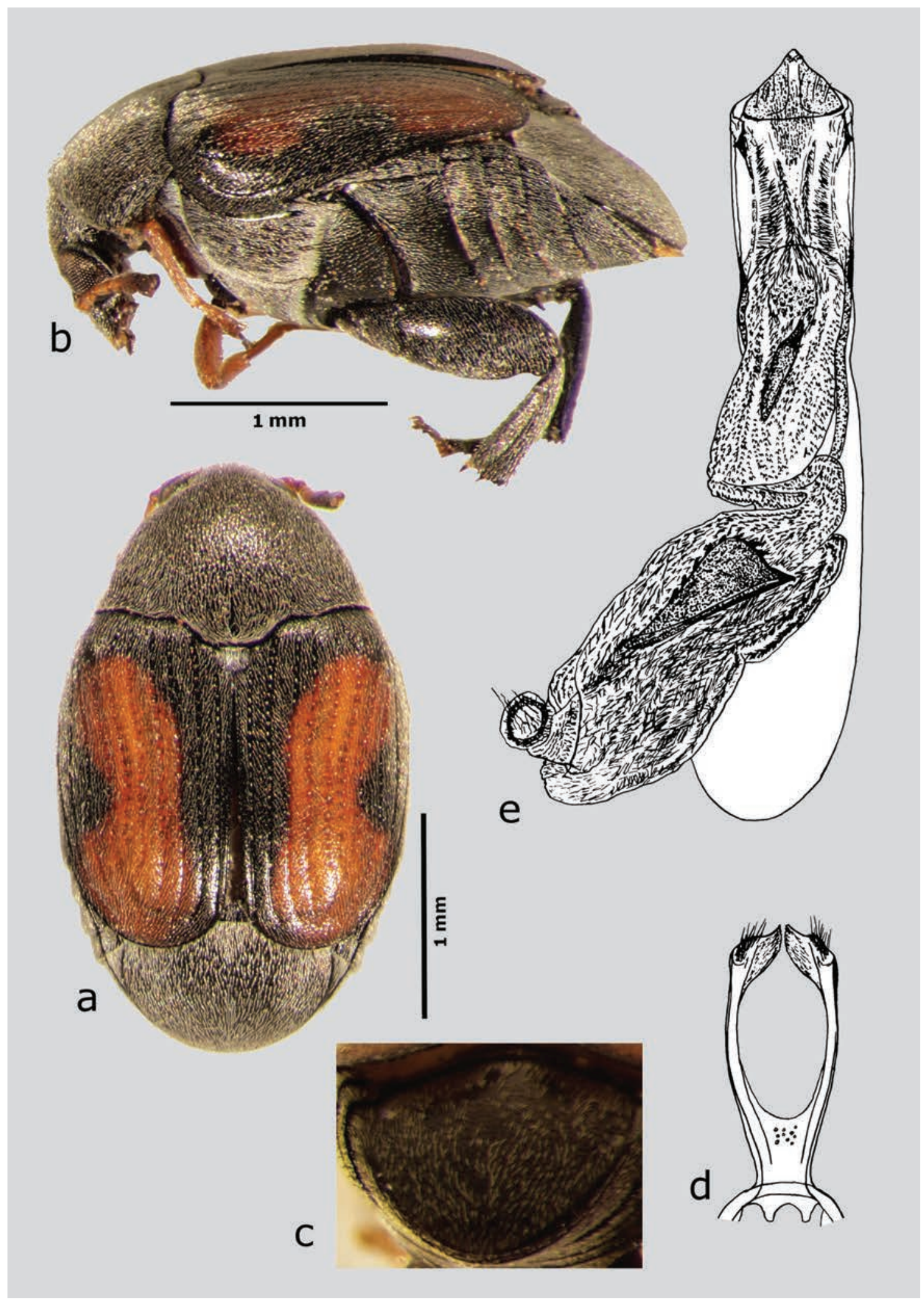

Figura 23. S. limbatus (macho), a) dorsal, b) lateral, c) pigidio, d) lóbulos laterales, e) lóbulo medio. Dibujos tomados de Johnson \& Kingsolver (1976). 


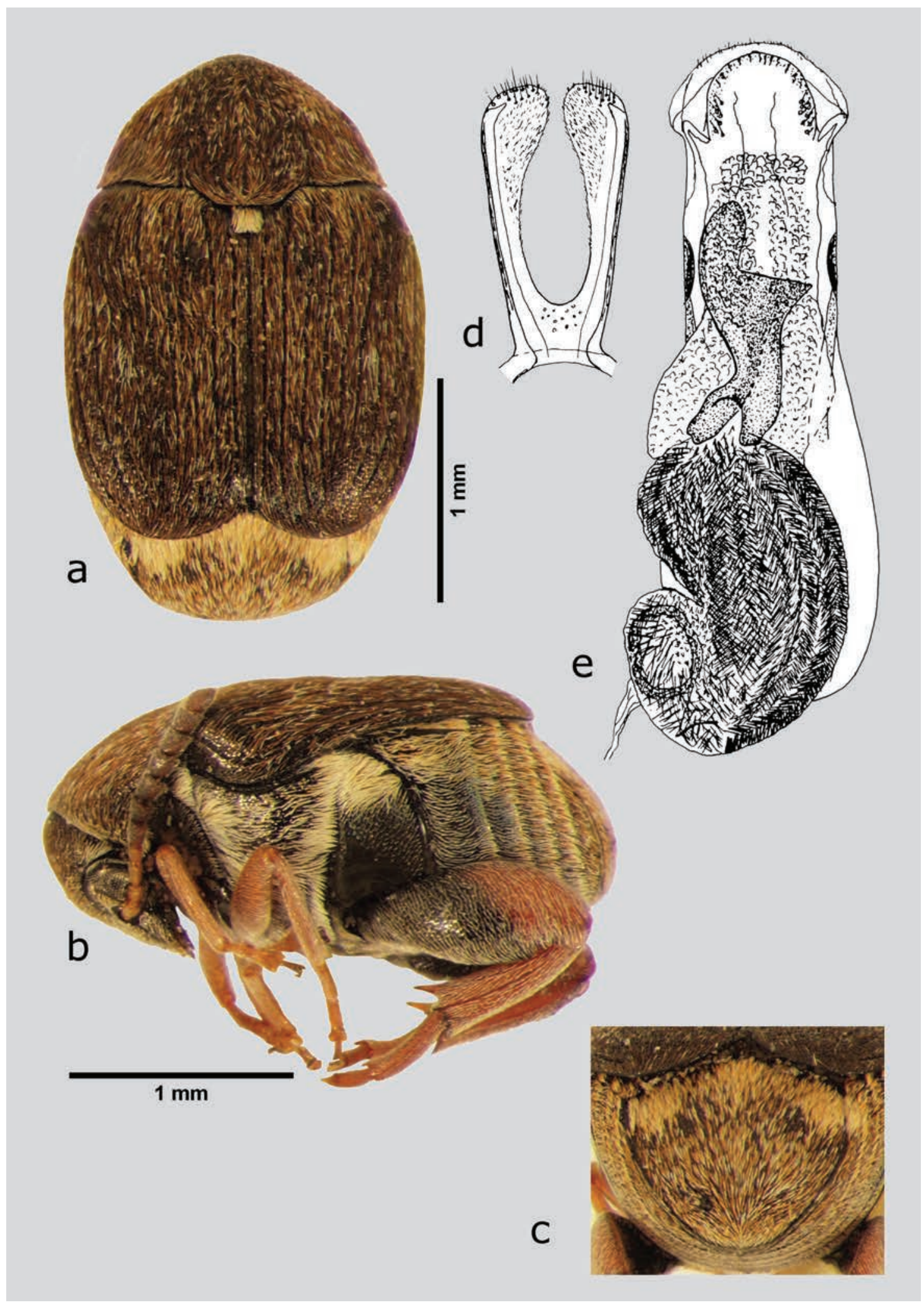

Figura 24. S. sordidus (macho), a) dorsal, b) lateral, c) pigidio, d) lóbulos laterales, e) lóbulo medio. Dibujos tomados de Johnson \& Kingsolver (1976). 
Morelos, Nayarit, Nuevo León, Oaxaca, Puebla, Querétaro, San Luis Potosí.

Hospedero asociado. No registrado.

Discusión taxonómica y comentarios ecológicos. Stator sordidus está reportado para el estado de Hidalgo en el Checklist de brúquidos de México de Romero \& Johnson del 2004, correspondiente a los datos de material examinado mencionados anteriormente. A pesar de no haber registro del hospedero en Zimapán para S. sordidus, se sabe que se alimenta de las semillas de al menos 11 especies de leguminosas en otras partes de México, con preferencia en las especies de acacias (Romero 2016). Por otro lado, aunque su tipo de oviposición no ha sido observado, Johnson (1981) y Johnson \& Romero (2004) indican que esta especie presenta un tipo de oviposición C, ya que varias de las plantas hospederas de la que se alimenta presenta frutos dehiscentes (Johnson 1981, Andrade et al. 2007), que finalmente terminan libres en el sustrato (Johnson \& Romero 2004); en lo que respecta al tipo de voltinismo, éste aún es desconocido.

Stator vachelliae Bottimer, 1973 (fig. 25 a-e) Material examinado. México: Hidalgo: ZIMAPÁN, a un costado de la carretera federal 85 México-Nuevo Laredo, matorral submontano, colecta con red de golpeo en Acacia sp., 25/IV/2012, 1894 m, colector Godínez-Cortés S., 2047'25.5" N, 99¹7'33.2" W, CEAM (1 ex); ZIMAPÁN, Km 97 carr- fed. Ixmiquilpan-Tamazunchale, 15/ VI/2004, 1750 m, colector Romero N. J., CEAM (1 ex).

Distribución en México. Aguascalientes, Baja California, Baja California Sur, Chiapas, Coahuila, Colima, Durango, Estado de México, Guanajuato, Guerrero, Jalisco, Michoacán, Morelos, Nayarit, Nuevo León, Oaxaca, Puebla, Querétaro, Sinaloa. Nuevos registros. Hidalgo (Cardonal, Jacala, Zimapán).

Hospedero asociado. No registrado.

Discusión taxonómica y comentarios ecológicos. Stator vachelliae fue encontrado como visitante sobre una especie no determinada de Acacia en Zimapán; y a pesar de no habérsele registrado hospedero, se sabe que se alimenta de las semillas postdispersadas de al menos cuatro especies más de acacias en México: A. cochliacantha, A. collinsii, A. farnesiana y A. pennatula (Johnson \& Kingsolver 1976, Kingsolver 2004, Romero 2016). Así mismo, Johnson (1981), Traveset (1990) y Johnson \& Romero (2004) indican que esta especie presenta un tipo de oviposición C; y ciclos de vida multivoltinos de por lo menos tres ciclos generacionales por año (Traveset 1990, Johnson \& Romero 2004). La presencia de S. vachelliae en el municipio de Zimapán y en otros municipios del estado (datos no publicados), representa un nuevo dato de distribución y un nuevo registro de esta especie para el estado de Hidalgo.

Stylantheus macrocerus (Horn, 1873) (fig. 26 a-e)

Material examinado. México: Hidalgo: ZIMAPÁN, Hwy. 85, 4 mi. N Zimapán, 26/VII/1982, 2042 m, colectores C.W. O’Brien, L. O. O’Brien \& G. Wibmer, CEAM (1 ex).

Distribución en México. Hidalgo (Zimapán).

Hospedero asociado. No registrado

Discusión taxonómica y comentarios ecológicos. A pesar de no existir registro del hospedero en Zimapán para $S$. macrocerus, se sabe que se alimenta de las semillas de Stylosanthes biflora en Estados Unidos y probablemente de alguna de las 11 especies de Stylosanthes registradas para el país (Gama-López et al. 2007, Romero 2009). Por otro lado, aunque su tipo de oviposición no ha sido observado (Johnson 1976), es posible que las hembras de esta especie presenten el tipo de oviposición A (Johnson \& Romero 2004); debido a que el género de plantas del que se alimentan presentan frutos indehiscentes (GamaLópez 2006) y posiblemente un monovoltinismo debido a que algunas especies del género hospedero son hierbas anuales (Gama-López 2006, Gama-López et al. 2007). En el 2009, Romero amplia la distribución para este género monotípico de brúquido, al encontrar un ejemplar en la colección CEAM colectado en el municipio de Zimapán, estado de Hidalgo, con los datos antes mencionados. Es importante mencionar que en el país, hasta el momento sólo se le ha encontrado en dicho sitio.

Tribu Megacerini Bridwell 1946

Megacerus maculiventris (Fåhraeus, 1839) (fig. 27 a-e) Material examinado. México: Hidalgo: ZIMAPÁN, El Llano Dos, dentro del jardín de una casa, colecta de la cría en cápsulas de Ipomoea sp., 4/I/2011, 1901 m, colector Godínez-Cortés S., 20³8'38.8" N, 99²6'04.9" W, CEAM (2 ex); ZIMAPÁN, en un extremo de la pista aérea, en un terreno baldío, colecta de la cría en cápsulas de Ipomoea purpurea, 5/I/2011, 1835 m, colector Godínez-Cortes S., 2044'49.8" N, 99²2'41.3" W, CEAM (39 ex); ZIMAPÁN, en un extremo de la pista aérea, en un terreno baldío, colecta de la cría en cápsulas de Ipomoea tricolor, 5/I/2011, 1835 m, colector Godínez-Cortes S., 2044'49.8" N, 99²2'41.3" W, IB-UAEH (10 ex).

Distribución en México. Chiapas, Chihuahua, Coahuila, Colima, Distrito Federal, Durango, 


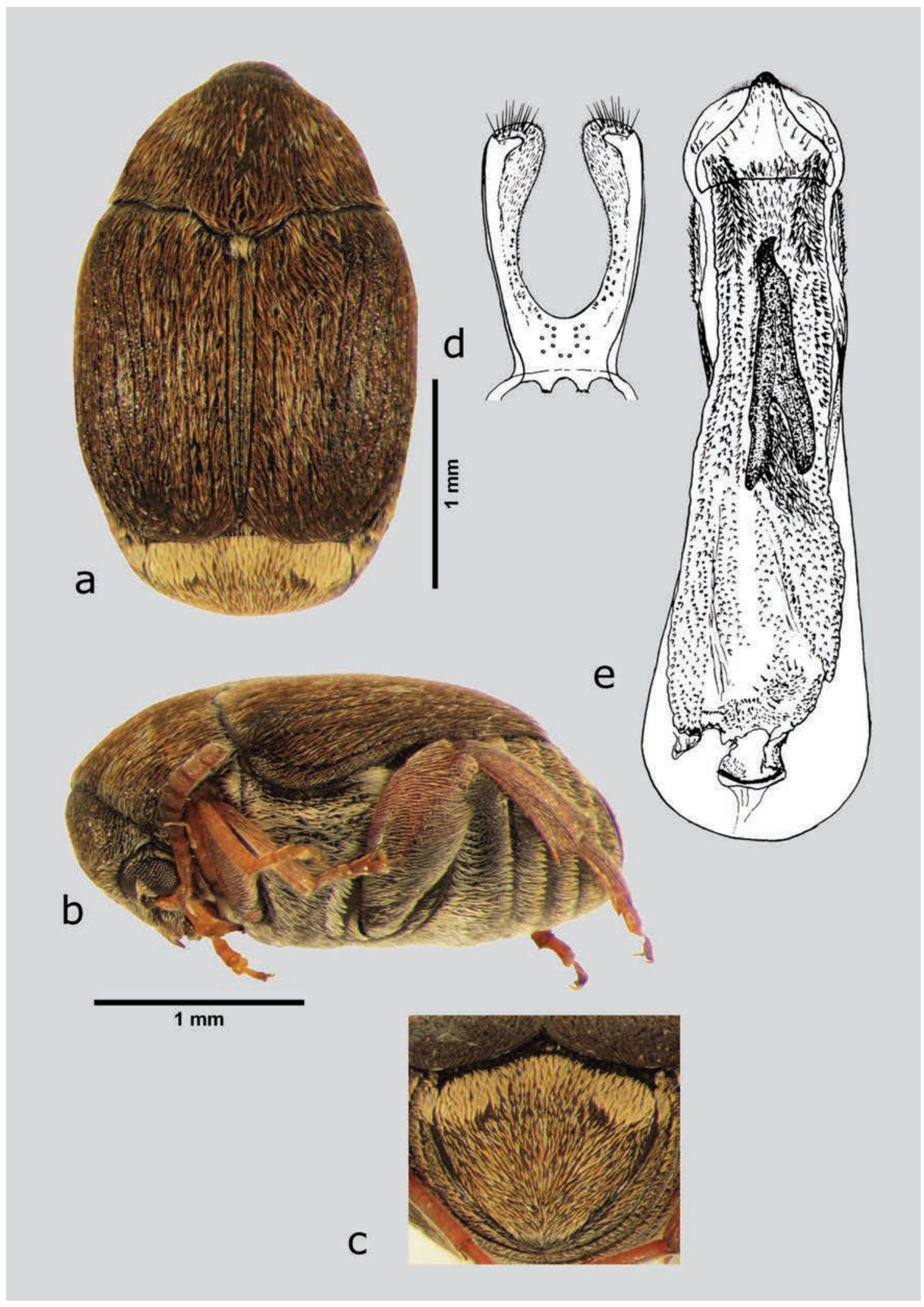

Figura 25. S. vachelliae (macho), a) dorsal, b) lateral, c) pigidio, d) lóbulos laterales, e) lóbulo medio. Dibujos tomados de Johnson \& Kingsolver (1976). 


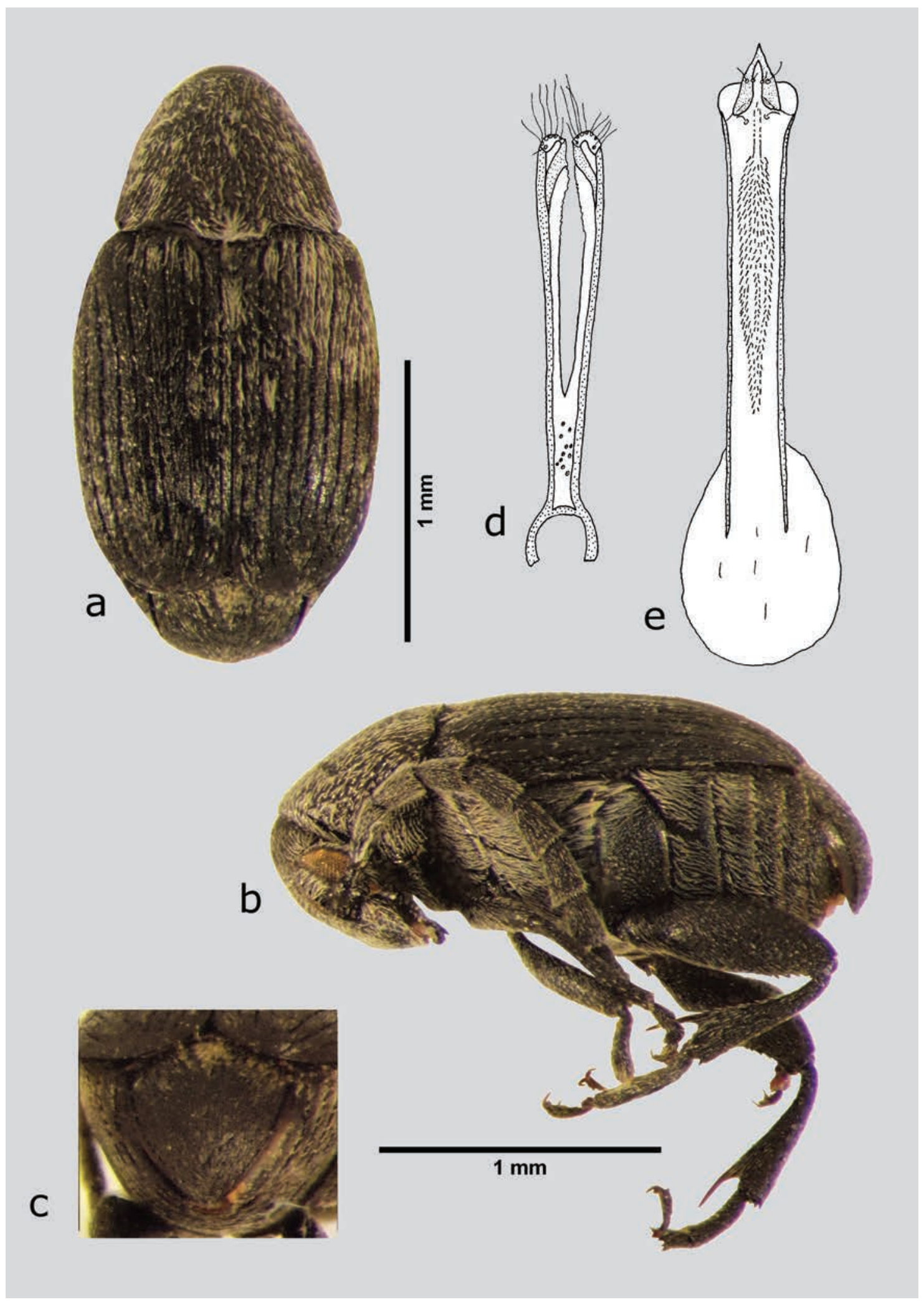

Figura 26. S. macrocerus (macho), a) dorsal, b) lateral, c) pigidio, d) lóbulos laterales, e) lóbulo medio. Dibujos tomados de Johnson (1976). 


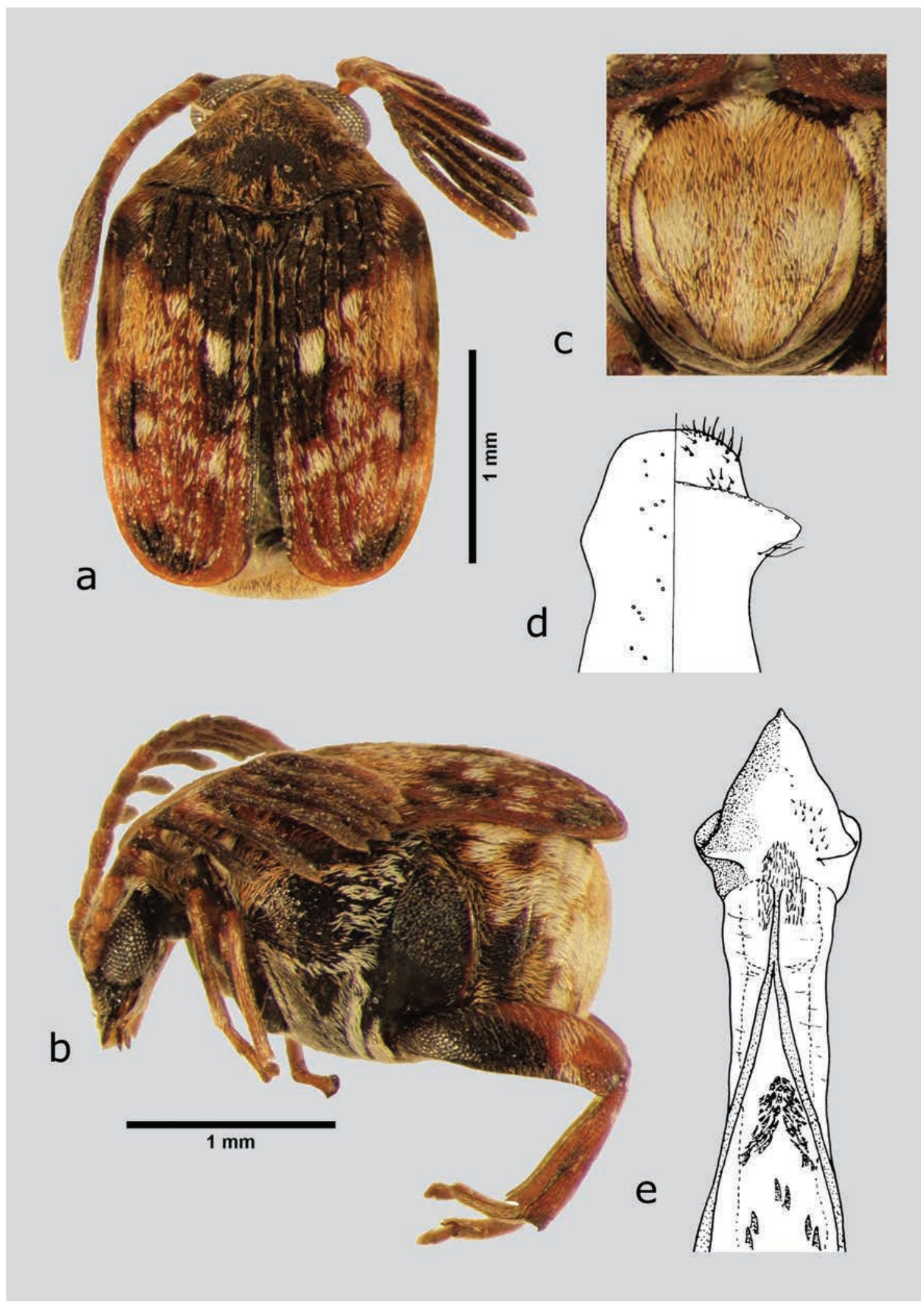

Figura 27. M. maculiventris (macho), a) dorsal, b) lateral, c) pigidio, d) lóbulos laterales, e) lóbulo medio. Dibujos tomados de Terán \& Kingsolver (1977). 
Estado de México, Guanajuato, Guerrero, Hidalgo (Cardonal, Jacala, Tulancingo, Zimapán), Jalisco, Michoacán, Morelos, Nayarit, Oaxaca, Puebla, Sinaloa, Sonora, Tlaxcala, Zacatecas.

Hospedero asociado. I. purpurea, nuevo hospedero en México; I. tricolor.

Discusión taxonómica y comentarios ecológicos. De las dos especies hospederas para $M$. maculiventris en Zimapán, I. purpurea se reporta por primera vez en México como hospedero de esta especie de brúquido, anteriormente sólo se había reportado en Argentina. Además de los hospederos mencionados, $M$. maculiventris se puede alimentar de al menos cinco especies más de convolvuláceas en México, estas son: I. cholulensis, I. cordatotriloba variedad torreyana, I. nil, I. triloba y Turbina corymbosa (Terán \& Kingsolver 1977, Terán \& Johnson 2002, Romero 2016). Las hembras de esta especie presentan una oviposición tipo A (Terán \& Kingsolver 1977, Johnson \& Romero 2004), ya que se le ha observado en las capsulas contenedoras de semillas de las dos especies de Ipomoea; y un monovoltinismo, debido a que las plantas en las que llevan a cabo su ciclo de vida son hierbas en su mayoría anuales (House 1908, Carranza 2007); sin embargo, tal vez alcancen a completar dos ciclos generacionales si la producción de las semillas es abundante y espaciada; es decir, va a depender mucho de la fenología de la planta y su duración en el ambiente (Terán \& Kingsolver 1977). $M$. maculiventris ya era conocido en territorio hidalguense, derivado de la revisión del género por Terán \& Kingsolver (1977); sin embargo, los hallazgos de este estudio amplían la distribución de esta especie en Zimapán y dentro del estado de Hidalgo.

\section{CONCLUSIONES}

De las tres subfamilias existentes de brúquidos en México, el municipio de Zimapán cuenta con dos de ellas; de los 27 géneros de brúquidos conocidos en México y 17 en Hidalgo, Zimapán cuenta con 12 géneros (44.4\% del total nacional y $70.5 \%$ del total estatal). En cuanto a especies se trata, de las 1800 conocidas en el mundo, Zimapán apenas tiene 27 especies (1.5\% del total mundial, $7.1 \%$ del total nacional y 52\% del total estatal). Estos resultados muestran que el municipio posee una alta riqueza de géneros y subfamilias de coleópteros Bruchidae, comparado a nivel nacional y estatal.

Dentro de los aspectos más relevantes de este estudio, se encuentra el nuevo registro del género Abutiloneus y nueve nuevos registros de especies de brúquidos para el estado de Hidalgo: Abutiloneus idoneus; Acanthoscelides aequalis, Acanthoscelides speciosus; Meibomeus hidalgoi; Merobruchus porphyreus; Mimosestes humeralis; Mimosestes janzeni; Sennius discolor y Stator vachelliae. Así como dos nuevas plantas hospederas, Acacia farnesiana para $M$. humeralis y M. janzeni, y Senna guatemalensis variedad hidalgensis para Sennius discolor y Sennius fallax; además de un nuevo registro de hospedero en México para Megacerus maculiventris, Ipomoea purpurea.

El presente estudio cumple con el objetivo de dar a conocer, ilustrar y determinar el número hasta ahora conocido de especies de brúquidos en Zimapán, Hidalgo; identificando sus hospederos y el tipo de vegetación en los que se encuentran, abordando aspectos de su biología, nuevas distribuciones geográficas y nuevos registros de plantas hospederas.

Además de lograr contabilizar distintos registros de datos de colecta exitosos, en un intervalo de tiempo de 60 años (desde 1956), gracias a la base de datos BRUCOL; se logra por primera vez que se publique, formalmente y en esta magnitud, información sobre esta familia de insectos para el estado de Hidalgo, incluyendo una gran cantidad de datos generados en campo.

Quizás alguno de los mayores inconveniente durante la exploración de esta fauna en el territorio estudiado, es la pérdida cada vez mayor de cobertura vegetal; Hidalgo por ejemplo, posee un poco más del $75 \%$ de su cubertura vegetal con algún grado de alteración; y Zimapán, a pesar de ser un municipio con gran riqueza florística, como muchas otras partes del país necesita un manejo del uso del suelo (Randell 2008). Si bien algunos brúquidos son capaces de soportar la alteración de su ambiente y colonizar nuevos sitios, si es importante pensar en la importancia de conservar la vegetación nativa de los sitios, para comprender la relación original con sus hospederos.

Aún con ésta y muchas más adversidades, podemos augurar un buen futuro para el conocimiento de los brúquidos de Hidalgo, pues, dado que la abundancia de especies depende en gran parte del tipo de vegetación y de la zona geográfica, el estado de Hidalgo forma parte de un mosaico de condiciones ambientales y microambientales adecuadas para esperar una gran cantidad de distintas especies de brúquidos conocidas y por conocer.

Por ejemplo, comparando el número de especies de brúquidos en el municipio de Zimapán (con apenas una superficie territorial de $906 \mathrm{~km}^{2}$ ), de 12 géneros y 27 especies de brúquidos (en su zona más seca), con otros paí- 
ses alrededor del mundo como: Omán, con una superficie territorial de $212457 \mathrm{~km}^{2}$, con siete géneros y 11 especies (Anton 1994); Irán, con una superficie territorial de 1648 $195 \mathrm{~km}^{2}$, con 11 géneros y 83 especies (Fard et al. 2016; Romero 2016); o incluso con países megadiversos como Perú, con una superficie territorial de 1285216 km², con 17 géneros y 55 especies (Chaboo \& Morse 2015); Zimapán resulta ser un lugar que alberga igual o una mayor biodiversidad que países completos o en proporción territorial. Tan solo, al comparar la fauna de brúquidos de México con la de Estados Unidos, que a pesar de que su territorio es tres veces más grande que México, basta con las especies halladas en los territorios de los estados de Oaxaca o Morelos para alcanzar la riqueza de todo Estados Unidos de América con una superficie de alrededor de $9833517 \mathrm{~km}^{2}$.

Por lo tanto, es oportuno e importante dar a conocer esta fauna de insectos, para conocer su diversidad en general; pero también para abordar desde distintas perspectivas y disciplinas científicas, ya que la base del estudio de cualquier grupo biológico es conocer su biología básica y su taxonomía; esta última, como la llave que abre la puerta a la generación de conocimiento para poder trabajar a cualquier nivel; y como muestra, la clave aquí incluida, la cual pretende servir como una herramienta para la identificación de esta fauna en esta región del país.

Sin duda, este trabajo es una aproximación más a un conocimiento más sólido sobre los brúquidos en México y la primera en específico a la fauna de brúquidos del estado de Hidalgo; un estudio que no se puede pasar por alto si se desea trabajar con estos insectos.

AGRADECIMIENTOS. El primer autor agradece a María del Consuelo Cuevas Cardona, Ulises Iturbe Acosta, Julián Bueno Villegas y Gerardo Sánchez Rojas, que de alguna u otra manera contribuyeron a la mejora de este trabajo; se agradece también a los tres revisores anónimos que ayudaron a mejorar el manuscrito; así mismo agradece el apoyo y compañía de Abigail González-Zúñiga durante las colectas y salidas de campo y su aliento durante la elaboración del manuscrito.

\section{LITERATURA CITADA}

Andrade M., G., Calderón de R., G., Camargo-Ricalde, S. L., Grether, R., Hernández, H. M., Martínez-Bernal, A., Rico, L., Rzedowski, J. \& Sousa S., M. 2007. Subfamilia Mimosoideae. Pp. 1-229. In: J. Rzedowski \& G. Calderón de R. (Eds.). Familia Leguminosae, Fascículo 150, Flora del Bajío y de Regiones Adyacentes. Instituto de Ecología A. C. y Centro Regional del Bajío, Pátzcuaro, Michoacán, México.

Anton, K.-W. 1994. The Bruchidae (Coleoptera) of Oman, with des- criptions of a new genus and two new species. Fauna of Saudi Arabia, 14: 105-112.

Arnett, J. R. H. 2000. American insects: A hand book of the insects of America north of México. CRC Press, Estados Unidos de América, 1024 pp.

Baltazar M., K. 2011. Efecto de la pérdida de vegetación natural sobre la depredación de semillas de mezquite por insectos (Coleoptera: Bruchidae) a diferentes escalas espaciales. Tesis de Maestría, Universidad Autónoma del Estado de Hidalgo, Hidalgo, México.

Carranza, E. 2007. Familia Convolvulaceae. Pp. 1-129. In: J. Rzedowski \& G. Calderón de R. (Eds.). Fascículo 151, Flora del Bajío y de Regiones Adyacentes. Instituto de Ecología A. C. y Centro Regional del Bajío, Pátzcuaro, Michoacán, México.

Chaboo, C. S., \& Morse, G. E. 2015. Beetles (Coleoptera) of Peru: A survey of the families. Chrysomelidae: Bruchinae. Journal of the Kansas Entomological Society, 88: 356-360.

Eaton, E. R. \& Kaufman, K. 2007. Kaufman, Field guide to Insects of North America. Hillstar Edition L. C., Estados Unidos de América, 392 pp.

Fard, L. A., Sadeghi, S. E., Ghajariyeh, H. R., Moniri, V. R., Yarmand, H., Shamszadeh, M., Zarnegar, A., Poor, A. M., Kalanatari, S. A., Golestaneh, S. R., Afrouzian, M., Nikdel, M., Rajabi-Mazhar, N. A., Ardekani, A. S. \& Delobel, A. 2016. Distribution and New Host Plants of Seed Beetles (Col.: Chrysomelidae: Bruchinae) from Iran. Journal of Entomological Society of Iran, 35: 9-15.

Fryxell, P. A. 1997. Familia Malvaceae. Pp. 1-174. In: J. Rzedowski \& G. Calderón de R. (Eds.). Familia Leguminosae, Fascículo 16, Flora del Bajío y de Regiones Adyacentes. Instituto de Ecología A. C. y Centro Regional del Bajío, Pátzcuaro, Michoacán, México.

Gama-López, S. 2006. Estudio sistemático del género Stylosanthes (Fabaceae). Tesis de Maestría, Universidad Nacional Autónoma de México, Distrito Federal, México.

Gama-López, S., Munaut, F., Strappen, J. V., Scheldeman, X. \& Van Damme, V. 2007. Diversity studies in the interaction between the anthracnose fungus Colletotrichum gloeosporioides and its host plant Stylosanthes spp. in Mexico. Bioversity International, 1-82.

García P., J. F., Aguirre C., Ó., Estrada C., E., Flores R., J., Jiménez P., J. \& Jurado Y., E. 2007. Germinación y establecimiento de plantas nativas del matorral tamaulipeco y una especie introducida en un gradiente de elevación. Madera y Bosques, 13: 99-117.

Godínez-Cortés, S., Romero-Nápoles, J., Castellanos-Sturemark, I. \& Baltazar-Meneses, K. 2011. Primer registro de las especies Merobruchus julianus HORN \& Sennius fallax BOHEMAN (Coleoptera: Bruchidae) para el Estado de Hidalgo, México. Pp. 774-778. In: S. G. Cruz M., J. Tello F., A. Mendoza E. \& A. Morales M. (Eds.). Entomología Mexicana, Volumen 10. Sociedad Mexicana de Entomología, Distrito Federal, México.

Godínez-Cortés, S., Romero-Nápoles, J., Parra-Gil, P. \& CastellanosSturemark, I. 2012. Primer registro y caracterización del género de brúquido Caryedon Schöenherr 1823 y de la especie Caryedon serratus (Olivier) (Coleoptera: Bruchidae) para el estado de Hidalgo, México. Pp. 1163-1168. In: A. Equihua M., E. G. Estrada V., J. A. Acuña S., M. P. Chaires G. \& M. G. Duran R. (Eds.). Entomología Mexicana, Volumen 11, Tomo II. Sociedad Mexicana de Entomología, Distrito Federal, México.

House, H. D. 1908. The North American Species of the genus Ipomoea. Annals of the New York Academy of Sciences, 58: 181-263. 
Instituto Nacional de Estadística Geografía e Informática. 1994. Anuario Estadístico del Estado de Hidalgo. Instituto Nacional de Estadística Geografía e Informática, México, 105 pp.

Johnson, C. D. 1970. Biosystematics of the Arizona, California and Oregon Species of the Seed Beetle Genus Acanthoscelides Schilsky (Coleoptera: Bruchidae). University of California Publications in Entomolgy, 59: 1-116.

Johnson, C. D. 1976. Systematics of the genus Stylantheus Bridwell (Coleoptera: Bruchidae). Journal of the Kansas Entomological Society, 49: 254-261.

Johnson, C. D. 1980. The use of host preferences as taxonomic characters of bruchid beetles (Coleoptera: Bruchidae) feeding in the seeds of Cassia (Leguminosae). Journal of the Kansas Entomological Society, 53: 27-34.

Johnson, C. D. 1981. Interactions between bruchid (Coleoptera) feeding guilds and behavioral patterns of pods of the Leguminosae. Environmental Entomology, 10: 249-253.

Johnson, C. D. 1983a. Ecosystematics of Acanthoscelides (Coleoptera: Bruchidae) of southern Mexico and Central America. Miscellaneus Publications of the Entomological Society of America, 56: 1-370.

Johnson, C. D. 1983b. New host records for Abutiloneus idoneus Bridwell (Coleoptera: Bruchidae). The Coleopterists Bulletin, 37: 378.

Johnson, C. D. \& Kingsolver, J. M. 1973. A revision of the genus Sennius of North and Central America (Coleoptera: Bruchidae). Technical Bulletin No. 1462, Department of Agriculture, Estados Unidos de América, 135 pp.

Johnson, C. D. \& Kingsolver, J. M. 1976. Systematics of Stator of North and Central America. (Coleoptera: Bruchidae). Technical Bulletin No. 1537, Department of Agriculture, Estados Unidos de América, 101 pp.

Johnson, C. D. \& Romero N., J. 2004. A review of evolution of oviposition guilds in the Bruchidae (Coleoptera). Revista Brasileira de Entomologia, 48: 401-408.

Kergoat, G. J. 2004. Le genre Bruchidius (Coleoptera, Bruchidae): un modèle pour l'étude des relations évolutives entre les insectes et les plantes. Tesis de Doctorado, Paris VI University. Paris, Francia.

Kingsolver, J. M. 1965. On the Genus Abutiloneus Bridwell (Coleoptera: Bruchidae). The Coleopterists Bulletin, 19: 125-128.

Kingsolver, J. M. 1970. A study of the male genitalia in Bruchidae (Coleoptera). Proceedings of the Entomological Society of Washington, 72: 370-386.

Kingsolver, J. M. 1986. A taxonomic study of the genus Algarobius (Coleoptera: Bruchidae). Entomography, 4: 109-136.

Kingsolver, J. M. 1988. Biosystematics of the Genus Merobruchus of Continental North America and the West Indies (Coleoptera: Bruchidae). Technical Bulletin No. 1744, Department of Agriculture, Estados Unidos de América, 63 pp.

Kingsolver, J. M. 1990. Biosystematics of the genus of Zabrotes of America north of Mexico (Coleoptera: Bruchidae). Transactions of the American Entomological Society, 116: 135-174.

Kingsolver, J. M. 2002. Bruchidae. Pp. 602-608. In: J. R. H. Arnett, M. C. Thomas, P. E. Skelley \& J. H. Frank (Eds.). American beetles. Polyphaga: Scarabaeoidea through Curculionoidea, Volume 2. CRC Press, New York, Estados Unidos de América.
Kingsolver, J. M. 2004. Handbook of the Bruchidae of the United States and Canada (Insecta, Coleoptera), Volume I \& II. Technical Bulletin No. 1912, Department of Agriculture, Estados Unidos de América, 324 pp \& 198 pp.

Kingsolver, J. M. \& Johnson, C. D. 1978. Systematics of the genus Mimosestes (Coleoptera: Bruchidae). Technical Bulletin No. 1590, Department of Agriculture, Estados Unidos de América, 106 pp.

Kingsolver, J. M. \& Whitehead, D. R. 1976. The North and Central American species of Meibomeus (Coleoptera: Bruchidae: Bruchinae). Technical Bulletin No. 1523, Department of Agriculture, Estados Unidos de América, 139 pp.

Manfio, D. 2011. Análise cladística e revisào das espécies de Gibbobruchus Pic, 1913 (Coleoptera: Chrysomelidae: Bruchinae). Tesis de Maestría, Universidad Federal do Paraná, Curitiba, Brasil.

McClintock, E. 2002. Senna. Pp. 325-326. In: B. G. Baldwin (Ed.). The Jepson desert manual: vascular plants of southeastern California. University of California Press, Berkeley, California, Estados Unidos de América.

Morrone, J. J. 2005. Hacia una síntesis biogeográfica de México. Revista Mexicana de Biodiversidad, 76: 207-252.

Parra G., P. de J. 2011. Herbivoría de semillas del Mezquite Prosopis laevigata por escarabajos (Coleoptera: Bruchidae) en el Valle del Mezquital, Hidalgo. Tesis de Licenciatura, Universidad de Occidente Unidad Los Mochis, Sinaloa, México.

Pennington, T. D. \& Sarukhán, J. 2005. Arboles tropicales de México: manual para la identificación de las principales especies. Universidad Nacional Autónoma de México y Fondo de Cultura Económica, México, 523 pp.

Pérez P., C. J. 2007. Germinación de semillas de Mimosa aculeaticarpa var. biuncifera (Benth) Barneby (Fabaceae). Tesis de Licenciatura, Universidad Autónoma del Estado de Hidalgo, Hidalgo, México.

Randell B., J. 2008. Ordenamiento ecológico territorial regional en los municipios donde se ubica el Parque Nacional Los Mármoles, Informe final SNIB-CONABIO proyecto No. DQ006. Gobierno del Estado de Hidalgo y Consejo Estatal de Ecología, México, 294 pp.

Reid, C. A. M. \& Beatson, M. 2012. A new genus and species of Bruchinae, with a key to the genera from Australia (Coleoptera: Chrysomelidae). Zootaxa, 3599: 535-548.

Ribeiro-Costa, C. S. \& Almeida, L. M. 2012. Seed-Chewing Beetles (Coleoptera: Chrysomelidae: Bruchinae). Pp. 325-352. In: A. R. Panizzi \& J. R. P. Parra (Eds.). Insect Bioecology and Nutrition for Integrated Pest Management. CRC Press, New York, Estados unidos de América.

Robinson, W. H. 2005. Urban insects and arachnids: A handbook of urban entomology. Cambridge University Press, Estados Unidos de América, 472 pp.

Romero-Gómez, G. 2013. Estudio faunístico de la familia Bruchidae (Insecta: Coleoptera) del Estado de Morelos, México. Tesis de Doctorado, Colegio de Postgraduados, Estado de México, México.

Romero, J. \& Johnson, C. D. 1999. Zabrotes sylvestris, a new species from the United States and Mexico related to Z. subfasciatus (Boheman) (Coleoptera: Bruchidae: Amblycerinae). The Coleopterists Bulletin, 53: 87-98.

Romero, J. \& Johnson, C. D. 2000. Revision of the genus Zabrotes 
Horn of Mexico (Coleoptera: Bruchidae: Amblycerinae). Transactions of the American Entomological Society, 126: 221-274.

Romero, J. \& Johnson, C. D. 2004. Checklist of the Bruchidae (Coleoptera) of Mexico. The Coleopterists Bulletin, 58: 613-635.

Romero N., J. 2002. Bruchidae. Pp. 513-534. In: J. B. Llorente \& J. J. Morrone (Eds.). Biodiversidad, taxonomía y biogeografía de artrópodos de México: hacia una síntesis de su conocimiento, Volumen III. Universidad Nacional Autónoma de México, Distrito Federal, México.

Romero N., J. 2009. Two new genera records of Bruchidae (Insecta: Coleoptera) from México. Acta Zoológica Mexicana (nueva serie), 25: 671-672.

Romero N., J. 2016. Date Base BRUCOL (up-today). Programa de Entomología y Acarología, Instituto de Fitosanidad, Colegio de Postgraduados, Estado de México, México.

Romero N., J. \& Johnson, C. D. 2002. BRUCOL, una base de datos para Bruchidae (Insecta: Coleoptera). Pp. 520-524. In: J. Romero N., E. G. Estrada V. \& A. Equihua M. (Eds.). Entomología Mexicana, Volumen I. Sociedad Mexicana de Entomología, Distrito Federal, México.

Romero N., J., De la Cruz P., A. \& Kingsolver, J. M. 2009. Seed beetles (Coleoptera: Bruchidae) associated with Acacia cornigera (L.) Willd., with description of a new species of Acanthoscelides Schilsky. Insecta Mundi, 0000: 1-11.

Romero N., J.; Kingsolver, J. M. \& Mejorada G., E. 2011. New Distribution and Host Records for the Genus Zabrotes Horn (Coleoptera: Bruchidae). The Coleopterists Bulletin, 65: 294-296.

Terán, A. L. \& Johnson, C. D. 2002. Dos especies nuevas y datos adicionales acerca del género Megacerus Fåhraeus, 1839 (Coleoptera, Bruchidae). Acta Zoologica Lilloana, 46: 51-65.

Terán, A. L. \& Kingsolver, J. M. 1977. Revisión del género Megacerus (Coleoptera: Bruchidae). Opera Lilloana, 25: 1-287.
Thakur, D. R. 2012. Taxonomy, distribution and pest status of Indian biotypes of Acanthoscelides obtectus (Coleoptera: Chrysomelidae: Bruchinae) - A New Record. Pakistan Journal of Zoology, 44: 189-195.

Torres-Colín, L. \& Delgado-Salinas, A. 2008. Fabaceae Tribu Desmodieae. Flora del valle de Tehuacán-Cuicatlán, 59: 1-52.

Traveset, A. 1990. Post-dispersal predation of Acacia farnesiana seeds by Stator vachelliae (Bruchidae) in Central America. Oecologia, 84: 506-512.

Tuda, M., Wu, L.-H., Tateishi, Y., Niyomdham, C., Buranapanichpan, S., Morimoto, K., Wu, W.-J., Wang, C.-P., Chen, Z.-Qi, Zhu, H.Ye, Zhang, Y.-C., Murugan, K., Chou, L.-Y. \& Johnson, C. D. 2009. A novel host shift and invaded range of a seed predator, Acanthoscelides macrophthalmus (Coleoptera: Chrysomelidae: Bruchinae), of an invasive weed, Leucaena leucocephala. Entomological Science, 12: 1-8.

Whitehead, D. R. \& Kingsolver, J. M. 1975. Biosystematics of the North and Central American species of Gibbobruchus (Coleoptera: Bruchidae: Bruchinae). Transactions of the American Entomological Society (1890-), 101: 167-225.

Yus R., R., Kingsolver, J. M. \& Romero N., J. 2007. Sobre el estatus taxonómico actual de los brúquidos (Coleoptera: Bruchidae) en los Chrysomeloidea. Dugesiana, 14: 1-21.

Zárate P., S. 1994. Revisión del género Leucaena en México. Anales del Instituto de Biología de la Universidad Nacional Autónoma de México, Serie Botánica, 65: 83-162.

Zamudio R., S., Rzedowski, J., Carranza G., E. \& Calderón de Rzedowski, G. 1992. La vegetación del estado de Querétaro, panorama preliminar. Consejo de Ciencia y Tecnología del Estado de Querétaro, México, $92 \mathrm{pp}$.

Zunino, M. \& Zullini, A. 2003. Biogeografía, la dimensión espacial de la evolución. Fondo de Cultura Económica, México, 359 pp. 